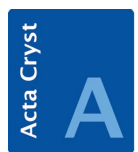

FOUNDATIONS ADVANCES
Keywords: International Union of Crystallography; Executive Committee.

Supporting information: this article has supporting information at journals.iucr.org/a

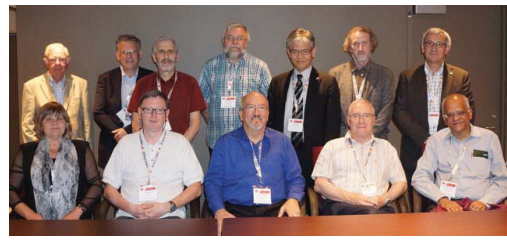

C 2018 International Union of Crystallography

\section{Report of the Executive Committee for 2016}

\section{Meetings}

The IUCr sponsored the following meetings held during 2016:

BioXFEL STC, San Juan, Puerto Rico, 13-15 January.

Macromolecular Crystallography School 2016: From Data Processing to Structure

Refinement and Beyond, São Carlos, Brazil, 3-12 April.

Powder Diffraction and Rietveld Refinement School, Durham, UK, 10-14 April.

Crystallography for Space Sciences, Puebla, Mexico, 17-30 April.

Crystallization: Focus on Micro and Nano Crystals and High-Throughput Methods

2016, Stanford, USA, 19-22 April.

RapiData 2016, Stanford, USA, 24-29 April.

6th Meeting on X-ray and Other Techniques in Investigations of the Objects of

Cultural Heritage, Krakow, Poland, 19-21 May.

5th International School on Crystallization: Drugs, Foods, Agrochemicals, Minerals, New Materials, Granada, Spain, 22-27 May.

High-Pressure Crystallography: Status Artis and Emerging Opportunities, Erice, Italy, 27 May - 5 June.

11th USPEX Workshop on Evolutionary and Interpretative Methods for Discovering the Structures and Rationalizing the Properties of Crystalline, Surface and Nanoparticle Materials, Lake Como, Italy, 5-9 June.

ED-XPD Workshop - Combining Electron and X-ray Powder Diffraction Techniques for Structural Characterization, Stockholm, Sweden, 6-10 June.

15th European Powder Diffraction Conference (EPDIC15), Bari, Italy, 12-15 June.

2016 Kuo Symposium on 3D Cryo-EM Molecular Imaging and 9th K. H. Kuo Summer School on Electron Microscopy and Crystallography, Beijing, People's Republic of China, 24-29 June.

7th European Charge Density Meeting (ECDM7): Latest Advances in Methodology and Applications of Charge Densities, Warsaw, Poland, 26 June - 1 July.

International School on Fundamental Crystallography with Applications to Electron Crystallography, Antwerp, Belgium, 27 June - 2 July.

ICCBM16 - 16th International Conference on the Crystallization of Biological

Macromolecules, Prague, Czech Republic, 2-7 July.

3rd International School on Aperiodic Crystals, Antwerp, Belgium, 4-9 July.

Annual Meeting of the American Crystallographic Association, Denver, Colorado, 22-

26 July.

Serial Crystallography Data Analysis Workshop, Denver, USA, 22 July.

Computational Approaches to the Structural Modelling of Biological Macromolecules

Using Small-Angle Scattering, Denver, USA, 23 July.

16th International Summer School on Crystal Growth (ISSCG-16), Shiga, Japan, 1-7 August.

18th International Conference on Crystal Growth and Epitaxy (ICCGE-18), Nagoya, Japan, 7-12 August.

12th International Conference on Biology and Synchrotron Radiation, Stanford, USA,

21-24 August.

PSI Powder Diffraction School 2016, Villigen, Switzerland, 22-26 August.

International School on Charge and Spin Density: From Experimental Determination to Interpretation, Nancy, France, 24-27 August.

30th European Crystallographic Meeting (ECM30), Basel, Switzerland, 28 August - 1 September. 
Fifth SMARTER Crystallography Conference, Bayreuth, Germany, 4-8 September.

AIC International Crystallography School 2016, Rimini, Italy, 7-11 September.

International Soft Matter Conference (ISMC2016), Grenoble, France, 12-16 September.

13th International Conference on Quasicrystals, Kathmandu, Nepal, 18-23 September.

2016 IUCr High-Pressure Workshop, Seoul, Republic of Korea, 20-23 September.

3rd European Crystallography School, Bol, Croatia, 25 September - 2 October.

First Pan-African Meeting on Crystallography, Dschang, Cameroon, 6-10 October.

2nd International Workshop on X-ray Crystallography in Structural Biology, Lahore, Pakistan, 15-20 October.

VIII Mexican Crystallography Meeting (VIII-SMCr) and III Latin-American Crystallography Meeting (III-LACA), Merida, Mexico, 23-27 October.

International School on Fundamental Crystallography (Fifth MaThCryst School in Latin America), Havana, Cuba, 30 October - 5 November.

VIII School of the Argentinian Association of Crystallography, San Luis, Argentina, 14-18 November.

6th Moroccan School of Crystallography - EMC6, Meknes, Morocco, 22-25 November.

14th Conference of the Asian Crystallographic Association, Hanoi, Vietnam, 4-7 December.

The Executive Committee met in Denver, USA, in July. The Finance Committee met in Leuven, Belgium, in March and in Denver, USA, in August, to prepare its advice and recommendations on finances, establishment and staff matters.

The most important items of business dealt with by the Executive Committee at its meetings, and in e-mail ballots, were:

editorial policy, pricing policy and subscription rates, approval of appointments of Editors and Co-editors, progress of $I U C r J$, journals development, Special Issues, open access, and other matters concerning the IUCr journals;

launch of IUCrData;

outreach and education; UNESCO OpenLabs;

approval of audited accounts for the previous year;

General Fund estimates and level of unit contribution;

status of membership subscriptions;

applications for membership;

proposal to introduce an IUCr Associates Programme;

application for funding from ICSU grants programme;

investment policy;

funding and uses of Publications and Journals Development

Fund, Research and Education Fund and Outreach and

Education Fund;

sponsorship and financial support for meetings, young scientists' support, Visiting Professorship Scheme, gender balance of programmes;

Diffraction Data Deposition Working Group, formation of Committee on Data; progress with Volumes A, A1, B, C, D, E, F, G, H and I of

International Tables and development of associated software; IUCr Newsletter;

World Database of Crystallographers;

Online Dictionary of Crystallography;

business development and promotional activities;

Ewald Prize;

proposals from National Committees for Officers of the

IUCr and members of Commissions;

discussion of arrangements for Hyderabad and Prague

Congresses.

Other items dealt with in this way were:

uses of the Crystallographic Information Framework (CIF), work of the Committee for the Maintenance of the CIF Standard (COMCIFS), provision of checking services to other publishers;

consideration of publications, jointly with Oxford University Press, in the IUCr/OUP Book Series;

Crystallography in Africa;

review of activities of Commissions, formation of new

Commission;

review of activities of Regional Associates;

review of reports of IUCr Representatives on other bodies. Items concerning the Chester office were:

staffing requirements in the IUCr office in Chester;

office premises;

risk analysis;

upgrading of office technology.

\section{Publications}

Volume 72 of Acta Crystallographica, Volume 49 of Journal of Applied Crystallography (JAC), Volume 23 of Journal of Synchrotron Radiation (JSR) and Volume 3 of IUCrJ were published.

\section{Adhering Bodies}

A list of Adhering Bodies of the Union, with names and addresses of the Secretaries of the National Committees for Crystallography, was published as Appendix D to the Report of the Twenty-Third General Assembly and International Congress of Crystallography [Acta Cryst. (2016), A72, 85167].

\section{Work of the Commissions}

\subsection{Commission on Journals}

4.1.1. IUCrJ

The journal has started to establish itself within the wider scientific communities that use results obtained from diffraction methods. All the indications are good in terms of the journal making a strong impact in attracting high-quality science papers of wide scientific significance from these communities. Impressions from authors, readers, referees and 
commentators are very positive with a number of papers receiving high downloads in line with high-impact publications.

IUCrJ aims to provide fast publication for authors. Submissions undergo preliminary screening by a panel consisting of the five Main Editors and the Editor-in-Chief (Samar Hasnain), and this has helped to provide a rapid and efficient review process. Preliminary screening is generally complete within 72 hours, and any articles that do not meet the journal's requirement for broad scientific significance are usually transferred, with the agreement of the authors, to one of our other journals. Such transfers are seamless and do not require any further work by the authors.

In 2015, the journal was included in the Science Citation Index and in 2016 received its first impact factor of 5.3. This is very encouraging for such a newly launched journal, with $I U C r J$ currently ranked first out of 25 journals listed in the Science Citation Index Crystallography category.

In 2016, new Co-editor and Advisory Board appointments were made to cover cryoEM (R. Henderson, W. Kühlbrandt and S. Subramaniam), chemistry and crystal engineering (P. Lightfoot and L. R. MacGillivray) and FELs (E. E. Lattman).

We hope that you will consider publishing in IUCrJ and, by doing so, help to establish the journal as one of the mainstream comprehensive science journals.

\section{Argyriou, E. N. Baker, G. R. Desiraju, C. R. A. Catlow} and J. C. H. Spence, Editors

\subsubsection{Acta Crystallographica Section A}

In 2016 we continued to offer rapid review and publication of potentially high-impact papers in the Advances section of the journal. This approach is working well: along with five standard research articles (Bragg-von Laue Diffraction Generalized to Twisted X-rays, by D. Jüstel, G. Friesecke and R. D. James; On the Possibility of Using X-ray Compton Scattering to Study Magnetoelectrical Properties of Crystals, by S. P. Collins, D. Laundy, T. Connolley, G. van der Laan, F. Fabrizi, O. Janssen, M. J. Cooper, H. Ebert and S. Mankovsky; Dynamic Quantum Crystallography: Lattice-Dynamical Models Refined Against Diffraction Data. I. Theory, by A. A. Hoser and A. $\varnothing$. Madsen; Coherent Diffraction Imaging: Consistency of the Assembled Three-Dimensional Distribution, by M. Tegze and G. Bortel; and Miniaturized Beamsplitters Realized by X-ray Waveguides, by S. Hoffmann-Urlaub and T. Salditt) we also published three Lead Articles (Computation in Electron Microscopy, by E. J. Kirkland; Topological Features in Crystal Structures: a Quotient Graph Assisted Analysis of Underlying Nets and Their Embeddings, by J.-G. Eon; and Observing Structural Reorientations at Solvent-Nanoparticle Interfaces by $X$-ray Diffraction - Putting Water in the Spotlight, by M. Zobel) and a Feature Article (Cryogenic Coherent X-ray Diffraction Imaging of Biological Samples at SACLA: a Correlative Approach with Cryo-Electron and Light Microscopy, by Y. Takayama and K. Yonekura) under the banner of the Advances section. Two of these were highlighted in accompanying scientific commentaries (Cryo-Coherent Diffractive Imaging of Biological Samples with $X$-ray FreeElectron Lasers, by H. Jiang; and Simple Graphs that Guide Combinatorial Materials Design, by P. M. Duxbury) and two were featured in news items on the IUCr web page ( $X$-ray Optics on a Chip and Twisted X-rays Unravel the Complexity of Helical Structures). In this way, we are attracting and retaining new authors who seem to appreciate the efforts made on their behalf, as several have continued to send us good articles for consideration as Advances.

We have also continued to promote our top papers through social media. We are finding that scientific commentaries that help to explain and highlight the potential uses of techniques described in some of our more mathematical papers are particularly useful.

In November we also published a Special Issue of six articles and an editorial celebrating 100 years of the Debye scattering equation, based on talks given at the DSE2015 workshop held in Trentino, Italy, in 2015, with Guest Editors P. Scardi, R. Neder and A. Cervellino. This continued the theme of celebrating centennials (after Special Issues devoted to Laue and Bragg in 2012 and 2013, respectively) but with an emphasis on how the Debye scattering equation has recently enjoyed widespread use in research into the structure of nanomaterials.

The Editorial Board have worked tirelessly with authors to ensure that all papers now explain the wider significance of the work, and to encourage authors who had previously been publishing frequent but rather incremental pieces of research to consider combining these into one longer article describing the whole body of work and its possible significance in more detail.

John Miao stepped down as a Main Editor of Acta $A$ at the end of the year: I would like to thank him and the rest of the Editorial Board for all their hard work and support over the year.

\section{S. J. L. Billinge, Editor}

\subsubsection{Acta Crystallographica Section B}

Having risen slowly to around 2.2 during the previous triennium, the journal's impact factor reached 2.9 in 2015, in part owing to the effect of several highly cited Feature Articles. These articles moved out of the citation window in 2016, so a modest dip in the impact factor for that year might be anticipated before some very highly cited articles published in 2016 should significantly increase the impact factors for 2017 and 2018.

During the triennium Acta $B$ underwent major changes in order to increase the quality and quantity of science it publishes, signalled by the change in subtitle to Structural Science, Crystal Engineering and Materials. The journal has developed a strong programme of Invited Articles and Special Issues in order to announce its renewed interests in these areas. 
Invited Articles are regularly sought from prominent scientists, including Keynote Lecturers at IUCr Congresses and Regional Associate Meetings. Analysis suggests that our programme of Invited Articles has had higher impact than our Special Issues: we intend to pursue both in the next triennium but will aim to publish only one or two Special Issues per year while vigorously pursuing a larger number of high-quality Invited Articles in the period 2017-2020. The journal is also experimenting with new categories of article such as the Opinion and Research Perspective articles.

Co-editors regularly report difficulties in identifying willing, qualified and competent reviewers. The Section Editors are available to advise as required. The contributions of reviewers are invaluable and we wish to express our deep thanks for their efforts in improving the quality of articles in Acta B and in identifying outstanding science.

Among the many Chester staff who have contributed to Acta $B$, we particularly appreciate the many contributions of our Managing Editor Jill Bradshaw, from editing articles to coordinating the work of the Section Editors.

Whilst preparing this report Professor Ashwini Nangia joined us as a Main Editor and we look forward to working together.

\section{A. J. Blake and M. de Boissieu, Editors}

\subsubsection{Acta Crystallographica Section C}

Our efforts on emphasizing the new focus of the journal continue and we recently published a Special Issue on Scorpionates: a Golden Anniversary. We are most grateful to Glenn Yap (University of Delaware, USA) and Kiyoshi Fujisawa (Ibaraki University, Japan) for putting together this excellent collection of articles, the second Special Issue we have published on this class of compounds. The journal has also published a Special Issue on NMR Crystallography. The Guest Editors, David Bryce (University of Ottawa, Canada) and Francis Taulelle (Université de Versailles Saint Quentin en Yvelines, France), have produced a substantial Special Issue on what has become a very important field where the marriage of traditional crystallography with the results from solid-state NMR can be very powerful for structure elucidation. The Commission on NMR Crystallography and Related Methods was established at the Montreal General Assembly in August 2014 and, promoted by this Special Issue, it is hoped that IUCr journals can become a natural home for articles relating to this exciting field.

A Review Board with over 60 members was introduced during 2016 and is working well. This should reduce the severe challenges some Co-editors had been facing with finding a quality reviewer who responds within a reasonable time. Members of the Review Board agree to review a certain number of papers each year.

We are pleased to announce that our recent efforts, including the publication of feature articles (on SHELXL, PLATON SQUEEZE and CRYSTALS), have started to show a substantial increase in the journal's impact. This can be seen by looking at the ScopusCiteScoreTracker for the journal, which was 0.57 in 2015 and is showing an interim value of 3.17 for 2016 at time of writing. We hope that this will make the journal attractive to many new authors and readers. Of course, raising the impact is only a start and we will be striving to sustain this by continuing to publish Special Issues on eminent topics, solicit feature articles of significant and general interest to those in the field of structural chemistry, as well as attracting scientific comments of appeal to the readership. As a step in this direction, Horst Puschmann (OLEX2) and Mathias Meier (CrysAlis PRO) were recently invited to submit Feature Articles highlighting some of the uses of their software for solving chemical crystallography problems. They accepted the invitations and we expect to publish their papers towards the end of 2017.

The positive tone of the above developments is somewhat tempered by the continued decline in the total number of papers submitted to the journal. This number fell from 407 in 2015 to 335 in 2016. It is hoped that a positive effect will result when the journal's latest impact statistics are released in mid2017 and that prospective authors will then feel more inclined to submit papers to Acta $C$. Although the Acta $C$ rejection rate is high $(50 \%)$, it should be noted that many of the rejected papers are being written in a style that is clearly more appropriate for Acta $E$ and such papers are usually recommended for resubmission there.

Tony Linden will retire as Main Editor of Acta C in 2017, having served nine years in that role. Paul Raithby will continue as a Main Editor and the IUCr recently appointed two additional Main Editors: Larry Falvello (University of Zaragoza, Spain) and Jonathan White (University of Melbourne, Australia). We are also extremely grateful to the team of Co-editors, both current and past, for their support, dedication and energy over the year. The journal would not exist without their valued contributions. The hard work and support of the Chester Editorial Office staff cannot be praised highly enough, as it is they who ultimately get the accepted papers through production into the final product that we all read.

\section{R. Falvello, A. Linden, P. R. Raithby and J. White, Editors}

\subsubsection{Acta Crystallographica Section D}

We have been working to increase the impact factor of the journal by expanding the scope - with a concomitant change in name in 2016 (to Acta D Structural Biology from Acta D Biological Crystallography). In terms of the expanded scope, in 2015 we published a CCP4 Proceedings issue on complementary methods that included papers on SAXS, sometimes in combination with fibre diffraction or DEER spectroscopy, and a paper describing the structural results of cryo-electron subtomogram averaging. We wrote an editorial that highlighted the new scope (published in the January 2016 issue), developed a workflow summary for Co-editors, and have been working closely with Acta F Section Editors to streamline 
the protocol and processes for transferring between the journals.

During the period 2014-2016, we have published four invited scientific commentaries and three invited Feature Articles. We are continuing to commission new articles from all areas of structural biology. In 2016, we published papers that included a broad range of structural methods including neutron crystallography, SAXS, EM and reflectometry.

We have also invited authors to write articles from Biology and Synchrotron Radiation 2016, ISDSB 2016, the 50th Erice International School of Crystallography, CCP-EM Spring Symposium and the IUCr Congress. We will report on these in next year's report.

We now take the opportunity to remind the IUCr community that the IUCr journals are there to support them, but in the same way the journals need the community's support to continue.

A popular feature of Acta $D$ has been the Special Issues. Most recently, the 2016 CCP4 Study Weekend Special Issue, guest edited by Charles Ballard, Airlie McCoy and Thomas Schneider, was on the topic of advances in experimental phasing and was published in the March 2016 issue.

Pleasingly, the proportion of open-access papers (an authorselected option requiring an additional payment) has increased considerably over the past few years. The percentages of open access in 2010-2012 were relatively static: in $2011 / 2012$ at $20 \%$ of accepted papers; this rose to $34 \%$ in 2014 and $35 \%$ in 2015 and a record high of $45 \%$ in 2016. Open access in Acta $D$ is competitively priced compared with other journals that publish structural biology papers. This pricing structure provides an opportunity for encouraging new submissions and we propose that IUCr journals should actively promote that aspect.

The average publication time for Acta $D$ remains steady at about five months, and this is in large part owing to factors outside of our control (time required for authors to revise, time required for reviewers to provide their comments).

While the excellent panel of Acta D Co-editors represents the span of expertise and geography in our community, we are keen to see that the historic gender imbalance of editors in our sub-discipline is addressed. In our view, it is an urgent priority to re-evaluate the policies and procedures underlying Coeditor appointments to address this imbalance. This will be critical to the future of the field and this journal. We need to ensure that the next generation is fully engaged in the discipline for healthy growth of the Union.

The electronic system of submissions continues to work very well for authors as well as the editors and reviewers. The quality of the journal is very high owing to the expert work of Louise Jones and Simon Glynn at the Chester Office. We thank them, Executive Managing Editor Peter Strickland, and Samar Hasnain, Editor-in-Chief, for their valuable help.

J. L. Martin, R. J. Read and S. Wakatsuki, Editors

\subsubsection{Acta Crystallographica Section E and IUCrData} The pre-review system, whereby the Section Editors preview the submissions to consider the quality of the paper and make sure that it is in the appropriate format, is working well. The Section Editors can decide if a submission should be published as a Research Communication in Acta $E$ or if it should be transferred, subject to the agreement of the authors, to IUCrData. The introduction of a new version of publCIF has made it easy for authors to prepare both types of publication and we must put more emphasis on the use of this software and its functionality to generate the correct format for the submission.

The new web site for the journal is an added plus, and makes attractive reading.

From January 2016 the journal only published Research Communications, and Data Reports are now published in IUCrData. Because of this reorganization, the number of papers submitted to Acta $E$ was down from 1273 in 2015 to 542 in 2016. The quality of papers has increased with authors often reporting two or more structures and choosing to discuss complementary techniques, and include extra tables and figures to illustrate their results and enhance the discussion of the underlying science. We also noticed that the Research Communications format was attracting new authors to the journal and that the range of structures was far broader. The proportion of papers from India in Acta E decreased (down $10 \%$ ) while the proportion of papers from the USA increased. The top three countries for Acta E were the USA (15\%), India (9\%) and Germany (9\%).

IUCrData. 585 data articles were submitted to IUCrData in its first year of publication. A total of 512 data articles were accepted and published in 2016 in 1396 pages. The highest proportion of data articles came from India (26\%), followed by Morocco (12\%), the USA (12\%), People's Republic of China $(8 \%)$ and Germany $(7 \%)$. The average length was 2.7 pages and the average publication time was 0.8 months. The rejection and withdrawal rate was $12 \%$.

One of the stated aims of the relaunch of Acta $E$ has been to regain indexing in the Science Citation Index. We are therefore delighted that the journal was included in the new Emerging Sources Citation Index (ESCI) when it was launched in November 2015. This means that articles published in Acta E can now be found in searches of the Science Citation Index. Importantly, it also means that the journal is under consideration for inclusion in the Science Citation Index Expanded. We hope that the final phase of the transformation of Acta E outlined above will herald the early re-indexing of the journal.

In 2016, the Advisory Committee was asked for a review of the performance of Acta E. Several recommendations made in that report are already being implemented and as always there is scope for improvement in view of obtaining inclusion in the Science Citation Index Expanded.

As always, we are extremely grateful for the excellent support that we receive from the staff in Chester, in particular Gillian Holmes, Sean Conway and Mike Hoyland, for their 
constant help and support, and to Peter Strickland for his sound advice and expert guidance.

W. T. A. Harrison, H. Stoeckli-Evans, E. R. T. Tiekink, L. Van Meervelt and M. Weil, Editors

\subsubsection{Acta Crystallographica Section F}

An important aspect in the last triennium was the consolidation of Acta F's publication tool publBio. publBio has been developed to streamline short manuscripts describing the crystallization and/or the structure determination of a macromolecule. It is available to authors as an online tool as well as in the form of publication templates. Although the structural biology community has been slower than expected in adopting this new tool, about $20 \%$ of all papers appear to be assembled and submitted nowadays using publBio. It will be an important responsibility of the Section Editors in the next triennium to make publBio even more popular in the structural biology community and to expand its use among Acta $F$ authors. With their more-or-less standardized content, we expect that these publBio-generated papers will prove to be even more useful to our readers and to the scientific community as a whole.

Another very positive development which we set out to achieve in the last triennium is the increase in papers describing a structure determination. While in 2014 only about $20 \%$ of all papers in Acta $F$ described a structure, this number rose to $42 \%$ in 2015 and $69 \%$ in 2016 . This is clearly the result of the new requirements for crystallization papers as laid down in the Notes for Authors.

A very successful endeavour of the journal in the last triennium was the publication of the IYCr series of papers dealing with various aspects of macromolecular crystallization. Twenty fine papers commissioned by our former Section Editor colleague Howard Einspahr appeared in the journal between 2014 and 2016. These papers are among the most downloaded ones of the journal and we anticipate that they will be highly cited as well. Plans to republish them as a book in time for the IUCr conference in Hyderabad are under way.

Importantly, the journal has become and remains a highquality structural biology journal. Its current impact factor (for 2015) is 0.65. Initial estimates for the 2016 impact factor suggest that it will be higher than that for 2015. Our ambition is still to increase our visibility and raise the journal impact factor to 1.0 or above. We do feel that by mandating more information content in the papers published, we have made a good step towards that goal. However, it will take another two or three years to see the full impact of this.

The referee panel, which was created in the journal's second triennium, continues to function well. This group of about 30 experienced scientists, who have agreed to referee 12 papers a year, to reply to requests promptly and to return reports within two weeks, can potentially provide half the number of referee reports needed in any publication year. Unfortunately, we have not been able to recruit as many new Co-editors from the panel or from outside as we would have liked in order to replace the retiring members and in order to fill the geographical gaps on the Editorial Board. With respect to the Section Editor team, we managed to recruit Zbigniew Dauter in 2016 after the term of our former colleague Howard Einspahr, who was one of Acta F's founding Editors, ended in 2014.

\section{Z. Dauter, W. N. Hunter and M. S. Weiss, Editors}

\subsubsection{Journal of Applied Crystallography}

The five-year impact factor remains very solid and the citation half-life continues to exceed ten years. The number of computer-program submissions, which generally attract above average citations, remains at a healthy level. Furthermore, the fraction of published papers that are open access has doubled over the last three years, and now stands at more than $20 \%$.

A Special Issue not associated with a conference: CCP-FEL: a Collection of Computer Programs for FEL Research, was published in August 2016 with Guest Editors Filipe Maia, Thomas White, Duane Loh and Janos Hajdu. Finally, a Special Issue on Small-Angle Scattering, associated with the 16th International Conference on Small-Angle Scattering (SAS2015) held in Berlin, Germany, in September 2015, was published in December 2016. Guest Editors were Michael Gradzielski and Andrew Allen. Work is currently under way on an issue associated with the XTOP 2016 conference held last September in Brno, Czech Republic (Guest Editors Vaclav Holý and Virgine Chamard). Further new Special Issues are planned, with a current call for papers for a Special Issue on Advanced Neutron Scattering Instrumentation, with Dimitri Argyriou and Andrew Allen as Guest Editors.

\section{A. J. Allen, J. Hajdu and A. R. Kaysser-Pyzalla, Editors}

\subsubsection{Journal of Synchrotron Radiation}

The past years have seen a continuously rising number of submissions, as in the previous triennial period. The journal's impact factor dropped in 2014 and 2015 and appears to have recovered in 2016. Although it is difficult directly to relate the fluctuating impact factor to our editorial actions, the published Special Issues with invited high-quality papers on XFELs and Diffraction-Limited Storage Rings have certainly helped to curb the trend of declining impact, as have the two Special Issues on Radiation Damage in 2015 and 2017. Therefore, our policy of publishing Special Issues on hot topics is to be continued. In 2018 a Special Issue will appear on the latest developments in the science of extremely bright synchrotron and XFEL sources. In addition, we consider publishing news and views summaries and editorial overviews, similar to what is being done in $I U C r J$. Finally, we believe that a prescreening of submitted papers by the editors will benefit the overall science quality of the journal and its impact. Prescreening 
tools should be available on the Main Editors's web portal as of 2018.

\author{
Y. Amemiya, M. Eriksson, G. E. Ice, I. Schlichting and J. F. \\ van der Veen, Editors
}

\subsection{Commission on International Tables}

International Tables for Crystallography is a book series published by the IUCr in conjunction with Wiley. Eight volumes designated A (and A1) through $\mathrm{G}$ are currently in print, a ninth ( $\mathrm{H}$, on Powder Diffraction) is expected to appear during 2017, and a tenth (I, on X-ray Absorption Spectroscopy and Related Techniques) is being written. Printed volumes can be purchased individually; online access is by subscription to the entire series. A new, considerably revised edition of the low-cost, printed Brief Teaching Edition of Volume A (SpaceGroup Symmetry) should appear in late 2017 or early 2018.

In common with print sales for many other major reference works, sales of the print editions of the volumes have continued to decline. However, sales of subscriptions to International Tables Online have increased. The issue of whether to continue printing all the volumes will need to be addressed quite soon: it might be possible to continue to make some volumes available by 'print on demand'. Several volumes in the series now contain or plan to include content that will only be available in the online version.

Descriptions of activities during 2016 for the individual volumes follow.

Volume A (Space-Group Symmetry; most recent online edition dated 2016). The sixth edition of Volume A became available, both online and in print, during December 2016. It is a great pleasure to thank Mois Aroyo for bringing this major project to fruition. Details of how this new edition differs from the fifth can be found at http://it.iucr.org/Ac/newedition.

Symmetry Database server of the Online Edition of International Tables. The work on the enhancement of the Symmetry Database of the Online Edition of International Tables continued through 2016 within the framework of two IUCr projects with the software company eFaber (Bilbao) and the research group headed by L. Casas and E. Estop (Departament de Geologia, UAB, Barcelona). The main activities focused on the extension of the online data for the crystallographic point groups and space groups. The recently integrated database of space-group normalizers gives access to Euclidean, chirality-preserving and affine normalizers. A prototype version of a visualization tool, based on $\mathrm{JSMol}$, for the visualization of the general-position data is now also available. The newly accessible crystallographic data of point groups include generators, general and special Wyckoff positions (Wyckoff letters, multiplicities, site-symmetry groups and coordinate triplets of the symmetry-equivalent points). The symmetry elements of each point group can be visualized using interactive tools developed by the Barcelona group. The work on the enhancement of the Symmetry Database has been supervised by the Volume A Editor, Mois Aroyo. The necessary databases and algorithms for the corresponding computation tools were provided by the team from the Bilbao Crystallographic Server.

BTE (Brief Teaching Edition of Volume A). Discussions of the sixth edition of the Brief Teaching Edition (BTE6) were renewed once the sixth edition of Volume A (ITA6) was completed. It was agreed that the BTE6 will contain two parts:

(i) Part 1 will be a lighter, i.e. shorter and less complex, version of Part 1 of ITA6 but will also provide additional illustrative examples. The new BTE should serve as an interface between elementary crystallography textbooks and ITA6. The BTE6 is definitely not intended for novices in the field; the potential readers are graduate students, young researchers etc. who have some previous acquaintance with the basics of symmetry and diffraction. The text will be supplemented by a number of current and accessible references $(a)$ to ITA6 (especially for additional table and figure data), $(b)$ to further specialized sources for those who need to go deeper into the subject, and (c) to textbooks and basic crystallographic literature. As in Part 1 of ITA6, the material of Part 1 of BTE6 will be distributed into seven chapters. A chapter introducing the magnetic space-group tables will be added.

(ii) Part 2 will follow closely the guide to the space-group tables of Part 2 of ITA6 (Chapter 2.1) but may be somewhat shorter. A representative set of tables of plane and subperiodic groups will also be included, with pages to be taken from Volumes A1 and E.

It is anticipated that the BTE6 will be completed by the end of 2017.

Volume A1 (Symmetry Relations Between Space Groups; most recent online edition dated 2011). Addition of tables for the subperiodic (i.e. frieze, rod and layer) groups is being considered, although it might be more appropriate to put that information in a new edition of Volume E. Appointment of another Main Editor is under consideration.

Volume B (Reciprocal Space; most recent online edition dated 2010). Proposed changes for the next edition are:

(i) an updated version of the chapter Fourier Transforms in Crystallography by Gerard Bricogne;

(ii) an extension of the chapter on Reciprocal Space in Crystal Structure Determination to include a new article on dual-space refinements including charge flipping and other similar methods, and a new article on the VLD (Vive la difference) algorithm developed by the group of Carmelo Giacovazzo;

(iii) a new article dedicated to the use of dynamical refinement in electron diffraction;

(iv) a new article on the use of the three-dimensional delta pair-distribution function (3D- $\triangle \mathrm{PDF}$ ) for the interpretation of diffuse scattering; and

(v) a new chapter on aperiodic crystals that will expand and regroup into a single section of Volume $B$ the topics of quasicrystals (currently in B) and incommensurate and composite crystals (currently in C).

Volume C (Mathematical, Physical and Chemical Tables; online edition dated 2006). Around 30 new articles and updates of existing articles have been commissioned for this very major 
revision; ten have been received so far, some of which have now been reviewed. While progress in some areas is very satisfactory other authors are taking more time than anticipated. Articles in 'hot' areas are a problem because the authors are so busy with other obligations.

Volume D (Physical Properties of Crystals; most recent online edition dated 2013). Since the second edition of Volume D was completed very recently no new action has been necessary in 2016. Some inaccuracies in one table of one chapter have been corrected in the online version.

During 2016 André Authier asked to retire as Editor of Volume D, which he has piloted since about 1990, when it was first being discussed. A search for his replacement is underway.

Volume E (Subperiodic Groups; most recent online edition dated 2010). It is with sadness that the passing in May 2016 of Joint Main Editor Vojtech Kopsky must be noted. Kopsky, together with Danny Litvin, created this volume. An obituary appeared in the September issue of Section A of Acta Crystallographica.

The Seitz symbols in the print and online version of the second edition are not the kind that were later approved by the IUCr. Modification of these symbols in the online edition will be made during 2017.

Volume F (Crystallography of Biological Macromolecules; most recent online edition dated 2012). The second edition of Volume F was completed in 2011 so it is time to consider a revision. The next edition should incorporate more material on the rapidly expanding activities in cryo-electron microscopy and in serial crystallography. It is likely that a new Main Editor will be needed.

Volume $G$ (Definition and Exchange of Crystallographic Data; online edition dated 2006). Progress on Volume G has been dependent on the process of converting legacy DDL1 dictionaries to DDLm, together with accompanying adjustments and approvals of the underlying standards. A semiautomated typesetting workflow for the DDLm dictionaries has been developed. As the majority of the dictionaries have now been converted, author invitations for the next edition will be sent out in the first half of 2017.

Volume H (Powder Diffraction; new volume). Of the 54 planned chapters for this new volume 46 are in final form. Type is being set; proofs for 13 chapters have been sent out. Publication in mid-2017 is planned.

Volume I (X-ray Absorption Spectroscopy and Related Techniques; new volume). Over 150 experts in experimental work, theory and analysis have agreed to provide chapters for the new volume. Of these, 71 have already submitted their chapters for review and 21 of those have been accepted or are near acceptance. Publication in 2018 is anticipated.

Further information about the volumes can be found at the home page of the Commission, http://www.iucr.org/resources/ commissions/international-tables. The Guided Tour available at http:/it.iucr.org/services/guidedtour/ is highly recommended because it shows what is available electronically. Access to the Tables of Contents of all the volumes is free, as are sample pages (including author lists and prefaces); see the home pages for the individual volumes (e.g. http://it.iucr.org/ A/).

The staff in Chester, and especially Nicola Ashcroft, are absolutely central to the development and advertisement of this series. They advise Commission members on historical precedents and conventions, and they provide guidance on English usage, always in a very tactful and encouraging way. And they layout the pages, set all the type, and insert links. It is difficult to thank them enough for all that they do.

\section{P. Brock, Chair}

\subsection{Commission on Aperiodic Crystals}

In 2016, the Commission (CAC) continued to actively promote aperiodic crystallography, in organizing, supporting and promoting meetings, workshops and educational activities worldwide. In doing so, CAC continued its ongoing coordination of interaction between the various sub-communities and disciplines involved in the different aspects of research in aperiodic crystals, as well as the dissemination of research results to the greater scientific community.

This year, we organized the 3rd International School on Aperiodic Crystals in Antwerp, Belgium, with the support of the CNRS (formation permanente), the European CMAC network and the European Crystallographic Association. Material and organizational support was provided by the University of Antwerp and specifically the Antwerp Summer University. The school, which followed on from the successful schools in Carqueiranne, France, in 2010 and in Bayreuth, Germany, in 2013, attracted 33 participants from 14 different nations, 18 of which were aged below 30. Teaching at the school was provided by nine lecturers. This school is our central educational activity, with the objective of providing an overview of aperiodic order, of the basics of the mathematical description of both modulated structures and quasicrystals, and of physical properties and chemical understanding of aperiodic crystals, as well as a working knowledge of structural analysis of aperiodic crystals. The Commission is immensely grateful to Joke Hadermann for organizing a fantastic event, which received univocally positive feedback from participants. Successful participation at the school was acknowledged with 3 ECTS (European Credit Transfer system) credits, which students could obtain by passing an online test within a month after the school. However, since half of the participants were already post-docs, not so many students made use of this possibility.

The second major event in the aperiodic community in 2016 was the 13th International Conference on Quasicrystals ICQ13, which was chaired by Hem Raj Sharma and An Pang Tsai and took place 18-23 September 2016 at Dhulikhel Lodge Resort near Kathmandu, Nepal. While this event was not organized by the Commission, it was supported by and organized in close collaboration with the Commission. ICQ13 was attended by 98 researchers from 22 countries, including $26 \mathrm{PhD}$ or Masters students. There were 13 invited talks 
(including a public lecture by Dan Shechtman, 2011 Nobel Laureate in Chemistry), three tutorial lectures, 50 contributed talks and 36 poster presentations. The conference was truly interdisciplinary, comprising theoretical and experimental physicists, chemists, materials scientists and mathematicians. At ICQ13, the 2016 Jean-Marie Dubois Award for Excellence in Quasicrystals was presented to Marek Mihalkovic for his theoretical work that has enabled and demonstrated the simulation of thermodynamic and dynamic properties of quasicrystals, based on realistic atomic-scale models and energetics. The proceedings of the conference have been published in the Institute of Physics open-access Journal of Physics: Conference Series as Vol. 809 (2017). The next meeting in this series will be held in Bled, Slovenia, 26-31 May 2019; the lead organizer will be Janez Dolinsek.

Further events supported by the Commission in 2016 include the JANA2006 ad hoc workshops in Prague, Czech Republic. Details of the workshops (Nos. 29, 30 and 31) can be found at http://jana.fzu.cz. In addition, a JANA2006 workshop at the 7th Shanghai Workshop on X-ray Crystallography at the College of Materials Science and Engineering, Shanghai University, in October/November 2016 attracted about 70 participants. Members of the Commission also contributed to the workshop New Trends in Magnetic Structure Determination, which took place in December 2016 at the Institut LaueLangevin, Grenoble, France, which was supported by the IUCr Commission on Magnetic Structures, as well as to events in other communities; examples are sessions at the SIAM Conference on Mathematical Aspects of Materials Science, Philadelphia, USA, 8-12 May 2016, and the workshop Combining Aperiodic Order with Structural Disorder, at the Lorentz Center in Leiden, The Netherlands, 30 May - 3 June 2016.

The Commission is proud to acknowledge the award of the 9th Max Perutz Prize of the European Crystallographic Association to Vaclav Petricek. The award was given in recognition of his practical application of the theory of aperiodic structures in the widely used computing system JANA. The prize was awarded at the 30th Meeting of the European Crystallographic Association ECM30 in Basel, Switzerland, 28 August - 1 September 2016.

The Commission is looking forward to 2017 and 2018. In 2018, we will be holding the 9th International Conference on Aperiodic Crystals (Aperiodic 2018). For the first time, a meeting in this series will take place in the USA. The conference will be held in Ames, Iowa, 13-18 July 2018. The local organizers are Alan Goldman, Gloria Borgstahl and Pat Thiel, with Andreas Kreyssig acting as the conference administrator.

\section{U. Grimm, Chair}

\subsection{Commission on Biological Macromolecules}

The aim of the Commission (CBM) is to support macromolecular crystallography worldwide through scientific exchange, training, and promotion of policies that encourage the generation and dissemination of knowledge and technologies.

Proposed mechanisms for enhancing ease of identification and correction of $P D B$ deposits with errors. The CBM is beginning discussions of mechanisms for making it easier for researchers to correct errors in the PDB and for users of the PDB to identify problematic or non-problematic entries in the PDB.

The principal goals of this proposal are:

(1) to allow users of the PDB readily to identify and filter out the structures that have exceptionally poor validation statistics including geometric or data-based validation criteria;

(2) conversely, to allow users of the PDB readily to identify experimental data in the PDB that are represented by more than one interpretation, compare these interpretations and select a single best interpretation based on the user's validation preferences;

(3) to provide users of the PDB with validation of individual ligands in a structure separately evaluating the geometric plausibility of each ligand and the evidence for the ligand coming from the data;

(4) to provide researchers with straightforward mechanisms for depositing new and hopefully improved interpretations of data in the PDB and associating the new deposits with these data.

Endorsement of a Letter to the Editor of Acta D on definitions of 'resolution'. The CBM considered a Letter to the Editor on definitions of 'resolution' by Dauter and Wlodawer and endorsed the letter with the following text:

The IUCr Commission on Biological Macromolecules endorses the concepts in the Letter to the Editor by Dauter and Wlodawer [Wlodawer \& Dauter (2017). Acta Cryst. D73, 379-380] and in particular supports the idea of developing community-agreed working definitions of 'atomic resolution' and 'near-atomic resolution'. The Commission notes that although there are limitations in the definition of 'resolution' itself these limitations should not prevent the X-ray, neutron, XFEL, cryo-EM and other communities from coming to a consensus on the use of the terms 'atomic resolution' and 'near-atomic resolution', as suggested in the Letter.

Meetings, workshops and other outreach activities. The CBM has recommended support from the IUCr for a number of meetings and workshops that can provide a teaching or major dissemination role for macromolecular crystallography.

\section{T. Terwilliger, Chair}

\subsection{Commission on Charge, Spin and Momentum Densities}

During 2016, the Commission has been active in the organization of meetings, schools and workshops. Moreover, indepth discussion has being ongoing concerning the emerging field of quantum crystallography, which has convinced the Commission to apply for a modification its name to Commission on Electron Densities and Quantum Crystallography; this will be proposed to the Executive Committee 
for submission at the next General Assembly of the IUCr. In 2017 and 2018 two important and prestigious conferences will take place on this subject: the CECAM discussion meeting Quantum Crystallography: Current Developments and Future Perspectives (Nancy, France, 19-20 June 2017) and The Erice School on Quantum Crystallography (Erice, Italy, 1-10 June 2018).

The 7th European Charge Density Meeting took place in Warsaw, Poland, 26 June -1 July 2016, organized by K. Wozniak and P. Dominiak, in conjunction with the annual Polish Crystallographic Meeting. There was a high attendance, with many experts worldwide and many young researchers. The charge-density community in Poland is in fact quite large, which was very important for the attendance and organization of the meeting. During the meeting very intense discussions also took place concerning the future of this field in view of new opportunities.

As a satellite meeting of the European Crystallographic Meeting in Basel, Professor M. Souhassou and Dr P. Macchi organized, with the collaboration of the LCRM2 of the University Lorraine, the first Robert F. Stewart School on Electron Density and Related Properties in Nancy, France, 22-26 August 2016. This was the inaugural school of a hopefully long series dedicated to the memory of Professor R. F. Stewart, who made enormous contributions in the field and unfortunately passed away in 2015. New schools are expected in 2017, such as the MoPro workshop at the University of Mexico, 12-15 June 2017.

At the 30th European Crystallographic Meeting in Basel, Switzerland, 28 August - 1 September, three dedicated Microsymposia were organized (Charge and Spin Density of Materials at Extreme Conditions, Beyond Multipolar Refinement, and Measuring Data Quality) and one Keynote Lecture was given by Dr Birger Dittrich. During this conference, the board of the Special Interest Group on charge, spin and momentum density (SIG2) was renewed. During the discussion, it was also suggested to review the name of this Special Interest Group in keeping with the proposed modification of the name of the Commission.

The Commission has also supported some multidisciplinary workshops and conferences that took place in 2016, such as the 11th USPEX Workshop on Evolutionary and Interpretative Methods for Discovering the Structures and Rationalizing the Properties of Crystalline, Surface and Nanoparticle Materials (organized in Villa Monastero, Lake Como, Italy, 5-9 June 2016, by Dr C. Gatti and Professor A. Oganov) and the first Pan-African Conference on Crystallography (PCCr1), organized in Dschang, Cameroon, 6-11 October 2016.

In 2016, the Commission project Round-Robin Test on Charge Density Determination using Synchrotron and HomeLaboratory Radiation Sources made significant progress and all data collected by various participants were analysed by $\mathrm{Dr}$ J. Overgaard (University of Aarhus, Denmark). Publication of the results is planned shortly.

P. Macchi, Chair
4.6. Commission on Crystal Growth and Characterization of Materials

In 2016 members and consultants of the Commission (CCGCM) had the chance to meet on 8 August at the XVIII International Conference on Crystal Growth and Epitaxy, Nagoya, Japan. This is the most important event organized by the International Organization for Crystal Growth (IOCG), and is described in more detail in my report as IUCr Representative to the IOCG in Section 9.5.

Several members and consultants were present at the meeting: Sonia Baldochi, Thierry Duffar, Haosu Luo, Tatiana Bekker, J. Wang, Andrea Zappettini and Janakiraman Kumar. Koichi Kakimoto and Tom Kuech could not be present owing to other duties. Hanna Dabkowska was also present as liaison with the IUCr Executive Committee. Xiang Yang Liu was present because he was personally interested in the work of the Commission.

Everybody expressed congratulations to the conference organizers (first of all, to Koichi Kakimoto) for the opening session of the conference, with the Plenary Lecture of Nobel Laureate Professor Akasaki in the presence of His Imperial Highness the Crown Prince of Japan.

Because I am the representative of the Commission on the International Programme Committee (IPC) of the Hyderabad Congress, I reported on the status of the Congress organization and in particular on the IPC meeting that took place in Hyderabad last March. Several Microsymposia suggested by the Commission were accepted by the IPC and will be organized.

One of the most important interests of the CCGCM is the organization of schools on crystal growth, so the Commission discussed the organization of these in the coming years. In fact, the week before the International Conference on Crystal Growth and Epitaxy, the International School on Crystal Growth was held - also in Japan. The school was very successful. The 6th International School on Biological Crystallization (ISBC2017) will be organized in Granada, Spain, 29 May - 2 June 2017. The Commission previously recommended that the IUCr should support this event. In 2018, together with the 6th European Conference on Crystal Growth, the 2nd European School on Crystal Growth will be held in Varna, Bulgaria. Then, in 2019, the International School on Crystal Growth will again be held in the USA. Thus, it seems that for the next few years there will be one international school every year and, most probably, two in 2018 and 2019, taking into account the school that will be held in Granada. However, it was observed that an international school in Asia in the coming years would also be welcome, taking into account the large interest in crystal growth in the Far East.

The work of the Commission in 2016 was mainly devoted to the organization of the Hyderabad Congress. Our Commission suggested and supports several Microsymposia. Among these are: (i) Topological Insulators, co-chaired by J. Kumar; (ii) Hybrid Perovskites, co-chaired by R. Mosca; (iii) Biological Macromolecules, co-chaired by Abel Moreno; (iv) Polymorphism and Solid-Form Investigations, co-chaired by S. 
Cuffini; (v) Crystal Growth and Nucleation, co-chaired by Jaime Gomez Morales; (vi) Multiferroic Materials, co-chaired by G. Mezzadri. Additionally, a Keynote speaker has been suggested.

In 2016 the IUCr supported the following schools/meetings that were important to the crystal-growth community:

16th International Summer School on Crystal Growth (ISSCG-16), Lake Biwa, Shiga, Japan, 1-7 August 2016.

18th International Conference on Crystal Growth and Epitaxy (ICCGE-18), Nagoya, Japan, 7-12 August 2016.

Fifth International School on Crystallization: Drugs, Foods, Agrochemicals, Minerals, New Materials (ISC2016), Granada, Spain, 22-27 May 2016.

First Pan-African Conference on Crystallography (PCCr1), Dschang Cameroon, 6-11 October 2016.

First Workshop on Crystallography for Space Sciences, Puebla, Mexico, 17-30 April 2016.

16th International Conference on the Crystallization of Biological Macromolecules (ICCBM-16), Prague, Czech Republic, 2-7 July 2016.

Finally, I wish to express my great honour and pleasure to remain as chair of this Commission. I hope I am making my own contribution to all the work done up to now by the Commission to bring more understanding of the role of crystals and their influence in many aspects of life and technology.

\section{A. Zappettini, Chair}

\subsection{Commission on Crystallographic Computing}

The organization is well in hand for the Computing School which will be held during the week before the Hyderabad Congress, i.e. 15-20 August 2017. The venue is the Molecular Biophysics Unit of the Indian Institute of Science in Bangalore, India, and the local organizer is Professor B. Gopal of the Indian Institute of Science, Bangalore. Professor Gopal is also a member of the INSA-ICSU Committee for the IUCr.

The school web site is hosted on the IUCr server at http:// www.iucr.org/resources/commissions/crystallographic-computing/ schools/bangalore2017.

Our speakers are drawn from across the different crystallographic sub-divisions and we are looking forward to a full programme of talks and tutorials for the students.

To date we have received 41 applications and can accommodate a total of 50 students; our planning aimed at 50 attendees including speakers, so provided that there are not too many late withdrawals, we would be more than satisfied with this. The Local Organizing Committee is currently working through the applications to ensure that all students are suitable. We are also making the course available to local students free of charge.

We are currently putting together a complete list of our sponsors with links for a sponsors' page on the meeting web site.

Our intention to keep the registration fee to an absolute minimum has been realized - the cost to students including all accommodation and meals has been set at INR 5000 (about EUR 70) by a combination of sponsorship, low local costs and making use of speakers who will already be travelling to India for the Congress.

We are in the early stages of planning the next school, which is intended to take place in the castle in Nove Hrady, Czech Republic, before the Prague Congress in 2020. I have had some correspondence with Professor Jindrich Hasek about this and have a provisional booking for the venue.

\section{H. R. Powell, Chair}

\subsection{Commission on Crystallographic Nomenclature}

The members of this Commission (the $\mathrm{CCN}$ ) are the Editors of the Union's journals and the Editors of the volumes of International Tables, the Chair of the IUCr/OUP Book Series Committee, the Chair of the Commission on Crystallographic Teaching, the Chair of the Committee for the Maintenance of the Crystallographic Information File, the President of the IUCr and the General Secretary of the IUCr. The total number of members and appointed consultants exceeds 50 . This number is somewhat unwieldy but there seems to be no good way to reduce it. In the case of a matter needing the vote of the whole Commission, a Working Group composed of members representing all important viewpoints would be asked to prepare a report to be circulated to the $\mathrm{CCN}$ in advance of the vote. The Commission's web page invites crystallographers to bring nomenclature problems to the attention of any Commission member. Three such problems were considered during 2016:

(1) Nomenclature for the Field of Crystal Engineering. In 2014 ICSU funded a project titled CONcepts and termINology in Crystal Engineering (CONvINCE). The Lead Applicant for the project was IUPAC; the IUCr was listed as a Supporting Applicant. Gautam Desiraju (then IUCr President) was named as the IUCr contact. After the Montreal Congress the $\mathrm{CCN}$ became involved.

In 2015 the CCN Chair attended a meeting connected with the project in Como, Italy. It seems that no proposed definitions have yet come out of that meeting but a project extension has been granted. A Special Activities Microsymposium titled Terminology Issues in Crystals Engineering will be held at the Hyderabad Congress, with the speakers having been invited by the IUCr Immediate Past President. The CCN Chair and Christer Aakeroy will preside.

(2) Definition of Miller Indices. In spring 2016 Edward Michalski contacted the CCN about statements in Volume B of International Tables and in the Online Dictionary that Miller indices must be relatively prime [i.e. that (010) and (120) are allowed but (020) and (240) are not]. That requirement is correct for a primitive unit cell, which is what mathematicians use almost exclusively. In the 'conventional' centred unit cells often used by crystallographers, however, Miller indices must be relatively prime in only some directions [see Nespolo (2015). J. Appl. Cryst. 48, 1290-1298]. Beginning 
in January 2016 Nespolo made a series of changes to the definition in the Online Dictionary to solve the problem. Later in the year U. Shmueli, the author of the article in Volume B, was contacted about making a minor change to Section 1.1.2. The printed Volume B cannot be changed before a revision is complete but it was decided that the online version could be corrected. A change proposed by Shmueli was made during March 2017.

(3) Nomenclature for Arithmetic Crystal Classes. In mid2015 Howard Flack proposed that the nomenclature of arithmetic crystal classes be changed so that the symbol of each class would start with the symbol for the Bravais-lattice type and conclude with the symbol for the crystal class (oriented point group). Thus for space group No. 45, Iba2, for which the current symbol is $m m 2 I$, the new symbol would be oImm2. Because the proposal would affect Volume A of International Tables, for which a revision was very close to completion, the proposal was not discussed much until mid2016. The proposal did not generate much enthusiasm, and with the untimely passing of its sponsor the proposal lost its impetus. An important consideration is the amount of work that would be required to change all occurrences of affected symbols in the various volumes of International Tables and in the Online Dictionary.

Online Dictionary of Crystallography $(O D C)$. The $\mathrm{CCN}$ is responsible for maintaining this dictionary, which was established in 2006 and published in paperback in 2014.

While many crystallographers believe the dictionary to be important, the number of contributed definitions is still below 300. Furthermore, important questions have been raised about how authoritative the included definitions should be considered to be, especially since the ODC is being cited in the scientific literature ( $c a$ eight times in 2015-2016). During 2016 the decision was made to discuss these matters informally before the 2017 Congress and then in Hyderabad. One plan would be to ask the various IUCr Commissions to be more formally involved in contributing and reviewing definitions.

\section{P. Brock, Chair}

\subsection{Commission on Crystallographic Teaching}

Since filing its last annual report, the Commission (CCT) has continued its efforts to reach out to the crystallographic community, the scientific community and the community at large by using social media. The CCT Facebook page (http://www. facebook.com/IuCrCommissionOnCrystallographicTeaching) has 970 'likes' (a 90\% increase since our last report), and our Twitter feed (@IUCrTeach) has 98 followers (a 26\% increase since our last report). The CCT has not been as active as it had planned to be on either social-media outlet owing to extensive professional and personal commitments of its members. We do try when possible to disseminate exciting findings and important information, post career opportunities in crystallography and allied fields, and stimulate discussion.
We still plan to share responsibilities on social-media sites, and also to make a concerted effort in the next year or so to review the content on our web pages on the IUCr site. We will examine resources for utility and audience, reorganize content as appropriate, and update information. Our ultimate goal remains to make all our communication channels and information targeted and relevant to specific audiences, and to strengthen the brand of the IUCr.

As noted in last year's report, the CCT sponsored three Microsymposia at the Montreal Congress. A paper reporting on MS92: Crystallography Education and Training in the 21st Century: New Pedagogies, New Paradigms was published as open access in the Journal of Applied Crystallography [S. Grazulis et al. (2015). J. Appl. Cryst. 48, 1964-1975]. The authors and the CCT felt that the article would have the largest and most appropriate audience in Journal of Applied Crystallography rather than IUCrJ.

Manfred Weiss, member of the CCT, is representing this Commission on the International Programme Committee for the Hyderabad Congress. The CCT will be sponsoring or cosponsoring four Microsymposia.

In the past year, the CCT has reviewed and written many supporting letters for several proposals of variable quality and made recommendations for workshops and summer schools focused on areas relevant to the discipline. As noted last year, since the Montreal Congress, the CCT now reviews and writes recommendation letters for all workshop and summer-school proposals. While we have been very pleased by this development implemented by the Executive Committee, the process has been a bit cumbersome. The proposals received by the CCT continue to vary considerably in quality, and proposers continue to expect an immediate response and automatic endorsement at full funding levels. The CCT plans to work with the IUCr to create a shared file system, whereby submitted proposals in electronic form are easily accessed and reviewed. Alternatively, the CCT proposes to work with the IUCr to receive applications by means of a web-based submission system. It would be ensured that all information was there, and that the CCT had enough time (two weeks) to review a submitted application and rate/rank it. The CCT this past year has attempted to develop and implement more formalized rubrics for evaluating proposals, which will enable proposers to make the best possible case in their request, and also enable the CCT to determine more easily whether the proposals meet the mission and goals of the IUCr, to provide more useful feedback to the Executive Committee. The CCT also hope that by streamlining the electronic process, the IUCr can avoid last-minute e-mail attachments from proposers, which may be incomplete or may not have been copied to the appropriate member of the Executive Committee. Moreover, we hope to avoid situations that have arisen in the past year, where proposals e-mailed to the CCT for review have been lost, blocked, or buried in busy e-mail inboxes.

K. A. Kantardjieff, Chair 
4.10. Commission on Crystallography in Art and Cultural Heritage

The Commission (CrysAC) continues to pursue the mission of spreading crystallographic knowledge related to artworks and ancient materials.

Conferences, sessions, lectures

(1) The Commission has started to hold Crys AC workshops. The first CrysAC workshop on Cultural Heritage Authentication and Forensic Science was held in Krakow, Poland, 18 May 2016. The programme of this first workshop follows:

Opening: Gilberto Artioli, Chair of the Commission.

Session 1 (Chair: Alicja Rafalska-Lasocha); Gilberto Artioli, introductory lecture; Filippo Terrasi, Forensic Applications of 14C Accelerator Mass Spectrometry; Zuzanna Brozek Mucha, Applications of X-ray Spectrometry and X-ray Diffraction in Forensic Investigations; Sariel Shalev, Unusual Objects in Archaeology: Genuine or Fake?; Paul Craddock, Artificial Patinas: Methods and Motives; Petr Bezdicka, Advanced Methodology for Quantitative X-ray Microdiffraction Analysis and Its Use in Provenancing Clay-Based Pigments in Paints.

Session 2 (Chair: Petr Bezdicka); Manfred Schreiner, Application of Computational Techniques and Material Analysis for the Authentication of Our Cultural Heritage; Koen Janssens, Authentication of Paintings via NonDestructive Chemical Mapping Analysis; Barbara LydzbaKopczynska, A Combined Imaging and Spectroscopic Approach to Fine Art Authentication; Stjepan Prugovecki and Jan Gertenbach, Authentication and Forensic Applications on PANalytical X-ray Systems; Round-table discussion chaired by G. Artioli.

(2) Crys AC was a co-organizer of the 6th Meeting on X-ray and Other Techniques in Investigations of the Objects of Cultural Heritage, Krakow, Poland, 19-21 May 2016 (A. Rafalska-Lasocha, G. Artioli and P. Bezdicka) (http:// www.biurokarier.chemia.uj.edu.pl/conf/x-ray16).

(3) Organization of Microsymposium MS48 Crystallography in Art and Cultural Heritage at ECM-30, Basel, Switzerland (Chair: A. Rafalska-Lasocha): A. Zürn, MAKING GOLD: Recent Developments and New Perspectives; K. Janssens, Micro-XRPD, XRPD Tomography and MA-XRPD: Three Related Methods to Better Understand Structural Alterations in Cultural Heritage Materials; M. Emami, Crystallographic Interpretation of Mineral Decompositions via Rietveld Refinement Strategy for Clustering Ancient Ceramics; in the absence of Professor Emani, Alicja Rafalska-Lasocha gave a talk on the Commission on Crystallography in Art and Cultural Heritage; P. Bezdicka, Provenancing of Clay-Based Pigments in Paints Using Quantitative X-ray Micro-Diffraction Analysis (http:// www.professionalabstracts.com/ecm2016/iplanner/\#/grid).

(4) The Commission actively participated in the organization of the Hyderabad Congress. Gilberto Artioli and Alicja Rafalska-Lasocha, as members of the International Programme Committee, took part in the meeting organized in March 2016 and were involved in the organization of Plenary and Keynote lectures as well as Microsymposia connected with the investigations of the objects of cultural heritage.

(5) The Commission is also a co-organizer of the 6th Interdisciplinary ALMA Conference, Brno, Czech Republic, in 2016 (Petr Bezdicka: Chair of the Organizing Committee; G. Artioli, A. Rafalska-Lasocha: members of the International Programme Committee).

Celerino Abad-Zapatero continued collaboration with $\mathrm{Mr}$ Painton Cowen to incorporate scientific content into the 'rose window' site (http://therosewindow.com/TheRoseWindow2/ Rose-numbers.htm).

Symmetry: Through the Eyes of Old Masters, by E. Malovicky, was published by Walter de Gruyter GmbH \& Co. in 2016.

Earth Sciences for Cultural Heritage, edited by G. Artioli and S. Quartieri, was published as a Special Issue of Elements [(2016), 12(1)].

The new CrysAC web site is now available at https:// www.iucr.org/resources/commissions/crysac.

\section{G. Artioli, Chair and A. Rafalska-Lasocha, Secretary}

\subsection{1. ad interim Commission on Crystallography of Materials}

Our ad interim Commission was approved at the meeting of the Executive Committee of the IUCr in Boston (July 2012). This is the newest and in many ways a unique Commission, which covers a crystallographic topic that has not been covered by other IUCr Commissions (web site http://uhp. iphy.ac.cn/CM/).

Members of the Commission took part in the following activities:

Hyderabad Congress. The Commission was represented on the International Programme Committee by Evgeny Antipov and Shilun Qiu. Organization of (1) Keynote Lectures: (a) Vladislav Blatov (Russia), Topological Approach for the Design of New Materials; (b) Juri Grin (Germany), Materials for Energy; (2) Unshared Microsymposia: (a) Computational Materials Design (MS6) (Chairs: Artem Oganov, Samrath Lal Chaplot); (b) Crystallography of Battery Materials (MS25) (Chairs: Nellie Khasanova, Prabeer Barpanda); (c) Crystallography of Materials for Energy (MS122) (Chairs: Artem Abakumov, Oliver Oeckler); (3) Shared Microsymposia: (a) Superconducting Materials (MS70) (Chairs: Irina Makarova, R. J. McQueeney); (b) Bio-Compatible Porous Materials for Drug Delivery; (c) Crystallographic Approach for Designing New Metal Organic Frameworks; $(d)$ Functional Materials on the Nano Scale; (e) In Situ and In Operando Characterization of Catalytic and Functional Materials; ( $f$ ) In Situ and In Operando Characterization of Energy Materials; ( $g$ ) Polyoxometalates as Building Blocks for Functional Materials; $(h)$ Porous Framework Materials for Sensing; (i) XAFS of Materials for Clean Energy.

Conferences and symposia:

NERM ACS Symposium Materials for Energy: New Trends and Challenges, Binghampton, New York, 5-7 October 2016; 
organizers: Marina A. Petrukhina, Stanley M. Whittingham; number of participants: $40-50$.

VIII Russian Crystal Chemistry Conference, Suzdal, Russia, 30 May - 3 June 2016 (http://conferences.icp.ac.ru/ NCCC2016/1st-announcement.php); Conference Chair Evgeny V. Antipov; number of participants: 255.

Symposium of Quantum Materials at Extreme Conditions, Beijing, People's Republic of China, 2016; Chair C. Q. Jin; about 80 participants.

Organization of workshops to disseminate knowledge and technical skills:

11th USPEX Workshop on Crystal Structure Prediction, Enrico Fermi Conference Center, Villa Monastero, Varenna, Italy, 5-9 June 2016; organizers: Carlo Gatti, Davide Ceresoli, Artem R. Oganov; number of participants: 40.

Modern Charge Density Analysis, edited by Carlo Gatti and Piero Macchi, was published by Springer.

Changqing Jin received the National Award for Natural Sciences (New Quantum Emergent Materials and the Effects of Pressures).

\section{A. R. Oganov, Chair}

\subsection{Commission on Electron Crystallography}

During the last year, representatives of the People's Republic of China and Bulgaria have asked for financial support for the 9th K. H. Kuo Summer School on Electron Microscopy and Crystallography in Beijing and the School on Fundamental and Electron Crystallography in Sofia, respectively. These two requests were fully approved by all members and consultants of the Commission. Accordingly, letters of support were provided.

The 3D Cryo-EM Molecular Imaging and the 9th K. H. Kuo Summer School on Electron Microscopy and Crystallography in Beijing, People's Republic of China, was held 24-30 June 2016. It was organized by Hongwei Wang (Tsinghua University, People's Republic of China) and Peijun Zhang (University of Pittsburgh, USA). The meeting had two parts: a two-day workshop and a three-day symposium on cryo-EM.

Altogether 321 participants attended the school in Tsinghua University: $169 \mathrm{PhD}$ students, 3 Masters students, 37 post-docs, 50 senior scientists (48 Professors, 2 Associate Professors) and 62 staff scientists; the ratio of women to men was 129:192. The participants came from many countries: Australia, Canada, People's Republic of China, Colombia, Germany, Hong Kong, Japan, Saudi Arabia, Singapore, South Korea, Sweden, Switzerland, United Kingdom and USA.

Lectures covered sample preparations using negative staining and cryo-freezing, EM operation for auto data collection, a theory of electron microscopy, image processing and micro-electron diffraction. There was also a demonstration of software and practicals on single-particle analysis. Speakers gave talks on the newest topics of cryo-EM, including advances in cryo-EM technologies, electron diffraction, cryo-EM on highly symmetric structures, singleparticle applications and dynamics, cryo-EM of membrane proteins, cryo-EM of cellular structures and electron tomography.

Forty-two posters selected from the submitted abstracts were presented by students and young scientists, among which five were selected to give oral presentations. The meeting provided an excellent opportunity for young scientists and students in the field of cryo-EM to have direct communication with the leading scientists of the field. The meeting also promoted international communication and cooperation in cryo-EM and structural biology. The majority of students would recommend it to other laboratories and scientists.

The Commission on Mathematical and Theoretical Crystallography and the University of Antwerp organized the International School on Fundamental Crystallography with Applications to Electron Crystallography, Antwerp, Belgium, 27 June 2016; organizer: Joke Hadermann.

\section{E. Orlova, Chair}

\subsection{Commission on High Pressure}

This report covers the triennial period between the IUCr Congresses in Montreal (August 2014) and in Hyderabad (August 2017). The Commission on High Pressure (CHP) in this term initially consisted of the following members: Andrzej Katrusiak (Poland) (Chair), Haozhe Liu (China) (Secretary), Ross Angel (USA), Elena Boldyreva (Russia), Simon Clark (Australia), Wilson Crichton (France), Francesca Fabbiani (Germany), Yasuo Ohishi (Japan), Chrystele Sanloup (France) and Guoyin Shen (USA). Consultants: Kamil Dziubek (Italy) (Treasurer), John Loveday (UK), Richard Nelmes (UK), Ingo Loa (UK) (web site), Przemek Dera (USA) and Boris Zakharov (Russia).

After about a year, Wilson Crichton (France) resigned from the Commission owing to the new commitments at work. Thus the CHP continued with nine members.

The main tasks of the CHP were to organize annual workshops, schools and other conferences and to undertake the task of preparing guidelines for high-pressure metadata and high-pressure data deposition, as well as other tasks, such as preparation for the systematic recording of historical contributions to high-pressure research.

IUCr High-Pressure Workshop. The 2015 IUCr workshop was held at the Brazilian Synchrotron Light Laboratory (LNLS) in Campinas, Brazil. It was attended by 61 participants from 14 countries. The workshop primarily focused on recent advances in high-pressure techniques and research. Lectures and posters covered various aspects of high-pressure crystallography, structural phase transitions and their kinetics, new materials synthesis, Earth and planetary science, soft and biological matter, physical and chemical properties, theory and computation, as well as technique developments for highpressure studies at synchrotron, neutron and laboratory-based facilities.

Nearly 30 lecturers presented their results: K. Dziubek, M. Zaworotko, L. Miyagi, S. Hunt, H. Marquardt, J. Haines, N. Brooks, D. Paliwoda, R. Wentzcovitch, K.-M. Ho, K. 
Umemoto, V. Solozhenko, A. Cairns, S. Deemyard, M. Pravica, M. Probert, R. Miletich, Y. Le Godec, S. Redfern, R. Conceicao, J. A. Lima Jr, J. Smith, R. Bini, C. Murli, A. Gomes, G. Finkelstein, M. Marcondes and O. Kurakevych.

Best-poster awards went to Zuzana Konopkova (Towards Time-Resolved Studies Using X-Ray Diffraction At Synchrotrons) and Marcelo Nobrega (High Pressure Study and Oligomerization of 2-Aminoterephthalate/Ni-Al Layered Double Hydroxide Composites).

The workshop was held just after the 1st Latin American Crystallographic Association (LACA) Meeting in São Paulo, promoted by LACA jointly with the 22nd Sociedade Brasileira de Cristalografia (SBC Meeting), and before the 25th RAU (LNLS Annual Users Meeting), promoted by LNLS, from September 16-17. This allowed those interested to participate in all these events. A few companies sponsored the workshop, namely: Agilent Technologies, Quantum Design, MCI/Princeton Instruments, Dectris, Almax-EasyLab and Huber. In addition to the support from the IUCr, the Brazilian funding agencies FAPESP and CAPES also supported the event.

IUCr High-Pressure Workshop 2016 at PAL in Pohang, South Korea. The 14th IUCr High-Pressure Commission (CHP) Workshop was held at the Pohang Advanced Laboratory in South Korea, 20-24 September 2016, with the Organizing Committee chaired by Professor Yongjae Lee (Yonsei University, Seoul). The workshop was primarily focused on recent advances in high-pressure techniques and research. Lectures and posters covered various aspects of high-pressure crystallography, structural phase transitions and their kinetics, new materials synthesis, Earth and planetary science, soft and biological matter, physical and chemical properties, theory and computation, as well as technique developments for high-pressure studies at synchrotron, neutron and laboratory-based facilities. The workshop was attended by 120 participants from 19 countries.

The workshop started with a welcoming speech by Professor Kibong Lee, the Director of PAL. Plenary talks were given by Dr Ho-Kwang Mao, the Director of HPSTAR, China, on Pressure and X-Radiation; Dr Chi-Chang Kao, the Director of SLAC, National Accelerator Laboratory, USA, on The Potential of X-ray Free Electron Lasers for High Pressure Research; and by Professor Takehiko Yagi, University of Tokyo, Japan, on Synchrotron Facilities and High Pressure Science in Japan.

Invited and contributing lecturers included Tomoo Katsura, Sang-Heon Shim, Vladimir Solozhenko, Timothy Strobel, Naoki Noguchi, Barbara Lavina, Byeongchan Lee, Kamil Dziubek, Takamitsu Yamanaka, Lin Wang, Keizo Murata, Wenge Yang, Hyunchae Cynn, Bin Chen, Stanislav Sinogeikin, Olivier Mathon, Yanbin Wang, Alfred Baron; Naohisa Hirao, Catalin Popescu, Cindy Bolme, Hae Ja Lee, Yanming Ma, Toshiaki Iitaka, John Tse, Garry McIntyre, Jack Binns, Boris Zakharov, Andrzej Katrusiak, Sung Keun Lee, Simon Clark and Luhong Wang.

Two special sessions were held to highlight PAL and High Pressure Research in Korea. Before an excursion to the PLSII and PAL-XFEL facilities, Jae-Young Kim (PAL) discussed the current status of PLS-II beamlines, and an introduction to PAL-XFEL was presented by its Director, In Soo Ko. Highpressure research in Korea was reviewed by Young-Ho Kim (Gyeongsang National University), and current high-pressure research and activities were introduced by a number of researchers from Korea; Young-Ho Ko (Agency for Defense Development, Korea), Research on Materials Under High Pressure or Temperature; Sung Keun Lee (Seoul National University), Glasses and Melts Under Compression and Extreme Confinement; Kee Hoon Kim (Seoul National University), Critical Behavior in Quasi-One-Dimensional Organic Conductors as Investigated by a Cubic Anvil Cell up to $8.5 \mathrm{GPa}$; Jaeyong Kim (Hanyang University), HYUHPSTAR-CIS High Pressure Research Center; Geun Woo Lee (KRISS), Study of High Pressure and High Temperature in KRISS; Yongjae Lee (Yonsei University), Construction of Max-X (Matter in eXtreme conditions X-ray) Beamline at Pohang Accelerator Laboratory.

Six young scientists were distinguished by a diploma and IUCr awards, and presented short talks. Four Young Scientist posters were awarded.

Following the positive experience from the previous $\mathrm{IUCr}$ CHP Workshop in Campinas (2015), we fully implemented a scheme of standby lecturers filling any gaps caused by lastminute cancellations. Consequently, no session suffered from missing lectures at all, as several scientists selected according to their contributed posters and all the CHP members were asked to step in with prepared lectures that replaced the missing ones. Only these presented lecturers are listed above.

The workshop was sponsored by a number of institutions including YONSEI-SLAC-USC Global Research Laboratory and HYU-HPSTAR-CIS High Pressure Center, funded by the Korean Ministry of Science, ICT, and Planning (MSIP) and the BK21Plus Institute at Yonsei University, funded by the Korean Ministry of Education. In particular, support from the IUCr, HPSTAR and PAL are gratefully acknowledged.

Detailed reports of the two workshops were given in the IUCr Newsletter.

Course on High-Pressure Crystallography: Status Artis and Emerging Opportunities, 27 May 27 - 5 June 2016. This third high-pressure course was held in Erice, Italy, and it continued the tradition of high-pressure crystallographic courses aimed at the dissemination of high-pressure techniques. The course directors were Dr Francesca Fabbiani (CHP member), Professor J. B. Parise and Dr M. Guthrie. The course attracted about 100 participants and was an occasion for several CHP members to meet. During the course several meetings of the Subcommission on High-Pressure (Meta)data Deposition were held.

High-Pressure Magic at Wits, Johannesburg, 19-23 October 2015. One of the main aims of the IUCr High Pressure Commission is the dissemination of high-pressure techniques in crystallographic laboratories, and in this spirit the HighPressure Magic Workshop was organized at the Jan Boeyens' Structural Chemistry Department of the Witwatersrand University in Johannesburg. To our knowledge, this was the first high-pressure crystallographic event in South Africa. The 
programme of the workshop included five working days, Monday to Friday, each morning starting with a two-hour lecture, followed by a coffee break, practical exercises in the laboratory, lunch and practical exercises. The workshop was sponsored by the National Research Foundation of South Africa, Research and Innovation Support and Advancement (RISA) grant, and by Bruker South Africa.

CHP Subcommission on (Meta)data deposition (SMDD). One of the main tasks of the CHP was the preparation of guidelines for metadata deposition. For this purpose a CHP Subcommission was established with the following members: Kamil Dziubek (Italy) (Subcommission Chair), Ross Angel (USA), Andrzej Katrusiak (Poland), Guoyin Shen (USA) and Boris Zakharov (Russia). The SMDD has met several times during conferences and has also corresponded throughout the term. We have established that guidelines for the deposition of both crystallographic data for high-pressure experiments and of the metadata have to be prepared. A report on the deposition of high-pressure data and metadata has been prepared and will be published soon.

\section{A. Katrusiak, Chair}

\subsection{Commission on Inorganic and Mineral Structures}

Members and consultants of the Commission (CIMS) discussed various issues via e-mail. Other communications were at occasional meetings or conferences or by using the web site. The latter is kindly maintained by M. Nespolo (http:// www.crystallography.fr/cims/).

The Commission on Structural Chemistry (CSC) and CIMS maintained their links. P. Mercier is now the liaison person representing CSC in CIMS and vice versa.

CIMS also maintains strong links with the new Commission on NMR Crystallography and Related Methods. J. Rocha is the liaison person and also consultant for that Commission.

P. Mercier continues to act as liaison officer of CIMS with the IUCr Newsletter.

Strong links exist between CIMS and the European Crystallographic Association: O. Yakubovich (CIMS member) was a member of the Executive Committee; the Secretary of the Special Interest Group SIG-05 is O. Siidra, the Chair is S. Krivovichev (CIMS consultant) and F. Hatert (CIMS member) is Vice-Chair (ECA - SIG5, http://sig5.ecanews.org/).

There are very good relationships between CIMS and the European Mineralogical Union (EMU, http://eurominunion. org/); R. Oberti (EMU Past-President) is a member of CIMS and also Commissioning Editor of the EMU Notes in Mineralogy and Co-editor of the volume entitled The Contribution of Mineralogy to Cultural Heritage to be printed in 2017. The volume Mineralogical Crystallography, co-edited by J. Majzlan, Sergey Krivovichev (CIMS consultant) and J. Plasil, will also be published in 2017.

M. Nespolo is Book Review Editor for the IUCr journals.

G. Ferraris was Co-editor of an issue of Rendiconti Lincei (to be published by Springer in 2017) containing some of the lectures delivered at the meeting Mineral Phases and Synthetic Analogues in Earth and Materials Science, at the Accademia dei Lincei, Rome, 13-14 June 2016.

C. Ling is the Vice-President of the Society of Crystallographers in Australia and New Zealand (SCANZ) and the Secretary of the Asia-Oceania Neutron Scattering Association (AONSA).

P. Mercier has been Chair of the Canadian National Committee for Crystallography since August 2015.

R. Oberti is Chair of the Committee on the Participation of CNR (Consiglio Nazionale delle Ricerche) to the IUCr.

Sergey Krivovichev served as President of the IMA 20152016.

CIMS was involved in the following meetings held in 2016:

C. Ling was a member of the Organizing Committee for Crystal-30 (http://crystal30.com), the 30th meeting of the Society of Crystallographers in Australia and New Zealand, held in Hobart, Australia, 29 March - 1 April 2016.

G. Ferraris organized the international meeting Mineral Phases and Synthetic Analogues in Earth and Materials Science at the Accademia dei Lincei, Rome, 13-14 June 2016, and Joao Rocha delivered one of the 12 invited lectures.

R. Oberti was a member of the Scientific Committee of the 2nd European Mineralogical Conference, Rimini, Italy, 11-15 September 2016 (http://emc2016.socminpet.it/). Sergey Krivovichev was also a member of the Scientific Committee. Twenty-eight scientific sessions discussed cutting-edge aspects of mineral sciences, and structure-based approaches played a major role. One of the six plenary lectures was delivered by Karen Appel (European XFEL, Hamburg) and was dedicated to the exciting perspectives provided to Earth sciences, and in particular to the study of mineral reactions, by XFEL techniques. The 2016 school of the Associazione Italiana di Cristallografia (Polymorphism, Stability and Phase Transitions in Crystals: Theory, Experiments, Applications), with an international audience and lecturers, was held as a satellite meeting (Rimini, 7-11 September).

J. Rocha was on the Organizing Committee of the 5th SMARTER 5 meeting in Bayreuth, Germany, which for the first time was a satellite meeting of the (30th) meeting of the European Crystallographic Association. (http://www. smarter5.uni-bayreuth.de/de/index.html). This event is now promoted jointly by CIMS and the Commission on NMR Crystallography and Related Methods.

O. Yakubovich was an invited speaker at the VII Russian School for Young Scientists: Experimental Mineralogy, Petrology and Geochemistry, Chernogolovka, Russia, 20-21 October, 2016. She also gave an oral presentation at the 1st Russian Crystallographic Congress (Moscow, Russia, 21-26 November 2016).

CIMS has been involved in the organization of the following meetings:

Preparation for the Hyderabad Congress. In particular, CIMS members and consultants are chairing the following Microsymposia: (i) MS7 Topology and Symmetry of Modular Structures (I. Pignatelli, S. V. Krivovichev); (ii) MS52 Minerals/Gems in Industrial Applications (P. Mercier). M. 
Nespolo will give the Keynote Lecture Crystal Rationale for the Formation of Twinned Crystals.

P. Mercier is a member of the Programme Committee for the 2017 IUCr Crystallographic Computing School, Bangalore, India, 15-20 August 2017.

R. Oberti is a member of the Scientific Committee of the 2017 EMU school Mineral Fibres: Crystal-Chemistry, Chemical Physical Properties, Biological Interactions and Toxicity, Modena, Italy, 19-23 June 2017 (http://emu2017. unimore.it). Lessons and tutorials will discuss both the present knowledge of the relations between structure, surface properties and activity of mineral fibres, and the advantages and limits of the most suitable experimental methods, among which are crystallography and spectroscopies.

CIMS supported applications for funding by the IUCr of the following meetings to be held in 2017:

Workshop on Mineral Fibres: Crystal Chemistry, ChemicalPhysical Properties, Biological Interaction and Toxicity, Modena, Italy, 17-21 June 2017.

First Pan-African Meeting on Crystallography, Dschang, Cameroon, 6-11 October 2016.

\section{J. Rocha, Chair}

\subsection{Commission on Magnetic Structures}

On 8 February 2016, Alexander Pirogov, Andrea Cornia, Andrew Wills, Branton Campbell, Manuel Perez-Mato, Vaclav Petricek, Vladimir Pomjakushin, Taku Sato and Wieslawa Sikora convened an internet-video meeting to prioritize the proposed Hyderabad Congress 2017 sessions and to prepare a list of potential Chairs for each session. The resulting list emphasized diversity and also provided opportunities for cosponsorship with other Commissions. Plans to complete the magCIF dictionary were set in motion, and strategies for encouraging its widespread adoption were discussed. Manuel Perez-Mato highlighted a new tool on the Bilbao Crystallographic Server that converts between OG and BNS settings of magnetic space groups. The magCIF working group also met on 8 February to discuss a collaboration with COMCIFS to convert our custom-markup version of magCIF into a proper DDLm dictionary. Recent progress on the support of OG settings was reviewed, and a number of tags from the prototype dictionary were abandoned, revised or converted to progress-pending place holders. Discussion on new tags for communicating symmetry constraints was initiated. Existing tags in the twinCIF dictionary appear sufficient for handling magnetic-domain twinning.

The Commission's 13 October 2016 internet-video meeting was attended by Alexander Pigorov, Andrea Cornia, Branton Campbell, Danny Litvin, Juan Rodriguez-Carvajal, Manuel Perez-Mato, Vaclav Petricek, Vladimir Pomjakushin, Taku Sato and Wieslawa Sikora. Taku Sato described volatility in the list of confirmed session Chairs, which continues to require attention. Because Hyderabad appears to be a daunting summer destination for some, the Commission determined to devote extra effort to advertising the meeting. Potential changes to Commission membership and leadership were discussed; excellent recommendations were received from several National Committees, and a vote is planned for late spring 2017. Summer efforts to finalize the magCIF dictionary were reviewed. Branton Campbell and Manuel Perez-Mato provided anecdotal evidence that the historical BNS and OG magnetic-space-group symbols can be an obstacle to understanding for beginners, and suggested that a new international standard for magnetic-space-group symbols might be helpful, particularly where the magnetic point group is concerned. It was proposed that the ISO-MAG tables of magnetic space groups by Stokes and Campbell should be subject to a formal IUCr review. Future priorities include $(a)$ a representationalanalysis CIF dictionary, $(b)$ descriptions of low-dimensional and short-range magnetic order, and (c) increased efforts to educate the community on the proper description of magnetic structures. Congratulations are extended to Wieslawa Sikora for her recent retirement, and also to Vaclav Petricek for receiving ECA's Max Perutz Prize in 2016!

In April 2016, Taku Sato, the Commission's representative to the International Programme Committee (IPC) of the Hyderabad Congress, travelled to Hyderabad to negotiate the final programme. His tireless efforts resulted in many sessions with strong magnetic-structure themes, including two Microsymposia and a Keynote Lecture sponsored by the Commission, five Microsymposia co-sponsored with other Commissions, and at least five other sessions created without our direct support. His service on the IPC is greatly appreciated.

Branton Campbell and the magCIF working group, in collaboration with James Hester (COMCIFS Chair), made extensive revisions to the magCIF dictionary in preparation for the COMCIFS review. Most of the changes required for DDLm conversion were straightforward, although some required changes to core tag names and were therefore quite painful owing to loss of some backwards compatibility with numerous prototype files (e.g. those presented on the MAGNDATA web site). Once the conversion to DDLm was complete, the dictionary was submitted to COMCIFS. Final approval came on 31 October 2016. The new dictionary is now available on a Github development site, and will be formatted for the IUCr web site early next year, after several existing dictionaries have been retrofitted to DDLm. Ideally, all relevant packages will soon be able to exchange final-version magCIF files. Assignments to coordinate with a variety of software developers were delegated to working-group members. The best way to balance the use of OG and BNS is still under discussion - we will try to include both where possible. A two-way magCIF-conversion utility that could directly convert between OG and BNS settings is needed, as is a utility for converting between commensurate-supercell and incommensurate-wave descriptions of a commensurate magnetic structure.

A workshop on New Trends in Magnetic Structure Determination, Institute Laue Langevin, Grenoble, France, 12-16 December 2016 (https://indico.ill.fr/indico/event/53/overview) was sponsored by the Commission. This highlighted much of 
the new infrastructure for magnetic-structure descriptions developed by the Commission during the past five years. The meeting was organized by Juan Rodriguez Carvajal and Oscar Fabelo, and generously supported by the ILL. Lectures and tutorials were given by Laurent Chapon and Juan RodriguezCarvajal (FullProf), Vaclav Petricek (JANA), J. M. Perez Mato (Bilbao Crystallographic Server), and Harold Stokes and Branton Campbell (ISOTROPY Suite). Of the 60 applicants, 40 were selected to attend. Most participants were accomplished magnetic neutron scatterers aiming to stay abreast of recent developments. The focus of the meeting was on new software capabilities for treating magnetic spacegroup and superspace-group symmetry, magnetic representation analysis, fully general magnetic structures, and incommensurate magnetic modulations. An underlying theme throughout was the use of the new magCIF format for communicating magnetic structure information between a variety of structure-analysis programs, visualization packages and data resources.

Two papers were published in 2016 by the Bilbao Crystallographic Server team describing their MAGNDATA database of over 400 published commensurate and incommensurate structures. Each structure is unambiguously presented with magnetic space-group or superspace-group symmetry in the magCIF format [see Gallego et al. (2016). $J$. Appl. Cryst. 49, 1750-1776 and 1941-1956]. Any of the stored structures can be immediately visualized and readily imported into a variety of other software packages.

The Commission supports a variety of scientific meetings each year through formal sponsorship, direct meeting organization, featured lecture presentations, workshop tutorials, the organization and chairing of conference sessions, and the presentation of lecture courses. Highlights from 2016 include the following:

Institute of Metal Physics Achievements Meeting, Ekaterinburg, Russia, 28 March 2016 (lecture by A. Pirogov).

Crystals 30 Meeting, Hobart, Tasmania, Australia, 29 March - 1 April 2016 (Plenary Lecture by B. Campbell).

Institute of Reactor Materials 50th Anniversary Meeting, Zarechny, Russia, 19 May 2016 (lecture by A. Pirogov).

REXS20016 Conference on Resonant X-ray Elastic Scattering, Hamburg, Germany, 13-17 June 2016 (invited lecture by J. M. Perez-Mato).

3rd International School on Aperiodic Structures, Antwerp, Belgium, 4-8 July 2016 (lectures and tutorials by V. Petricek).

UFOX - Unveiling Complex Phenomena in Functional OXides, Salerno, Italy, 7-8 July 2016 (lecture by V. Pomjakushin) (http://sinq.web.psi.ch/sinq/instr/pomjakushin/ doc/pomjakus_ufox16_fin.pdf).

ACA Satellite Workshop on Magnetic Structure Determination, Denver, USA, 22 July 2016 (lectures and tutorial by B. Campbell).

MAGSTR2016 Workshop on Symmetry-Based Modeling of Magnetic Structures, Tallahassee, Florida, USA, 23-26 August 2016 (lectures and tutorials by J. M. Perez-Mato and J. Rodriguez-Carvajal) (https://conference.sns.gov/event/ 22/page/5).
ECM-30, Basel, Switzerland, 28 August - 1 September 2016 (Max Perutz Prize lecture by V. Petricek: On the Fascinating Way from an Abstract Superspace Theory to the Practical Structure Analysis of Modulated and Composite Crystals.

XIII International Conference on Crystal Chemistry of Intermetallic Compounds, Lviv, Ukraine, 25-28 September 2016 (lecture by V. Petricek).

New Trends in Magnetic Structure Determination, Institut Laue-Langevin, Grenoble, France, 12-16 December 2016 (described above).

\section{B. Campbell, Chair}

4.16. Commission on Mathematical and Theoretical Crystallography

During 2016, e-mail and the internet were the main communication tools used by the members and consultants of the Commission (MaThCryst), supplemented by personal contacts at occasional events, meetings, conferences or schools. Most of the discussions were devoted to the planned activities of the Commission for 2017, including:

(i) Activities of the Commission during the Hyderabad Congress and General Assembly. Thanks to the hard work and very successful and efficient negotiations of $L$. Suescun, as our MaThCryst representative on the International Programme Committee of the Congress, the Commission is responsible for a Keynote Lecture and two Microsymposia (MS35 CrystalStructure Relationships and Their Applications, and MS26 A Bridge Between Two Worlds: Graphs as Standard Descriptors), and will co-share the organization with other Commissions of five Microsymposia. Further, the Commission is the organizer of a satellite event of the Congress, namely the International School on Fundamental Crystallography and Workshop on Structural Phase Transitions, Rourkela, India, 30 August - 4 September 2017 (MaThCryst coordinator: M. I. Aroyo, local organizer: Dillip Pradhan).

(ii) The Second Philippine Workshop on Mathematical Crystallography, planned initially for 2016, has been rescheduled, and will take place 20-25 May 2017; M. L. A. N. De Las Peñas will act as the main local organizer and MathCryst coordinator.

(iii) Shanghai International Crystallographic School working with Bilbao Crystallographic Server, Shanghai University, People's Republic of China, 11-17 June 2017; MaThCryst coordinator: M. I. Aroyo, local organizers: A. Stroppa and Wei Ren.

(iv) International Autumn School on Fundamental and Electron Crystallography, Sofia, Bulgaria, 8-13 October 2017; MaThCryst coordinators: J. Hadermann and M. I. Aroyo, local organizer: D. Karashanova.

(v) Training Course on Symmetry and Group Theory (ongoing series in Japan); fifth course 6-10 March 2017, sixth course 31 July - 4 August 2017, both at KEK Tsukuba; MaThCryst coordinator and lecturer: Massimo Nespolo. 
In 2016 the Commission continued actively to promote mathematical and theoretical crystallography by organizing, supporting and promoting worldwide meetings, workshops and educational events. The main educational and scientific activities can be summarized as follows:

(A) International schools and workshops

(i) SIAM Conference on Mathematical Aspects of Material Science, Philadelphia, USA, 8-12 May 2016; MaThCryst coordinator and local co-organizer: Gregory McColm (together with J.-G. Eon, M. Krajcevski and M. Senechal).

There was a series of four Mathematical Crystallography Minisymposia in the 2016 meeting of the Special Interest Activity Group on Mathematical Aspects of Materials Science (SIAG-MS) in the Society of Industrial and Applied Mathematics (SIAM). Altogether, 511 people attended the meeting, which had 145 Minisymposia and thirteen Plenary talks. The four mathematical-crystallography Minisymposia, on Tilings, Packings, Graphs and Other Discrete Models, on Polyhedra, Cluster Models and Assembly, on Groups, Lattices, Spaces and Superspaces, and Beyond Crystallography, had sixteen speakers from seven nations (and three continents). Attendance at the talks ranged from 18 to 34 . SIAM is the leading organization in the USA devoted to applied and industrial mathematics, and one of the five leading mathematics organizations in the USA. SIAG-MS is a relatively new group, with 264 members as of last May. The next meeting will be in July 2018 in Portland, Oregon.

(ii) International School on Fundamental Crystallography with Applications to Electron Crystallography, Antwerp, Belgium, 27 June - 2 July 2016; MaThCryst coordinator and local organizer: Joke Hadermann.

The school started with an optional day on matrix crystallography, as a necessary background, followed by two lecture days on fundamental crystallography, given by Massimo Nespolo and Mois Aroyo. The lectures, alternated with exercises, included topics such as crystallographic symmetry in general, point and space groups, group-subgroup relations and the reciprocal lattice. The essential part of the course consisted of three full days of lectures given by Joke Hadermann on electron crystallography, focusing on different electron-diffraction techniques and the crystallographic information that could be extracted by them. A poster session was organized, in which 17 students participated, showing their own TEM work or related crystallographic studies. The students had an opportunity to obtain 3 ECTS (European Credit Transfer System) credits for the completion of the school, by passing an online exam after the school. The school was attended by 38 participants from 21 nations, of which 30 were under the age of 30 . Thanks to grants provided by the IUCr and the ECA, and redistribution of part of the income from registration fees, ten young students (India 3, Russia 2, Czech Republic 1, Poland 1, Brazil 2, Austria 1) could be provided with scholarships covering all of their travel and/or subsistence costs. Part of the organization costs of the school were covered by the scientific organization EMS and the companies Nanomegas, FEI and Calidris. Apart from MaThCryst, the school was also supported by the ECA Special
Interest Group on Electron Crystallography. Material and organizational support was also provided by the University of Antwerp and, in particular, the Antwerp Summer University.

(iii) International Scientific School Combined Topological and DFT Methods for Prediction of New Materials II, Samara, Russia, 4-10 July 2016; MaThCryst coordinators and local organizers: Vladislav Blatov and Davide Proserpio.

The 2016 school continued the series of educational activities of the Samara Center for Theoretical Materials Science (SCTMS) started in 2008. As in the previous cases, the school was organized by SCTMS and MaThCryst; it was an intensive training course on ToposPro and related topological and quantum methods. D. Proserpio and V. Blatov, the principal developer of ToposPro, acquainted the participants with the principles of the program and its numerous applications and opportunities for prediction of new materials. The school started with a two-day workshop Applications of Topological Methods in Materials Science, which was organized in the format of a mini-conference where SCTMS representatives and foreign researchers presented their reports on ToposPro applications, research findings and achievements. Among the 45 participants (16 from Brazil, Switzerland, Germany, Spain, UK, Italy, India, Nepal, Vietnam etc.), there were graduate and postgraduate students, as well as scientists - active users of ToposPro.

(iv) AIC School on Polymorphism, Stability and Phase Transitions in Crystals: Theory, Experiments and Applications, Rimini, Italy, 7-11 September 2016; MaThCryst coordinator: Mois I. Aroyo, local organizer: S. Tarantino.

The school was organized by the Commission on Crystallographic Teaching of the Italian Crystallographic Association (AIC) in partnership with MaThCryst, and the Italian Society for Mineralogy and Petrology (SIMP). It was a satellite event of the European Mineralogical Conference 2016. The school was attended by 42 students from 14 countries (Albania, Algeria, Brazil, France, Germany, Israel, Italy, The Netherlands, Russia, Spain, Tunisia, Turkey, Uzbekistan and USA; over $60 \%$ from outside Italy) with different scientific backgrounds (chemistry, mineralogy, material sciences, biology, pharmaceutical sciences) and 16 invited lecturers and organizers. In addition, five representatives of the supporting institutions and sponsors (IUCr, ECA, Dectris, Bruker, Assing) were present. AICS2016 was financially supported by AIC and SIMP, and sponsored by other scientific institutions (IUCr, European Mineralogical Union and Mineralogical Society of Ireland and Great Britain) and several companies (ICDD, Dectris, Bruker AXS, Assing-Rigaku, Crystal Impact, Oxford Cryosystems, MDPI Crystals, STOE). Thanks to the contributions of organizing institutions and sponsors, almost all students were granted some bursaries towards their registration fee. The scientific programme of AICS2016 addressed various aspects of the crystallographic analysis of polymorphism and structural phase transitions in inorganic, organic and hybrid compounds, with molecular or extended structures. The following specialists presented lectures at the school: Mois I. Aroyo (University of the Basque Country); Tiziana Boffa Ballaran (Bayerisches Geoinstitut); Michael A. 
Carpenter (University of Cambridge); Angelo Gavezzotti (University of Milan); A. Mike Glazer (University of Oxford); Matteo Leoni (University of Trento); Lucia Maini (University of Bologna); Marco Milanesio (University of Piemonte Orientale); Marcus Müller (Dectris Ltd); Massimo Nespolo (Université de Lorraine); Serena C. Tarantino (University of Pavia); Ian D. Williams (Hong Kong University of Science and Technology).

(v) ISFC5 - Fifth MaThCryst School in Latin America, Havana, Cuba, 30 October - 5 November 2016; MaThCryst coordinator and local organizer: Ernesto Rams.

The series of MaThCryst schools in Latin America (International School on Fundamental Crystallography) started ten years ago at the University of Havana, Cuba, and, in 2016, celebrated its tenth anniversary again in Havana. The biennial schools have been important for students from all over Latin America. This year the school held at the University of Havana gathered around 35 students from Cuba, Uruguay, Argentina, Costa Rica, Mexico, Puerto Rico, Brazil, Colombia and Ecuador. The teaching staff included Mois Aroyo, Massimo Nespolo, Leopoldo Suescun, Raimundo Lora Serrano, Arbelio Penton Madrigal and Ernesto Estevez Rams, four of whom are members of MaThCryst. The school programme includes the fundamentals of the discipline such as the crystalline lattice, group theory, space groups, Fourier transforms, reciprocal space, the basis of diffraction and the use of the Bilbao Crystallographic Server. Space and time were also favourable for direct exchange between students (who presented posters of their work) and lecturers; students could discuss their study projects with the lecturers. On the last day a workshop on nanocrystallography took place that included presentations from Raimundo Lora Serrano, Arbelio Penton Madrigal, Cristy Azanza Ricardo and Ernesto Estevez Rams. The next edition of the Latin American MaThCryst school is due in 2018 in Colombia.

(vi) Training Courses on Symmetry and Group Theory in Japan; MaThCryst coordinator and lecturer: Massimo Nespolo: (a) Fourth Training Course on Symmetry and Group Theory, Tsukuba, Japan, 7-11 March 2016; (b) First Advanced Training Course on Symmetry and Group Theory, Tsukuba, Japan, 1-5 August 2016.

The main organizer of the courses was the Photon Factory, with co-organizer the Crystallographic Society of Japan, with support from the Japanese Society for Synchrotron Radiation Research, the Japanese Society for Neutron Science and MaThCryst. The courses were held at the campus of the Photon Factory at Tsukuba. The fourth basic course was attended by 43 participants from various places in Japan while the first advanced training course, restricted to those who had attended and completed the basic course, was attended by 30 participants. The lectures were given in Japanese by $\mathrm{M}$. Nespolo. A series of articles is now being published by the Journal of the Crystallographic Society of Japan based on the content of the basic course: the first article appeared in the December 2016 issue and the second will be published in the April 2017 issue. The fifth basic course will be held in March 2017 and will be the first course from which participants can obtain credits from the Graduate University of Advanced Studies, Sokendai.

\section{(B) Publishing activities}

Members and consultants of the Commission have contributed actively to different IUCr publishing activities:

(i) The 6th edition of International Tables for Crystallography Volume A, Space-Group Symmetry, published in 2016 (print and online): M. I. Aroyo (Editor); B. Souvignier (chapters on general introduction to group theory, on spacegroup symmetry, on space groups and their descriptions); K. Momma (generation of the general-position diagrams for cubic space groups, chapter on computer preparation of Volume A); E. Koch (chapters on lattice complexes of space groups and space-group normalizers); D. Litvin (chapters on special topics of space groups, and magnetic subperiodic groups and magnetic space groups).

(ii) Editors of IUCr journals: M. Nespolo (Book-Review Editor for all IUCr journals); J.-G.Eon (Co-editor for Acta Cryst. Section A); D. Pandey (Co-editor of Journal of Applied Crystallography).

\section{(C) Other activities}

During 2016, members of the Commission have also been involved in a number of other activities related to MaThCryst purposes:

(1) Participation in crystallographic meetings and conferences:

(i) V. Blatov and D. Proserpio organized the International Workshop on Applications of Topological Methods in Materials Science, SCTS, Samara, Russia, 1-2 July 2016; (ii) L. Suescun participated in the VIII Congreso Nacional de Cristalografia de la Sociedad Mexicana de Cristalografia, II Reunion de la Asociacion Latinoamericana de Cristalografa y VI Reunion de Usuarios de Luz Sincrotron, Merida, Mexico, 23-27 October 2016; (iii) L. Suescun was the local organizer of the IUCr-UNESCO Bruker OpenLab Uruguay 2; Determinacion de Estructuras Cristalinas por Difraccion de Rayos X de Monocristal, Montevideo, Uruguay, 23-29 February 2016.

(2) Tutorships and lectureships: (i) Within the activities of the Samara Center for Theoretical Materials Science, D. Proserpio and V. Blatov regularly hold series of webinars for all interested in materials science; (ii) S. Hyde: co-organizer and lecturer on Crystallographic 2D Orbitfolds and Classical Crystallography at a Winter School for Young Researchers, Murdoch University, Perth, Australia; (iii) M. I. Aroyo gave a series of lectures on crystallographic groups and their representations at the International School on Topological Matter States, Donostia-San Sebastian, Spain, 22-26 August 2016.

All the activities of the Commission are recorded regularly on MathCryst's web page, http://www.crystallography.fr/ mathcryst/index.php, thanks to M. Nespolo. G. McColm maintains a blog on mathematical crystallography, called Crystal Mathematician, at http://blogs.iucr.net/crystalmath; this is devoted to mathematics of crystal design and analysis.

\section{I. Aroyo, Chair}




\subsection{Commission on Neutron Scattering}

The Commission on Neutron Scattering promotes the use of neutron scattering by encouraging the publication of information on the capabilities of neutron sources and instrumentation and by supporting symposia, schools and workshops that educate researchers on the unique information that can be provided by neutron scattering.

Several members of the Commission are actively involved in developing neutron sources and new neutron-scattering technologies and methods. Notable developments in these areas over the period of 2014-2016 include: ongoing construction of the European Spallation Source in Sweden, which is projected to produce the first neutrons in 2019, and the Chinese Spallation Neutron Source, which is expected to be operational in 2018; operation of the Spallation Neutron Source in the United States at a world-record level of $1.4 \mathrm{MW}$ and progress toward a major upgrade of the power capability of the accelerator complex to $2.8 \mathrm{MW}$; the continued progress at the spallation neutron source at the Japan Proton Accelerator Research Complex (J-PARC) toward operation at $1 \mathrm{MW}$ and progress toward obtaining the authorization to restart the Japan Research Reactor, perhaps as early as 2018. Further, several new neutron-scattering instruments were brought into user programs at facilities across the world.

One major event in Australasia in 2016 was the Bragg Institute at the Australian Nuclear Science and Technology Organization (ANSTO) being renamed the Australian Centre for Neutron Scattering. As part of an ongoing restructure of the research side of ANSTO, emphasis has moved away from the former institute model to a structure that distinguishes the rich instrumental capability on one side and the internally driven research with a nuclear focus on the other. This research should make considerable use of the extensive ANSTO research infrastructure. It was with mixed feelings that the neutron-scattering group relinquished the Bragg name, but the new titles of the infrastructure 'platforms' do reflect more explicitly their capabilities on a global scale, and plans are afoot for the Bragg name to be associated with another entity at ANSTO that is equally worthy of the title. A major event in the United States was a reduction in the scope of the user program at the Lujan Center for Neutron Scattering, which has been highly productive over the past couple of decades.

Commission members were also involved in organizing several meetings, including the Montreal Congress and various annual meetings of regional crystallographic associations. Notable neutron conferences include: the American Conference on Neutron Scattering, which was held in Knoxville (USA) in 2014 and Long Beach (USA) in 2016, and which is sponsored by the Neutron Scattering Society of America; the Asia-Oceania Conference on Neutron Scattering, which was held in Sydney (Australia) in 2015, and which was hosted by the Asia-Oceania Neutron Scattering Association (AONSA) and sponsored by ANSTO; the European Conference on Neutron Scattering, which was held in Zaragoza (Spain) in 2015 (the International Union of Crystallography provided partial financial support for students working in neutron crystallography to attend the conference); the inaugural Gordon Research Conference on Neutron Scattering, which is a new series featuring several world-leading neutron-scattering scientists, took place in Hong Kong in 2016; the triennial International Symposium on Diffraction Structural Biology, which was held in Knoxville (USA) in 2016; and a conference on neutron scattering organized at Bhabha Atomic Research Centre at Mumbai (India) in 2016. Neutron scattering was well represented in various regional meetings and conferences.

Several neutron schools were supported by Commission members, including: the AONSA Neutron School held in Japan, Indonesia and India (this school was cancelled in 2011 and in 2013 owing to the accident at the Hadron Experimental Hall in J-PARC); the Oxford School on Neutron Scattering in the United Kingdom; the Paul Scherrer Institute (PSI) Summer School on Condensed Matter Research at PSI in Switzerland; the Inelastic Neutron Scattering School at ANSTO, Australia; the National School on Neutron and X-ray Scattering, jointly organized by Argonne and Oak Ridge National Laboratories, USA; the annual Center for High Resolution Neutron Scattering Summer School on Neutron Scattering, NIST Center for Neutron Research, USA; the biennial meeting of the Spanish Neutron Society held in Pamplona (2014) and Bilbao (2016), Spain; the annual Berlin School on Neutron Scattering at Helmholtz-Zentrum Berlin, Germany; the Canadian Neutron Scattering Summer School; and the Neutron and Muon School at J-PARC, Japan.

In addition to schools, numerous workshops were organized by Commission members across a broad range of neutronscattering topics. For example, a workshop on New Trends in Magnetic Structure Determination was co-organized with the Commission on Magnetic Structures at the Institute Laue Langevin (France) in 2016. The aim of this workshop was to contribute to training scientists in the treatment of neutrondiffraction data for magnetic structure determination with new and improved methods and tools. Dozens of similar workshops hosted by neutron user facilities across the world continue to engage the research community in identifying emerging scientific challenges and needs that can be best addressed using the unique capabilities of neutron scattering.

\section{P. Langan, Chair}

\subsection{Commission on NMR Crystallography and Related Methods}

These are still early days for our Commission, which was only established in mid-2014. However, our activities are increasing as our existence becomes more widely known. Thus, relevant national and international conferences have occurred in several countries, for instance the 5th SMARTER conference in Bayreuth, Germany, which was designated as a satellite meeting of the European Crystallographic Meeting. Paul Hodgkinson and Gareth Lloyd organized a session on NMR crystallography at the annual spring meeting of the 
British Crystallographic Association, held in Nottingham in April. NMR crystallography talks have been included in a number of conferences, for instance in the IX Symposium on NMR in Chemistry, Physics and Biological Sciences, held in Warsaw, Poland, in September, in the meeting of the Canadian Society for Chemistry in Halifax in June, and in the 2016 Rocky Mountain Conference. Solid-state NMR was also involved in a national training course on Modern Methods of Structure Elucidation held in Lisbon, Portugal, in September.

Contact has been made with the American Crystallographic Association with a view to incorporating NMR in future conferences.

Details of the objectives and activities of the Commission can be found on the IUCr web site at http://www.iucr.org/iucr/ commissions/nmr-crystallography.

\section{F. Taulelle, Chair}

\subsection{Commission on Powder Diffraction}

The steady stream of requests for meeting sponsorship kept coming in 2014-2017. Some of them were for the latest in a series, such as the Durham Powder Diffraction School, but a number of other meetings in developing countries, notably in Africa, requested support. It is gratifying to say that support was forthcoming from the Commission (CPD) membership in the majority of cases

Financial travel restrictions did not permit a CPD meeting in 2015, but the European Powder Diffraction conference in Bari in 2016 brought together the majority of the commission members. The EPDIC conference is the premier powderdiffraction conference and the standard of the scientific content was, as always, very high. In a more sombre vein, 2016 also was notable for the passing of Hugo Rietveld shortly before the EPDIC meeting where he was due to give the opening Plenary Lecture. As the pioneer of the technique that bears his name, he had an immense impact on powder diffraction and materials analysis, and he will be greatly missed.

As one of the principal EPDIC organizers, CPD member Angela Altomare is to be commended for finding time to attend the CPD meeting in a hectic schedule. A variety of topics were covered in the meeting, ranging from the Hyderabad meeting to desired future activities. A discussion regarding the Rietveld guidelines led to additional time brainstorming a possible extension to PDF analysis with a number of people from central facilities.

There are indications that the long-delayed Volume $\mathrm{H}$ of International Tables will finally be published in the not-todistant future. The continuing delays to the volume have been an ongoing irritant to the powder-diffraction community and I shall be relieved to see the labours of many in the community at long last come to fruition.

Unfortunately ongoing health issues had an adverse impact on my ability to carry out many of the tasks I wanted to accomplish, even medical leave during a recovery period ended up being much less productive than I had hoped. I relinquish the position of CPD chair after three terms at the Hyderabad meeting (unfortunately I am unable to attend myself) and sincerely hope that whoever succeeds me can take the Commission forward with renewed energy.

\section{P. Whitfield, Chair}

\subsection{Commission on Small-Angle Scattering}

For 2016, the business of the Commission (CSAS) was conducted principally via e-mail and during personal meetings at national and international conferences. There was good engagement from many of the CSAS members and consultants. What follows is a summary of highlights of activities for 2016.

Tribute to the passing of Ritva Serimaa (1957-2016), CSAS member (2008-2016). It was with sadness that we learned of the passing of our colleague Ritva Serimaa on 12 July 2016. We prepared an obituary that was published in the Journal of Applied Crystallography [Trewhella (2017). J. Appl. Cryst. 50, 331] noting her contributions to science, to small-angle scattering in particular, and as a valued colleague to many.

Commission activities. The Commission contributed to planning for the Hyderabad Congress. The Commission nominated Kristina Djinovic Carugo for the International Programme Committee, who worked collaboratively to put forward an excellent set of recommendations for the scientific programme, including:

Keynote speaker: Dmitri Svergun.

Commission-sponsored Microsymposia: SAS Data Formats, Standards and Repositories; SAS Studies of Biomacromolecular Kinetics.

Shared Microsymposia with other Commissions: Macromolecular Structures by Hybrid Methods (CSAS, CBM, CEM); New Challenges in Interpretation of Structural Data (CSAS, CBM, CEM); Expression of Macromolecular Complexes (CBM, CSAS, CEC); Functional Materials on the Nanoscale (CCM, CAC, CSAS).

Joint Workshop: Validation Including Data from MX, SAS, XAFS, EM (CM, CSAS, CAC).

Completion of bid process and outcome for triennial SAS meeting SAS2021. A major event for the international SAS community is the triennial SAS meeting [recently held in Oxford, UK (SAS2009), Sydney, Australia (SAS2012), and Berlin (SAS2015)] with the next meeting in Traverse City Michigan, USA (SAS2018). The location for successive meetings is chosen by first inviting bids from all interested parties with a set of criteria specified. Meeting attendees then are polled for their preference, usually at the meeting six years prior, followed by an assessment of the bids in the context of the community vote by a Bid Evaluation Committee (BEC) of the past and present meeting Chairs and IUCr CSAS Chairs; the 2021 conference BEC included: Andrew Allen, Jill Trewhella, Elliot Gilbert (SAS2012), Randall E. Winans, Pete Jemian, Jan Ilavsky (SAS2018), Stephen King, Nick Terrill (SAS209), Matthias Ballauff and Michael Gradzielski (SAS2015), with Daniel Clemens (SAS2015) coordinating. 
For SAS2021, there were no completed bids submitted in time for a vote to be held at SAS2015, and so the BEC recommended a modified process that was endorsed by the SAS2015 meeting attendees and is described in our 2015 report. In this process the deadline for submission of bids to host SAS2021 was extended to 1 February 2016, which resulted in three submitted proposals that were reviewed by the $\mathrm{BEC}$ and recommended to progress to review and discussion by the broader community. The bids were from Campinas (Brazil), Gyeongju (Korea) and Taipei (Taiwan) and were posted online (https://www.helmholtz-berlin.de/ events/sas/bid/index_en.html). The next steps, as agreed at SAS2015, by the attendees were followed:

Dr Daniel Clemens managed communications to attendees of the past three meetings (800 individuals) concerning the posting of the bids, allowing for a period of review and then polling to obtain preferred sites. A total of 187 votes were received from eligible voters (with no multiple counts ensured via an e-mail, IP-address originality and eligibility check for each individual voter), indicating a clear preference for Campinas, Brazil, but also substantial support for Gyeongju (Korea) and Taipei (Taiwan).

The results of the voting were provided to the BEC, who made the final decision to support the community preference for SAS2021 to be hosted in Campinas (Brazil), and also to ask that the bid teams from Gyeongju (Korea) and Taipei (Taiwan) update and re-submit their bids for SAS2024 for a vote at SAS2018, Traverse City.

Commission support for other meetings. The Commission evaluated and ultimately supported requests to the IUCr for sponsorship and travel funds for a number of meetings, including:

4th International Soft Matter Conference, Alpexpo, Grenoble, France, 12-16 September 2016;

International Summer School To.Sca.Lake 2017, to be organized in Como, Italy, 29 May - 2 June 2017;

50th Course of the International School of Crystallography, Erice, Italy, in 2017, as the theme will be Integrative Structural Biology, for which SAS is highly relevant.

Educational activities. EMBO continues to be a strong supporter in growing the SAS community with good support from Commission members and consultants; for example:

EMBO Practical Course on the Structural Characterization of Macromolecular Complexes, Grenoble, France, 21-27 May 2016, with good representation of the SAS community; Keynotes by Jill Trewhella and Rob Rambo from ISIS.

An EMBO Global Exchange Lecture Course was held in Korea: Structural and Biophysical Methods for Biological Macromolecules in Solution, organized by Dmitri Svergun with Sangho Lee and participants Jill Trewhella and Bente Vestergaard.

EMBO Practical Course on Solution Scattering, Hamburg, Germany, 17-24 October 2016; organized by Dmitri Svergun with Jill Trewhella a participant.

EMBO Conference on Molecular Machines: Integrative Structure and Molecular Biology, Heidelberg, Germany, 20-23 November 2016; organizers included Dmitri Svergun, with
Bente Vestergaard and Jill Trewhella invited speakers; special EMBL Advanced Training Centre Corporate Partnership Programme travel grants for European participants and EMBO travel grants provided for researchers working in laboratories in India, Taiwan, South Africa and Singapore.

Also, individual members and consultants were engaged in the development and delivery of a variety of courses across the globe. For example:

Elliot Gilbert lectured in the Croucher Neutron School in Hong Kong and at Universitat Politecnica de Valencia in Spain.

Vladimir Volkov gave two spring and one fall semester lecture courses devoted to the methods of studying the structure of nanosystems by small-angle X-ray and neutron scattering to students of the Moscow State University and three 6-hour training courses on Mathematical Methods in Small-Angle Scattering Data Treatment to young scientists from several physics institutions in Russia.

Toshiji Kanaya was a principal organizer of the 1st Neutron and Muon School held in J-PARC MLF in November 2016 and presented a seminar on polymer thin films. He also gave tutorial talks on SANS and neutron reflectivity for soft matter at IIT in Hyderabad, Mumbai and Bangalore, India, in March 2016, to introduce the activities at J-PARC MLF. Again he travelled to India to deliver an invited lecture at the 8th AsiaOceania Neutron Scattering Association (AONSA) Neutron School held in Mumbai in November 2016.

Community-building activities. CSAS members and consultants served on various SAS-related committees, panels and editorial boards in 2015 .

Andrew Allen and Michael Gradzielski edited a fully openaccess virtual Special Issue of the Journal of Applied Crystallography highlighting research presented at the 16th International Conference on Small-Angle Scattering (SAS2015) held in Berlin, Germany, in September 2015. The issue provides insights into ongoing developments in the field of small-angle neutron and X-ray scattering (SANS and SAXS) covering different areas of fundamental and applied research (http://journals.iucr.org/special_issues/2016/sas2015/).

Andrew Allen continues as one of the Main Editors of Journal of Applied Crystallography with Elliot Gilbert, Gernot Kostorz and Dmitri Svergun as Co-editors.

Dmitri Svergun is a member of the Associate Editorial Board of Frontiers in Molecular Biosciences, section Structural Biology.

Jill Trewhella serves as a Co-editor (biology and medicine) for IUCrJ and as an editorial-board member of the Cell Press journals Biophysical Journal (Proteins) and Structure.

Iris Torriani serves as Treasurer and Counsellor of the Teaching Commission of the Brazilian Crystallographic Association $(\mathrm{ABCr})$ and is the Provisional Treasurer of the Latin-American Crystallographic Associaton (LACA), for the home page and for networking.

Toshiji Kanaya organized the annual meeting of the Advanced Soft Material Beamline (FSBL), SPring-8 (a dedicated SAXS beamline for industry-oriented polymer and softmaterials science) held in Nagoya, Japan, in January 2016. He 
continues as Chair of the Steering Committee of the Advanced Soft Material Beamline (FSBL) for 2016, and organized several Committee meetings, including a subresearch group dedicated to GISAS and educational meetings for industry researchers.

The International Biology and Synchrotron Radiation conference (BSR2016) was held at the Stanford Linear Accelerator site in La Jolla, 21-24 August, and was well attended by the SAS community, with multiple talks highlighting the contributions of SAS and an invited talk by Jill Trewhella.

Members and consultants of CSAS were prominent contributors to meetings around the world supporting the dissemination of research using small-angle scattering: Iris Torriani gave a Plenary Lecture, X-ray Scattering of Macromolecular Biological Structures: Dealing with Intrinsic Disorder, at the VIII Mexican Crystallography Congress and LACA II Meeting in 2016; Toshiji Kanaya organized a Bioscience Seminar in J-PARC MLF in May 2016, gave an invited talk at the International Symposium on Polymer Physics in Guizhou, People's Republic of China, in June 2016, and another invited talk at the International Conference of Molecular Engineering of Polymers in Shanghai, People's Republic of China, in November 2016; U-Ser Jeng has delivered invited talks for SAS promotion in several local universities, as well as invited talks for BioSAXS promotion at the Workshop of the 7th Japan-Taiwan Joint Meeting on Neutron and X-ray Scattering, Kumatori, Osaka, Japan, 10-12 March 2016, and for SAXS promotion in the broader Asian region at the Grand Challenges in Small-Angle Scattering meeting, Okazaki, Japan, 18-20 March 2017.

Consultant activities. CSAS members continue to support the worldwide Protein Data Bank (wwPDB) initiatives to establish a federated systems of interconnected databases, similar to what exists presently for the PDB (RSCB, PDBe, PDBj) but extended to include SAS data and models. The wwPDB SAS Task Force (SASvtf) continues its work on requirements for validation of biomolecular SAS data and modelling (chaired by Jill Trewhella with Dmitri Svergun, and additional members have recently been recruited, including Masaaki Sugiyama).

David Babonneau continues to serve on Peer Review Committee 3: Matter and Material Properties: Structure, Organization and Characterization, Elaboration for beamtime allocation at the SOLEIL synchrotron, France. In 2016, he was nominated as co-Chair of this Committee.

Vladimir Volkov is a consultant for studies of nanosystems by small-angle scattering, giving lectures to staff of several research institutes throughout Russia. This activity was performed in the framework of the Shared Research Center IC RAS. He also is a referee providing expertise for SAS-oriented projects submitted to the Russian scientific funds.

Organizational activities. CSAS members and consultants have served on a broad range of Programme or Organization Committees for SAS-related conferences and workshops in 2016. For example:
Vladimir Volkov served on the Committee for Small-Angle Scattering in Biopolymers at Petersburg State University, Russia, the Organizing Committee of the Conference of the National Union of Crystallographers (2016, Russia), and the Organizing Committee of the III International Conference on Small-Angle Neutron Scattering (SANS-YuMO 2016), Dubna, Russia.

Toshiji Kanaya organized the annual meeting of the Advanced Soft Material Beamline (FSBL), SPring-8 (a dedicated SAXS beamline for industry-oriented polymer and softmaterials science), Nagoya, Japan, January 2016. He continues as Chair of the Steering Committee of the Advanced Soft Material Beamline (FSBL) for 2016, and organized several Committee meetings.

Iris Toriani was a Counsellor for the elaboration of By-Laws and Statutes of the Latin-American Crystallographic Association (a Regional Associate of the IUCr).

U-Ser Jeng was a co-organizer of the Workshop on Synchrotron for Industry: SAS for Polymer Industrials, Taiwan, 21-22 September 2016.

Technical activities. In response to the recommendations of the wwPDB SASvtf (see above), Dmitri Svergun's group in Hamburg, Germany, continues to maintain and curate the publicly available Small-Angle Scattering Biological Data Bank (SASBDB, http://www.sasbdb.org), which as of the drafting of this report has 527 models and 323 experimental data sets, with 261 models and 134 experimental data sets on hold. The Hamburg team is also working with the PDBe on data deposition and validation tools for hybrid NMR-SAS models.

Dmitri Svergun with John Westbrook (Protein Data Bank, Rutgers, USA) led an effort to provide a universal dataexchange format for the bio-SAS community, based on the use of the widely adopted crystallographic information framework (CIF). For a full description see the open-access article by Kachala et al. [J. Appl. Cryst. (2016), 49, 302-310]. An earlier version of the sasCIF format, implemented as an extension of the core CIF dictionary, available since 2000, has been extended to describe comprehensively the necessary experimental information, results and models, including relevant metadata for SAS data analysis and for deposition into a database. Processing tools for these files (sasCIFtools) have also been developed, and these are available both as standalone open-source programs and integrated into the SAS Biological Data Bank (SASBDB), allowing the export and import of data entries as sasCIF files. Software modules to save the relevant information directly from beamline dataprocessing pipelines in sasCIF format are also developed. This update of sasCIF and the relevant tools is an important step in the standardization of the way SAS data are presented and exchanged, to make the results easily accessible to users and to promote further the application of SAS in the structural biology community.

U-Ser Jeng is leading a BioSAXS beamline project to design and construct a new dedicated high-brilliance biological SAXS/WAXS beamline at the new $3 \mathrm{GeV}$ synchrotron of NSRRC, Taiwan. 
In summary, it is fair to say that CSAS continued its busy and productive agenda for 2016, and with new leadership and renewed membership the CSAS will continue supporting and promoting the application of SAS techniques in a broad range of scientific fields.

\section{J. Trewhella, Chair}

\subsection{Commission on Structural Chemistry}

The Commission met in Montreal and had robust discussions on a number of matters, including increasing support from chemical crystallographers for IUCr Journals and the direction and strategy of these journals, and the need for the Commission to actively encourage and support crystallography schools and regional meetings, particularly in nonFirst World countries. The committee was also renewed at Montreal, with a new chair and a number of new members joining and old members leaving.

Since Montreal, the commission supported the following meetings:

The SAGAMORE XVIII Conference on Charge, Spin and Momentum Densities, organized by the Charge, Spin and Momentum Densities Commission, held in Sardinia, Italy, in June 2015 (http://www.sagamorexviii.org). Chairs: C. Gatti, P. Macchi.

The 22nd International Conference on the Chemistry of the Organic Solid State (ICCOSS XXII), held in Niigata, Japan in July 2015 (http://www.iccoss2015.org). Chairs: K. Ogawa, H. Uekusa.

The 2015 meeting of the Zurich School of Crystallography, held in June 2015. Chair: A. Linden.

INDABA8, an interdisciplinary workshop organized by the South African Crystallographic Society, and with the theme Serendipity versus Prediction, held in August 2015 in Skukuza, South Africa (http://www.sacrs.org.za/indaba). Chair: A. Roodt.

The 2nd North African Crystallography Conference (NACC2), held in Tunisia in November 2015 (http:// www.nacc2.com). Chair: H. Boughzala.

A workshop on Powder Diffraction of Organic Compounds, held in Frankfurt, Germany, in October 2015 (http://www. anorg.chemie.uni-frankfurt.de/AK_Schmidt/chemkrist2015). Chair: M. U. Schmidt.

Looking forward to the Hyderabad IUCr Congress, it is important that chemical crystallography is well represented and supported. To this end, an extensive list of potential advisory committee members was provided to the organisers, with the aim of having a good chemical crystallography programme at the meeting, and thus good support for the meeting from the chemical crystallography community. Four of these nominees were appointed to the International Programme Committee, and a very strong scientific programme of interest to structural chemists has resulted, including 14 microsymposia on the Crystal Engineering of MOFs and Open Framework Compounds, 13 microsymposia on the Crystal Engineering of Organic and Pharmaceutical
Compounds, and 12 microsymposia in the Materials and Minerals theme.

\section{S. Batten, Chair}

\subsection{Commission on Synchrotron and XFEL Radiation}

The aim of the Commission is to promote access and awareness of crystallographers worldwide to the world's synchrotron radiation (SR) and X-ray free-electron laser (XFEL) facilities. To this end, the Commission promotes the development of crystallographic instrumentation, technology and standards, and the synergies between storage-ring-based and LINAC-based next-generation sources such as XFELs. The bulk of the Commission's work is carried out via e-mail, with occasional face-to-face meetings held at selected conferences attended by sufficient of the Commission members.

Synchrotron radiation and free-electron laser facilities. There has been continued strong progress in construction and commissioning of new XFEL facilities. The Pohang Accelerator Laboratory XFEL in South Korea achieved hard X-ray laser light in November 2016 and user operation is scheduled to begin in March 2017. Construction of the European XFEL in Hamburg, Germany, is complete and commissioning began in October 2016 with user operation expected in the second half of 2017.

Storage-ring-based synchrotron light sources also saw a significant milestone in 2016 with the inauguration of the first 'fourth-generation' storage ring, MAX IV, in Sweden. The new 'multi-bend achromat' ring designs, such as MAX IV, will be more than an order of magnitude brighter than the thirdgeneration light sources. Most existing facilities, including the three original third-generation hard X-ray facilities, the ESRF, APS and SPring-8, are either undertaking or planning significant upgrade programmes based on these new designs. New facilities, such as the $6 \mathrm{GeV}$ High Energy Photon Source to be built near Beijing, People's Republic of China, and the $3 \mathrm{GeV}$ facilities SLiT-J (Tohoku, Japan) and SIRIUS (Campinas, Brazil) will also use the new high-brightness designs.

Supported meetings, schools and workshops. The Commission provided letters of support and endorsement for the following two meetings in 2016:

The RapiData course on automated data collection to support participation of Latin-American students. The Commission has endorsed this annual event for many years, and did so again for the school held in April 2016.

The 12th International Conference on Biology and Synchrotron Radiation (BSR), held at SLAC, 21-24 August 2016.

In general, the Commission has strongly supported $\mathrm{IUCr}$ sponsorship for the purpose of assisting attendance by young researchers and scientists from developing countries.

Commission member activities. The members of the Commission are active in key synchrotron and crystallographic communities and conferences. For example:

Soichi Wakatsuki chaired the 12th International Conference on Biology and Synchrotron Radiation (SLAC, USA, 
2016) and Pawel Grochulski served on the Organizing Committee;

Richard Garrett organized and co-chaired a synchrotron Microsymposium at the AsCA 2016 conference in Hanoi, Vietnam;

Maciej Kozak is President of the Polish Synchrotron Radiation Society and a member of Polish Synchrotron - a council supporting the construction of the Polish synchrotron SOLARIS;

Pawel Grochulski represented the Commission on the International Programme Committee of the Hyderabad Congress.

Asia-Oceania Forum for Synchrotron Radiation Research. The Asia-Oceania Forum for Synchrotron Radiation Research is an international network whose mission is to foster collaboration among synchrotron-radiation facilities and user communities in Asia and Oceania, as well as promoting collaborations with facilities and communities in America and Europe. The eight facility-operating nations in the region are full members of the AOFSRR, and the forum's mission includes promotion of synchrotron-based science throughout the region. To this end Malaysia, New Zealand and Vietnam are associate members of the AOFSRR. Two members of the Commission play active roles in the organization: Youichi Murakami (AOFSRR President, 2015-2016) and Richard Garrett (Executive Committee member and Treasurer). The AOFSRR holds an annual conference/workshop, hosted by each full member nation in turn. The workshop in 2016 was hosted by the People's Republic of China.

One of the core activities of the AOFSRR has been the Cheiron School, a two-week international synchrotron school, which has been held annually at SPring-8 since 2007. The 2015 Cheiron School was the ninth and final year that SPring-8 hosted this event. Following a review it has been decided to change the format of the SPring-8 school to a shorter higherlevel workshop aimed more specifically at staff members of the AOFSRR synchrotron light-source facilities. At its 2016 Council Meeting the AOFSRR decided to establish the AOF Synchrotron Radiation School as an annual school rotating between the member countries. An initial rotation has been decided, with Australia hosting the first AOF school in 2017, to be followed by Republic of Korea in 2018 and Thailand in 2019.

\section{R. F. Garrett, Chair}

\subsection{Commission on XAFS}

The activities of the Commission (CXAFS) in 2016 concentrated on preparation for the Hyderabad Congress.

(1) Preparation for the satellite workshop for the Hyderabad Congress (Q2XAFS2017: International Workshop on Improving Data Quality in XAFS Spectroscopy, Diamond, UK, 14-15 August 2017). This meeting includes a strong presence by members of the Commission and by members of the International X-ray Absorption Society (IXAS) Executive. It aims to increase the recognition of the importance of combined techniques for crystallography and for structurefunction investigations.

(2) W1 X-ray Absorption Spectroscopy for the Crystallographer, Hyderabad, India, 21 August 2017. This one-day, free tutorial workshop will provide an overview of the physics and chemistry of X-ray absorption spectroscopy with a particular emphasis on its complementarity with diffraction techniques. The curriculum will include introductions to beamline instrumentation, measurement methods, and methods of data processing and analysis. This workshop, which is organized by the Commission and IXAS, with local support from the Board of Research in Nuclear Science (India), will be held 21 August 2017 at the Hyderabad International Convention Centre. Chairs: Christopher Chantler, Farideh Jalilehvand and Bruce Ravel. Local organizer: Dibyendu Bhattacharyya.

(3) The following Microsymposia were organized:

Two unshared Microsymposia: MS90 Spectroscopy Applications in Biologically Relevant Systems, co-Chairs: Sofia Diaz-Moreno and Bhoopesh Mishra; MS51 Recent Developments in XAFS Spectroscopy: Theory, Instrumentation and Data Analysis, co-Chairs: Hiroyuki Oyanagi and Konstantin Klementiev.

Six shared Microsymposia:

MS107 Synchrotron Measurement in Conservation and Cultural Heritage, co-Chairs: Bruce Ravel and Eric Dooryhée; shared with the Commission on Crystallography in Art and Cultural Heritage.

MS60 XAS at Extreme Conditions, co-Chairs: Giuliana Aquilanti and Daniel Haskel; shared with the Commission on High Pressure.

MS96 XAFS of Materials for Clean Energy, co-Chairs: Pieter Glatzer and Steve M. Heald; shared with the ad interim Commission on Crystallography of Materials.

MS121 Synchrotron-Based X-ray Techniques and the Environment, co-Chairs: Richard Garrett and Hugh Harris; shared with the Commission on Synchrotron and XFEL Radiation.

MS42 High-Resolution Spectroscopy, co-Chairs: Dimosthenis Sokaras and Hamid Reza Khavasi.

MS74 Porous Framework for Catalysis and Renewable Energy, co-Chairs: Christian Doonan and Gustav Van Tendeloo.

(4) XAFS database. Work on the preparation of the database was continued by B. Ravel and M. Newville. Many decisions remain to be discussed.

(5) Conference support and proposals. An application for support for an International Workshop on Improving Data Quality in XAFS Spectroscopy (Q2XAFS2017), to be held at Diamond, UK, 14-15 August 2017 as a satellite meeting to the Hyderabad Congress, was submitted to the IUCr. The meeting has been endorsed and sponsored by several groups.

(6) International Tables for Crystallography Volume I, $X A F S$. C. T. Chantler and F. Boscherini have been heavily involved in this as two of the three Main Editors, with Bruce Bunker, ex-Chair of IXAS, as the third. All of the Commission has continued to be involved in this extensive activity. Currently experts have completed their drafts using the IUCr 
templates and these have been sent to expert referee panels for review. The reviewing process is progressing well. All chapters will be fully reviewed in a normal journal peer-review process.

(7) CXAFS web page. G. Aquilanti and M. Tabuchi were responsible for the web site. Updates in the XAFS beamlines section continued to be implemented. The information about forthcoming events is continuously updated.

\section{T. Chantler, Chair, and K. Jablonska and G. Aquilanti, Secretaries}

\section{Sub-committee on the Union Calendar}

The Sub-committee receives and considers requests for IUCr sponsorship and nominal financial support, and makes recommendations to the Executive Committee. Acting on the recommendations made by the Sub-committee, during 2016 the Executive Committee approved sponsorship of various schools and meetings, mostly with financial support. Those held in 2016 are listed at the beginning of this Report of the Executive Committee. Those scheduled for 2017, but approved in 2016, are listed below.

XVI Intensive Teaching School in X-ray Structure Analysis, Durham, UK, 25 March - 2 April 2017.

4th School on Crystal Structure Determination from Diffraction Data: application on Powder Samples, Hammamet, Tunisia, 7-9 April 2017.

RapiData 2017, Stanford, USA, 16-21 April 2017.

Understanding Biology through Structure, Santa Fe, USA, 13-17 May 2017.

Modern Trends in Mathematical Crystallography - 2nd Manila International Workshop on Mathematical Crystallography, Manila, Philippines, 20-24 May 2017.

6th International School on Biological Crystallization, Granada, Spain, 29 May - 2 June 2017.

To.Sca.Lake 2017: Total Scattering for Nanotechnology on the Como Lake, Como, Italy, 29 May - 2 June 2017.

6th ALMA Conference 'Painting as a Story' and 2nd CrysAC Workshop, Brno, Czech Republic, 31 May - 3 June 2017.

Shanghai International Crystallographic School Working with Bilbao Crystallographic Server, Shanghai, People's Republic of China, 11-17 June 2017.

Zürich School of Crystallography 2017: Bring Your Own Crystals, Zürich, Switzerland, 11-23 June 2017.

School on Charge Density and MoPro, Mexico City, Mexico, 12-15 June 2017.

Mineral Fibres: Crystal Chemistry, Chemical-Physical Properties, Biological Interaction and Toxicity, Modena, Italy, 17-21 June 2017.

4th European Crystallography School (ECS4): HighThroughput Structure Analysis - From Routine Chemical Problems to Advanced Applications, Warsaw, Poland, 2-7 July 2017.
International School on Fundamental Crystallography and Workshop on Structural Phase Transitions: Satellite School of the 24th IUCr Congress 2017, Odisha, India, 30 August - 4 September 2017.

Macromolecular Crystallography School 2017: Structural Biology to Enhance High Impact Research in Health and Disease, Montevideo, Uruguay, 13-23 November 2017.

Organizers of meetings wishing to seek IUCr sponsorship should submit applications at least nine months in advance of the meeting, writing to the Chair of the Sub-committee. For up-to-date contact information, application procedures and rules, see http://www.iucr.org/iucr/sponsorship/meetings.html.

Requests from satellite meetings may be submitted, and possible financial support requested, separately or through the Organizing Committee of the main meeting.

Meetings (other than satellite meetings) scheduled to be held within one month before or after an IUCr Congress will not be considered for sponsorship. For any meetings scheduled to be held between one and two months before or after a Congress, the application for sponsorship will be sent to the Chair of the Congress Programme Committee for approval, or otherwise. For meetings (other than satellite meetings) scheduled to be held, in the respective region, within one month before or after a meeting of a Regional Associate (American Crystallographic Association, Asian Crystallographic Association, European Crystallographic Association, Latin-American Crystallographic Association), the applicants for sponsorship must seek approval of the Chair of the Regional Associate Organizing Committee.

IUCr sponsorship can only be given to meetings that are international in character and open to participants from all countries. For international meetings the membership of the Programme Committee is a good indication of this. National meetings are only supported if held in developing countries.

Explicit support from the relevant IUCr Commission(s) is required for any international meeting (except for the meetings of Regional Associates) and from the Commission on Crystallographic Teaching for any international schools (except for those organized by an IUCr Commission).

The IUCr continues to support and uphold ICSU's policy of non-discrimination and adheres to its decisions and procedures concerning the free circulation of scientists. Organizers of any meetings seeking IUCr sponsorship or support must assure the Sub-committee on the Union Calendar that the authorities of the country in which the meeting is to take place guarantee free entrance of bona fide scientists from all countries.

Visiting Professorships. The IUCr Visiting Professorship Scheme aims to support some of the costs of having internationally recognized scientists as lecturers for short courses at workshops or schools organized in developing countries. These schools or workshops may have national or international character. Up to a maximum of three Visiting Professorships can be granted for a single event. Travel and insurance costs will be met by the IUCr, while the local organizers cover the accommodation/subsistence expenses. Visiting Professorships can be requested in conjunction with 
the application for IUCr funding of a meeting, or independently as a single action to obtain highly qualified international teaching support within a teaching programme of local character. Support from at least one IUCr Commission is required. Full details may be found at http://www.iucr.org/iucr/ sponsorship/vp.html.

6. Committee for the Maintenance of the Crystallographic Information File Standard (COMCIFS)

COMCIFS is tasked with maintaining and developing the Crystallographic Information Framework (CIF) on behalf of the IUCr. The Committee consists of five voting members and a broad collection of advisers and observers. The current voting members are James Hester (Chair), Brian McMahon (Secretary), Herbert Bernstein, John Westbrook and John Bollinger.

New dictionaries. A dictionary describing magnetic structures (magCIF) was produced by the Commission on Magnetic Structures with technical advice from COMCIFS members. It has been approved by COMCIFS and has seen rapid adoption in software dealing with magnetic structures.

Updating legacy dictionaries. At the 2014 Montreal meeting, COMCIFS resolved that all dictionaries written in the legacy DDL1 language would be converted to the new DDLm language. A DDLm version of the core CIF dictionary, upon which most other dictionaries depend, was approved by COMCIFS towards the end of 2016. Draft DDLm versions of the remaining dictionaries are being sent out to the original authors for checking. As part of this process, authors are able to provide any updates and new definitions, and will be invited to contribute or update chapters for the second edition of International Tables Volume G.

Macromolecular standards. The wwPDB continued to promote CIF usage in the macromolecular community, with sponsorship of SASCIF expansion efforts [Kachala, Westbrook \& Svergun (2016). J. Appl. Cryst. 49, 302-310] and hybrid methods dictionary extensions (https:/github.com/ ihmwg/IHM-dictionary/blob/master/dictionary_documentation/ documentation.md).

The new wwPDB OneDep Deposition and Annotation System [Y. Young et al. (2017). Structure, 25(3), 536-545] (http://deposit.wwpdb.org) was released with added support for NMR and 3D-EM structures. The OneDep system is built on a $\mathrm{PDBx} / \mathrm{mmCIF}$ data infrastructure representing all of these experimental methods [Adams et al. (2015). Nat. Struct. Mol. Biol. 22, 433-434]. The X-ray refinement applications CCP4/REFMAC and Phenix.Refine both support the production of $\mathrm{PDBx} / \mathrm{mmCIF}$ data files ready for deposition. Current dictionaries used by this system are made available on the PDBx/mmCIF resources site http://mmcif.wwpdb.org.

Interaction with other data-management initiatives. For the past five years, we have worked to achieve interoperability between imgCIF/CBF and NeXus/HDF5 NXmx in describing metadata for macromolecular crystallography diffraction images. This effort has contributed to successful handling of diffraction images from XFEL detectors and Dectris Eiger detectors in both $\mathrm{CBF}$ and HDF5 formats [Brewster et al. (2014). Comput. Crystallogr. Newsl. 5, 19-24; Forster et al., https://www.dectris.com/tl_files/root/applications/macromolecular_ crystallography/application/White_Paper_EIGER_May2016. pdf; Bernstein et al. (2016). Scientific Data Summit (NYSDS), New York, IEEE, pp. 1-4; Hester (2016). Data Sci. J. 15].

Starting in 2016 there have now been four High Data-Rate Macromolecular Crystallography (HDRMX) meetings (see http://www.medsbio.org/hdrmx/). At the most recent HDRMX meeting (March 2017), it was agreed to begin mapping both the mmCIF and coreCIF dictionaries into NeXus, so that complete descriptions of the samples studied can be included with diffraction image metadata in the earliest stages of crystallographic studies. This will facilitate both publication and archiving.

\section{J. Hester, Chair}

\section{IUCr Newsletter}

Three issues were produced in 2016. One issue of Volume 23 and two issues of Volume 24 were 24 pages in length. As in previous years, the content covered topics such as activities of the IUCr, its Regional Associates and Commissions, IYCr Activities, Letters to the Editor, news concerning crystallographers and crystallography in general, awards, book reviews, election results, resources, meeting reports, obituaries, future meeting announcements, and a general meeting calendar.

Each issue carried a President's column written by Marv Hackert and an editorial by Jonathan Agbenyega. Bill Duax handled most of the editorial responsibilities. Patti Potter was responsible for layout and all phases of production and distribution.

Each issue devoted two pages to articles related to IUCr journals. All three issues contained several pages of articles pertaining to IYCr. We created a new feature, 'Products', that appeared in Volume 24, Issue 2. This feature was created to entice advertisers by offering a free article on these pages.

Additional meeting and workshop reports were published covering activities in Brazil, Croatia, Cuba, Czech Republic, Italy, Japan, Mexico, USA and Poland. Future meeting announcements included the Hyderabad Congress as well as a meeting in Italy.

Distribution was carried out electronically for all three issues. Messages were sent to an average of 12705 people for the electronic version. Print copies went to an average of 560 libraries and individuals, and copies went to several meetings, including the Regional Associates' annual meetings.

W. L. Duax, Editor, and P. Potter, Production Manager 


\section{IUCr/Oxford University Press (OUP) Book Series}

Although no books appeared in 2016, this has been an accident of scheduling - there are a good number in the pipeline.

Sadly, Professor Davide Viterbo, Chair of the Committee, died in May 2017. The Committee is very interested in proposals for new volumes and, until a new Chair is appointed, encourages prospective authors to contact the Executive Secretary (execsec@iucr.org). Readers may suggest topics and/or authors, as they know the subjects that are not well covered in the literature. Manuscripts covering important aspects of crystallography and related fields are very welcome.

\section{Regional Associates and Scientific Associates}

\subsection{American Crystallographic Association (ACA)}

The American Crystallographic Association, Inc. (ACA) (http://www.amercrystalassn.org) is a non-profit, scientific organization with under a thousand registered members. ACA was founded in 1949 through a merger of the American Society for X-ray and Electron Diffraction (ASXRED) and the Crystallographic Society of America (CSA). The objective of the ACA is to promote interactions among scientists who study the structure of matter at atomic (or near atomic) resolution.

The 2016 ACA Council consisted of Tom Terwilliger (President), Amy Sarjeant (Vice-President), Christopher Cahill (Past-President), S. N. Rao (Chief Financial Officer and Interim Treasurer), Sue Byram (Treasurer), Diana Tomchick (Secretary) and Martin Donakowski as Young Scientists Special Interest Group (YSSIG) representative to the Council (ex officio). Michael James served as the Canadian National Committee for Crystallography (CNCC) representative, Bill Duax as Chief Executive Officer, Marcia Colquhoun as Executive Secretary and Hanna Dabkowska as the IUCr representative (ex officio). The Council met three times in 2016.

The ACA 66th Annual Meeting in 2016 was held in Sheraton Downtown Hotel, Denver, 22-26 July. It was attended by 570 participants, with some first-time attendees.

The Programme Chairs were Amy Sarjeant and Eddie Snell; Martin Donakowski and George Lountos were responsible for outstanding YSSIG sessions and great social events. The Would You Publish This session, chaired by Louise Dawe and Danielle Gray, as well as Career Development One, featuring Brad Conrad (AIP), were very well attended and appreciated by young participants.

The 2016 ACA Award winners are Jason Benedict (Etter Award), Axel Brunger (Trueblood Award), Elspeth Garman (Fankuchen Award) and Benno Schoenborn (Bau Award). Phil Plait (also known as 'Bad Astronomer', Slate Magazine) delivered an entertaining banquet talk. The meeting was supported by about 20 sponsors, including the IUCr.

At the General Business Meeting it was voted that the ACA membership renewal rates should slightly increase; these are posted on the web site. The importance of the educational impact of the Denver meeting was very much applauded.
More information about the Denver meeting and details about the programme may be found at http://www. amercrystalassn.org.

The 2017 (67th) Annual Meeting (http://www. amercrystalassn.org/2017-meeting-homepage) will be held at the Hyatt-Regency Hotel in New Orleans, 26-30 May. Yulia Sevryugina and Ilia Guzei will co-Chair this meeting. At the 2017 planning meeting it was suggested to the Programme Chairs that invited speakers should be encouraged to bring one or more students to the ACA meetings. Diana Tomchick will write a short piece How to Write and Submit a Compelling Meeting Abstract to be included on the 2017 meeting web site. 2016 Nobel Laureate in Chemistry, Sir James Fraser Stoddart, accepted the invitation to be the Special Plenary Lecturer.

The 2018 (68th) Annual ACA Meeting will be held in Toronto, Ontario, Canada, 20-24 July.

The 2019 (69th) Annual ACA Meeting is planned for Covington, KY.

The ACA 2016 Summer School Course in Chemical Crystallography was hosted at the University of Notre Dame, 12-19 June (http://acasummercourse.net) with 27 attendees, mostly - but not only - from the USA. As in previous cases the School was a very much appreciated by the participants. The organizers were Allen Olivier, Amy Serjeant, Charlotte Stern and Christos Malliakas.

The IUCr and the ACA. The IUCr Executive Committee (EC) met with the ACA Council on Sunday 24 July 2016 in Denver. The ACA was represented by Tom Terwilliger, Sue Byram, Diana Tomchick, Chris Cahill, Bill Duax, Marcia Colquhoun and S. N. Rao, whereas from the IUCr were Marvin Hackert, Michael Glazer, Hanna Dabkowska, Mitchell Guss, Peter Strickland, Samar Hasnain and Jonathan Agbenyega. The main topic of discussion was how the IUCr and the ACA can work together. Invitation of representatives from the ACA and other Regional Associates (RAs) to the IUCr Executive Committee meetings was considered. The purpose of this would be to strengthen the relations between the organizations and to have the RAs informed about the outreach programmes sponsored by the IUCr. Hosting of the ACA web site at the IUCr web site was also discussed, as were the advantages of the IUCr Associates Programme.

The IUCr could provide services such as organizing conferences, workshops, fund raising, collecting dues and bookkeeping. It is essential that the ACA knows about these possibilities; it does not have to use them.

After the meeting, Peter Strickland sent Marcia Colquhoun the specifications of the metadata required to index meeting Abstracts in Acta A, and it was agreed that the ACA will archive the 2017 and 2018 meeting Abstracts with the IUCr.

A direct link to the IUCr journals and another to the Hyderabad Congress are now prominently displayed on the ACA home web site.

Interaction of the ACA with the Latin-American Crystallographic Association (LACA) and with the Pan-African association was discussed.

The ACA also encouraged the IUCr to adopt a diversity statement similar to that the ACA has recently adopted. 
In 2017 the IUCr Newsletter will be handed over from Bill Duax to the IUCr.

Hyderabad Congress. The letter from Gautam Desiraju Why Participate in IUCr2017? had been submitted to the Council and was published in the 2015 edition of $A C A$ RefleXions.

The AIP and the ACA. Tom Terwilliger was the ACA member representative to the American Institute of Physics.

There is a plan to identify a new contact with the AIP that could focus on what the AIP can do for the ACA.

Chris Cathill (ACA Past-President) spent several months as the 2015-2016 American Institute of Physics State Department Science Fellow at the Bureau of International Security and Nonproliferation's Office of Weapons of Mass Destruction Terrorism. His excellent reports can be found in the 2016 Spring and Summer ACA RefleXions.

The January 2016 issue of AIP's Physics Today included information about the ACA Denver Meeting.

Structural Dynamics - ACA/AIP journal. The relatively new, potentially profitable, ACA online journal Structural Dynamics (http://sd.aip.org) is co-published with the AIP. Journal topics include structural dynamics of molecular systems, biological systems, solid materials, liquids and solutions, surfaces and interfaces studies using highly coherent sources. It is not yet bringing any profit to the ACA.

Strategic planning. For the Fall Council meeting Chris Cahill prepared an excellent overview of the current situation and of the possible changes that the ACA has to implement in the future. Some options were discussed looking for different staffing models. It was decided that Council needs to find a meeting planner to assist in 2017 and to do the complete job in 2018.

Kristina Vitale will be working full time for the ACA Buffalo office from 1 January 2017. Her title is Membership Secretary, and a review of her salary and performance will occur after six months.

Marcia Colquhoun will continue to work half time until the end of 2017. The Chief Financial Officer reported to the Council stressing that the 2016 and 2017 budgets project losses and ways to cut costs were discussed. Bill Duax provided recommendations for CEO and Headquarters transition in 2017-2018. The Outreach Budget was supported at USD 2500.

Another action item at the Council meeting was setting up a Committee to develop a fundraising plan for the ACA. As this is a major commitment and requires some intensive work from both the Council and the ACA, it will be discussed again.

2016 ACA Fellows - a title that recognizes a high level of excellence in scientific research, teaching and professional duties, but also service, leadership, and personal engagement in the ACA and the broader world of crystallography and science. The ACA Fellows - Class of 2016 are Gerard Bricogne, I. David Brown, Charles Campana, Bryan Chakoumakos, Yu Sheng Chen, Frank Fronczek, Michael James, Brian Matthews and Arnie Rheingold.

Elections. The fall 2016 elections resulted in introducing Lisa Keefe (as Vice-President), George Lountos as YSSIG representative to the Council and Tomislav Friscic as Canadian Representative.

Social Media. ACA now have presence on Facebook (American Crystallographic Association) and on Twitter and Instagram (ACAxtal).

Canadian National Committee for Crystallography (CNCC). The main office of the CNCC has been re-located to the Canadian Light Source (Saskatoon), the terms of reference agreement between the NRC (the group that has been responsible for the CNCC and membership in the IUCr) have been updated, so are the roles of CNCC members in the future. The new $\mathrm{CNCC}$ web site has been established and may be visited at http://xtallography.ca/.

The new Chair of the CNCC is Patrick Mercier, the ViceChair is Tomislav Friscic, the Executive Secretary is Michel Fodje and the Treasurer is Brian Patrick. Their terms will be three years.

The Spring 2017 ACA Council Meeting will take place in New Orleans, 26 May.

\section{H. A. Dabkowska, IUCr Representative}

\subsection{Asian Crystallographic Association (AsCA)}

AsCA continues to play a leading role in the nurturing of collective crystallographic activities in the Asia-Pacific region with successful scientific meetings being held in those years in which there is no IUCr Congress and General Assembly.

AsCA Executive officers. The new office-bearers for the term 2016-2019 were elected in Hanoi, Vietnam, and are: Jennifer Martin (President, Australia), Xiao-Dong Su (VicePresident, People's Republic of China), Edward R. T. Tiekink (Secretary/Treasurer, Malaysia) and Pinak Chakrabarti (Immediate Past President, India).

AsCA scientific meeting 2016. The 14th Conference of AsCA (AsCA 2016) was held in Hanoi, Vietnam (Venue: Hanoi University of Science and Technology, 4-7 December 2016), coinciding with the 60th anniversary of the host Institute. Professor Duong Ngoc Huyen was the Chair of the Local Organizing Committee and Professor Masaki Kawano was the Chair of the International Programme Committee. The AsCA2016 meeting consisted of two parallel satellite meetings, 18 Microsymposia, an education conference workshop on minerals and gems, crystallographic software sessions, a special section on materials and a Rising Star session for young scientists. The scientific scope of AsCA2016 covered many important aspects of crystallography-related areas, including synchrotron/neutron, structural biology, chemical crystallography, materials and polymer science, crystal growth/ crystallization, electron microscopy, informatics, and much more. There were 457 participants from 38 countries. The breakdown was: Japan (119), Korea (59), Vietnam (42), India (38), People's Republic of China, including Hong Kong (32+ 9), Australia (24), Thailand (19), Taipei, China (18), Singapore (18), UK (17), Malaysia (12), Russia (7), USA (6), New Zealand (5), Germany (5), Nigeria (3), Turkey (2), Sweden 
(2), Philippines (2), Italy (2), Iran (2), Canada (2), Bangladesh (2), UAE (1), Belgium (1), Côte d'Ivoire (1), Cameroon (1), Czech Republic (1), Spain (1), France (1), Croatia (1), Indonesia (1), Sri Lanka (1), Mongolia (1), The Netherlands (1), Tunisia (1), Yemen (1), South Africa (1).

Planning for future meetings. At the AsCA Council meeting held in Hanoi (6 December 2016), it was confirmed that the 15th AsCA Conference (AsCA 2018) would be held in Auckland, New Zealand, 2-5 December 2018. Professors Chris Squire and Kurt Krause were charged with leading the Local Organizing Committee and Professor Ted Baker was approved as the Programme Chair. AsCA 2019 is planned to be held in Singapore, and Professor J. J. Vittal would be the Local Chair.

At the Council meeting a proposal was received from the Malaysian representative to host the 17th AsCA Conference at Sunway University, Petaling Jaya, Malaysia, in December 2021 (noting that there will be no AsCA meeting in 2020 as there would be an IUCr Congress that year).

Sponsorship. AsCA was a proud sponsor of the 1st PanAfrican Conference on Crystallography, held at the University of Dschang, Cameroon, 6-10 October 2016.

AsCA Regional Committee membership. As Singapore and Bangladesh are in the process of becoming full members of the IUCr, it is planned to include Cambodia and Sri Lanka in their place as members of the AsCA Regional Committee of IUCr (along with Malaysia, Thailand and Vietnam).

\section{Takata, IUCr Representative}

\subsection{European Crystallographic Association (ECA)}

The ECA is a scientific association among national and individual members, and corporate affiliates. It has 12 SIGs (Special Interest Groups) and three GIGs (General Interest Groups). The youngest GIG is GIG3 - Education in Crystallography. These bodies are involved in the preparation of the programme of the ECA main event - the ECM (European Crystallographic Meeting), as a rule in five focus areas.

In 2016, ECM30 took place in Basel, Switzerland (28 August - 1 September 2016). The programme scheme was as usual and similar to that for ECM29. There were even more scientific contributions - 931 delegates from 47 countries, 30 exhibitors, nearly 300 speakers and 467 posters. The organizers have provided some additional numbers: 296 women, 36 retired people from 15 countries, 179 students from 32 countries. The most strongly represented countries were: Switzerland (181), Germany (173), UK (120) and France.

The organization of ECM31 had already been assigned to the Spanish Crystallographic Association - Ovideo, Spain, 2227 August 2018 (Chair: Santiago Garcia-Granda). It will be held in the Palace of Exhibitions and Congresses of Oviedo. The organizers also suggested a programme for families and their children in order to attract young crystallographers with families, and also streaming of lectures. ECM32 will take place at the University of Vienna, Austria, in 2019 (Chair: Klaudia Hradil). France is preparing a bid for the ECM in 2021 in Paris.
The main ECA prize is the Max Perutz Prize awarded in recognition of meritorious achievements in any branch of crystallography by a crystallographer having a clear affiliation with the ECA region. The 9th Prize was awarded to Dr Vaclav Petricek from the Institute of Physics of the Czech Academy of Sciences, Prague, Czech Republic, for 'his practical application of the theory of aperiodic structures in his computing system JANA ... JANA has made aperiodic structures accessible to a wide community of crystallographers and chemists'.

The Erwin Felix Lewy Bertaut Prize is awarded to a young scientist having a clear affiliation with the ECA/ENSA region (up to 5-8 years after finishing a $\mathrm{PhD}$ thesis) and an individual member of ECA/ENSA (European Neutron Scattering Association), in recognition of notable experimental theoretical or methodological contributions in the field of investigation of matter using crystallographic or neutron-scattering methods. The 8th Prize was given to Dr Linda Reinhard for her pioneering contributions to the crystallographic analysis of enzymes and the optimization of protein preparations for diffraction studies.

The ECA Executive Committee's regular winter meetings took place in February 2016 in Parma (the city of the ECA President, because in 2017 there is no ECM).

The ECA gives increasing attention to the education of crystallography and organizes European Schools of Crystallography (ECSs). The third school was organized by the Croatian Association of Crystallographers in Bol, Brac Island, Croatia, 25 September - 2 October 2016, with 24 lecturers and 77 participants. The programme consisted of three-and-a-half days of fundamentals and then two parallel modules: (i) Structure Solution of Small Molecules from Single Crystals and (ii) Structure Solution from Powder Data. The fourth ECS will take place in Warsaw, Poland, 2-7 July 2017 and the fifth ECS in Stellenbosch, South Africa, in 2018. The ECA has prepared quite detailed guidelines for both organizers/bidders for ECMs and ECSs.

Some SIGs organize their own events, seminars and schools. The largest one is EPDIC - European Powder Diffraction Conference, prepared by SIG8. The last one took place in Bari, Italy, in June 2016 and was organized in the usual way with Plenary Lectures, two parallel sessions, poster sessions for three days and two preceding workshops - Phase Identification and Materials Characterization by the ICDD, and Lachlan Cranswick's Software Fayre. There were over 360 participants.

There are also activities in the Africa region. The First PanAfrican Conference on Crystallography took place in Cameroon (October 2016) with 197 participants, mostly from Cameroon (87) and South Africa (17) but also another 20 from other African countries, Europe, America and Asia. An African Crystallography Steering Committee is being prepared.

The ECA now has about 300 individual members (annual fee EUR 10), about 20 corporate members (annual fee EUR 250), 37 national members and three observers. The income allows some support of schools and conferences but it is not 
too high. It was decided to distribute the support for attendance of young crystallographers at an ECM directly (via the ECA scholarship fund) rather than through the bursary committee of the ECM.

The successful arrangement of the IUCr-UNESCO OpenLab, 30 May - 3 June 2016, sponsored among others by the IUCr and the ECA, led to an application from Albania and Kosovo, represented by Dritan Siliqi, to become a full national member of the ECA, which was accepted in Basel.

The ECA stopped financial support to six countries of the region as the Adhering Body of the IUCr, since three were accepted as full IUCr members in 2014. It was decided that such groups of countries should be mainly created by them first and not from the top. There are still problems with Russian membership in the ECA. However, the ECA President Alessia Bacchi and Past-President Andreas Roodt were invited to attend the 1st Russian Crystallographic Conference (http://www.crys.ras.ru/rcc), Moscow, 21-26 November, chaired by the Director of the Kurchatov Institute, Professor Mikhail Kovalchuk. The Conference was organized by the Russian National Committee for Crystallography, the Kurchatov Institute National Research Center and the FSRC 'Crystallography and Photonics' of the Russian Academy of Science. More than 2000 participants were registered at the conference, among which more than 800 were under 35 years of age. There was also a proposal to establish a Eurasian Crystallographic Association.

The ECA has two internet domains (http://crystallography.eu and http://ecanews.org) and there are also links in the main social networks [@social_eca (Twitter), ecanews (Facebook)].

Discussion continues as how to strengthen the position of the ECA as a European Association - which has some legal issues (it is registered in The Netherlands according to Dutch law) - and also the possibility of establishing professional management (connected also to the organization of the ECMs).

\section{R. Kuzel, IUCr Representative}

\subsection{Latin-American Crystallographic Association}

At the Montreal Congress, the Latin-American Crystallographic Association (LACA) became the fourth Regional Associate of the IUCr. Also in Montreal, I was appointed the IUCr Representative to LACA and was also a member of the LACA Council. The LACA Provisional Executive Committee in 2014 comprised the following members: Marcia Carvalho de Abreu Fantini, President (Brazil), Diego German Lamas, Vice-President (Argentina) and Lauro Bucio Galindo, Secretary (Mexico).

The countries of the North, Central and South American regions, historically bound by the Luso/Hispanic heritage and language, have constantly made efforts to work together promoting the advance of science and education in all countries. The formation of LACA was approved in Cordoba, Argentina, to gather together all the already consolidated crystallographic groups in the region. The region involved in the LACA initiative includes important scientific communities and well established crystallographic societies, associations and consolidated crystallographic groups. The initial groups are Mexico (SBCr), Venezuela (consolidated groups), Brazil (ABCr), Chile (consolidated groups), Argentina (AACr), Colombia (consolidated groups), Peru (consolidated groups) and Uruguay (consolidated groups). New existing groups have started their own national societies, like Costa Rica (UCRC) or the recently established collaborative projects to become a united and active group of countries. The mere existence of this very dedicated and scientifically productive crystallographic community in the Latin-American countries contributed significantly to support the construction of a synchrotron facility in Campinas, Brazil, in operation since 1997, and crystallographers represent the majority of its users. Some LACA countries have been affiliated to the IUCr for more than three decades, and are very aware of the importance of linking the regional scientific community acting in the crystallographic area with the activities and aims of the IUCr.

Through its association with the IUCr as a Regional Associate, LACA expects to increase international interaction among the countries of the LACA region with the rest of the world. As a Regional Associate, LACA will configure the consolidation of the science of crystallography in the LACA countries and acquire an international institutional level that will greatly help the development of new laboratories, student exchange and financial support from governmental institutions in all countries of the region. A newsletter dedicated to reporting all activities related to crystallographic research in Latin America will be published. This will contribute to improving the level of interaction among students and researchers in all areas of science where crystallography plays a key role.

The LACA Provisional Executive Committee was renewed in October 2016, at the II LACA Meeting in Merida (Mexico), and is formed by the following members: Diego German Lamas, President (Argentina), José Reyes Gasga, Vice-President (Mexico), Graciela Diaz de Delgado, General Secretary (Venzuela), José Roberto Vega Baudrit, Adjoint Secretary (Costa Rica) and Iris Torriani, Treasurer (Brazil). A Deliberative Council was established, formed by the following members: Sebastian Klinke (Argentina), Marcia Fantini (Brazil), Mauricio Fuentealba (Chile), Jesus Angel Arenas Alatorre (Mexico) and Leopoldo Suescun (Uruguay), with Andrea Araya (Costa Rica) and Alexander Briceno (Venezuela) as alternates.

These authorities remain provisional until the Statutes are registered in Brazil and an election is called following the approved procedures. A Special Education Commission is being organized, which will be in charge of evaluating the proposals for courses and schools that request the support of LACA, and proposing activities for LACA.

The most important LACA activities during 2016 were the 2nd LACA Meeting, Merida, Mexico, 23-27 October 2016, with more than 100 participants from Mexico and LACA countries; three OpenLabs held in Montevideo (23-29 
February 2016, with the support of Bruker); and the third IUCr-UNESCO OpenLab in Mexico [held at the Advanced Materials Research Center (CIMAV), Chihuahua (16-18 May 2016) and in La Paz (12-16 September 2016, with the support of Rigaku)]. Another important event was the International School on Fundamental Crystallography - Fifth MaThCryst School in Latin America, Havana, Cuba, 30 October - 4 November 2016.

The activities of the national societies for 2016-2017 follow.

Argentina - AACr. XII Annual Meeting of the AACr, San Luis, 9-11 November 2016. VIII School of the AACr, San Luis, 9-11 November 2016. V Workshop of the AACr: Synchrotron and Neutron Techniques for the Characterization of Materials, San Luis, 8 November 2016. Third National Crystal Growing Contest for Secondary Schools (April to November 2016). About 300 schools from across the country participated; 13 prizes and 21 mentions of honour were granted. Training Courses on Crystallography and Crystal Growth for Teachers were organized all over the country: 42 courses with a participation of over 1600 attendees (April to July 2016). As in 2014 and 2015, the AACr sponsored the participation of Argentinian Schools in the 2016 IUCr crystalgrowing competition for schoolchildren and Argentina received the largest number of distinctions: two gold medals and two bronze medals (as in 2015). As in 2014 and 2015, $\mathrm{AACr}$ members organized several dissemination activities, giving lectures and seminars in several primary and secondary schools, and at universities as well as at science and technology fairs. Postgraduate courses on X-ray techniques were given in Buenos Aires (two courses), Mendoza and San Luis. One was focused on small-angle scattering, while the others included several techniques: diffraction, absorption, low-angle scattering, fluorescence etc.

Brazil-ABCr. The Workshop on Applied Crystallography that is organized every one or two years at the Engineering Department of the Universidade Federal do Espirito Santo was held on 13-14 May 2016 in Vitoria (ES). At the 68th Annual Meeting of the Brazilian Society for the Progress of Science (SBPC), a short course on Methods of Molecular Structure Determination was offered by Professors Y. P. Mascarenhas, G. Oliva and M. C. A. Fantini, 4-7 July 2016, at Porto Seguro, BA. A short course on the Rietveld method took place at Universidade Federal do ABC, São Paulo, SP, 12-16 September, organized by Professor Fabio F. Ferreira.

Marcia C. A. Fantini represented the Latin-American Crystallographic Association at the First Pan-African Conference on Crystallography in Dschang, Cameroon, 6-11 October 2016.

Costa Rica - UCCr. Participation in the organization of a European event including conferences and poster sessions entitled 7th Workshop on Green Chemistry and Nanotechnologies in Polymer Chemistry, 4th National Conference on Nanotechnoscience, 4th National Conference on Polymers, and ADAM 2016 Workshop, which included topics related to crystallography in San José, Costa Rica, 21-23 September 2016. A doctoral research internship was held at the University of Cambridge, UK, in the Department of Chemistry of Dr
William Jones's research group with the subject Screening of Cocrystals of Lovastatin and Irbesartan by Means of Mechanical Synthesis, October to December 2016. Participation in the VIII National Congress of Crystallography, Merida, Yucatan, Mexico, 23-27 October 2016 with the presentation of a poster Characterization of the Polymer Biodegradable Bionolle [Poly(butylene succinate)-PBS]. A course was given on Polymers and Biopolymers in Medical Devices (that included crystallographic topics) with Boston Scientific: Heredia, Costa Rica (total 4 months, from 1 February - 30 May 2016). A project entitled High Technology Applied to the Development of Low-Cost Methods to Evaluate Properties that Impact the Bioavailability of Drugs in Original and Generic Medicines Available in the National Market, TEC, UCR, LANOTEC, 2016 was presented and approved. A FEES project called Engineering of Crystals Applied to Natural and Synthetic Bioactive Substances: Polymorphs, Nanocrystals and Cocrystals, coordinated by Andrea Araya, TEC, UNA, UCR, LANOTEC, 2015-2016, ends in 2017. An OpenLab with support from Bruker will be held in 2017.

Mexico - SMCr. The VIII National Meeting of Crystallography was held 23-27 October 2016 - a regular meeting of the SMCr, in conjunction with the Second Meeting of LACA. As a joint event, the VI Meeting of Users of Synchrotron Light was also organized [by the TULS Network (Thematic Network of Users of Synchrotron Light)]. Six courses covering topics related to crystallography were also held 22-23 October.

PANalytical Mexico and CIMAV Chihuahua decided to organize the Third IUCr-UNESCO OpenLab Mexico, 16-18 May 2016. The programme consisted of a three-day seminar to give participants access to an update about how crystallography has developed in Mexico and about different and new applications related to the X-ray diffraction technique through presentations given by ten national crystallographers and Dr Scott Speakman, Principal Scientist at PANalytical, all of them having a relevant background in the academic research environment. In addition, practical sessions were organized in order to show how to take advantage of XRD and XRF techniques in the research environment. The event took place at the Advanced Materials Research Center (CIMAV), Chihuahua, and even though places were limited to 70 people, about 120 people applied, showing a strong interest in crystallography, so the number of places was extended to 100.

Venezuela (SVC) and Colombia Crystallographic Societies. The exhibit The Chemistry of the Mineral Kingdom was presented at Encuentro con la Fisica, Quimica, Matematica y Biologia, Facultad de Ciencias, Universidad de Los Andes (ULA), 13-15 June 2016, by student members of the Crystallography Laboratory at ULA, Merida, Venezuela, under the direction of Professors J. M. Delgado and G. Diaz de Delgado. This is the third year in a row that the exhibit has been presented; it included specimens from the laboratory's collection. The event is aimed at encouraging elementary- and secondary-school students to pursue undergraduate studies in 
science. The event will take place again in June 2017. During 2016 through to May 2017, undergraduate and graduate degree theses including crystallographic work were presented by students from Centro de Quimica of Instituto Venezolano de Investigaciones Cientificas (IVIC) and from Departamento de Quimica, Universidad de Los Andes (Merida). Venezuelan crystallographers participated in the following national and international events: XX Congreso Venezolano de Catalisis, IVIC, Caracas, Venezuela, November 2016; II Reunion Latinoamericana de Cristalografia (LACA) and VIII Congreso Nacional de la Sociedad Mexicana de Cristalografia (VIII-CNCr) in Merida, Yucatan, Mexico, 22-27 October 2016. Invited talks: Professor G. Diaz de Delgado (ULA, Venezuela), Characterization of Active Pharmaceutical Ingredients (APIs), New Solid Forms of APIs and of Organic and Metal Derivatives of APIs; and Professor José Miguel Delgado (ULA, Venezuela), At One Hundred Years of X-ray Powder Diffraction. A Brief Review of Its Beginnings.

Professors Miguel Delgado and Graciela Diaz de Delgado (ULA) organized a Workshop on Crystallography Databases, 23 October 2016, at CINVESTAV, Merida, as a pre-Congress event to the meeting II-LACA. Dr Amy Sarjeant (Cambridge Crystallographic Data Centre, CCDC, USA) and Dr Thomas Blanton (International Centre for Diffraction Data, ICDD, USA) participated as instructors.

The IUCr-UNESCO OpenLab, co-sponsored by Rigaku Latin America, took place at Universidad Mayor de San Andres (UMSA), La Paz, Bolivia, 12-16 September 2016. The OpenLab was preceded by a mini-course on 8-9 September. About 100 students and young researchers from different universities and research institutes from Bolivia, Chile, El Salvador, Mexico, Nicaragua and Peru attended this unprecedented event. The instructors were Ing. Mario Blanco Cazas and Ing. Ariana Zeballos (UMSA, Bolivia), Professor Diego Lamas (U. San Martin, Argentina/LACA Vice-President at the time), Professor José Antonio Henao (UIS, Colombia), and Professors José Miguel Delgado and Graciela Diaz de Delgado (ULA, Venezuela), along with Dr Akilesh Tripathy (Rigaku Americas, USA).

Professor José Antonio Henao (Universidad Industrial de Santander, Bucaramanga, Colombia), Professor José Miguel Delgado and Professor Graciela Diaz de Delgado (ULA, Venezuela) were Invited Speakers at the XV Latin-American Seminar of Analysis by X-ray Techniques (SARX 2016), 18-22 September, Petropolis, RJ/Brazil. A Workshop on the PDF-4 Database was organized by Professor Miguel Delgado and taught by Dr Tom Blanton (ICDD, USA) and by Professor Delgado.

Professor José Miguel Delgado visited Universidad Mayor de San Andres, La Paz, Bolivia, 25-28 January 2016. During this period, he and Dr Akihiko Iwata of Rigaku-Latin America were instructors at the Workshop de Cristalografia at this University. They participated in meetings with university officials and students, and professors of the School of Chemistry of Facultad de Ciencias Puras y Naturales of UMSA to plan the activities for the OpenLab Bolivia, which took place in September of the same year.
As part of the very fruitful collaboration between Laboratorio de Rayos $\mathrm{X}$ at Universidad Industrial de Santander (UIS) in Bucaramanga, Colombia, and Laboratorio de Cristalografia of Universidad de Los Andes (ULA) in Merida, Venezuela, several activities took place in 2016 and in the first semester of 2017. Some are planned for the remainder of 2017 and into 2018.

Professors J. M. Delgado and G. Diaz de Delgado (ULA, Venezuela) visited UIS during July-August 2016, February 2017 and April 2017.

A collaborative network in the area of pharmaceuticals and catalysts has been established between the laboratories at UIS, Colombia, and ULA, Venezuela. It is hoped that this collaboration will be extended to neighbouring countries such as Ecuador, Peru and Bolivia, and to other Latin-American countries.

The XVII Congreso Colombiano de Quimica will take place 25-27 October 2017, at UIS, Bucaramanga, Colombia. Professor José Antonio Henao leads the Organizing Committee. Several pre-Congress courses are being organized, in particular an X-ray Diffraction Course (22-24 October) where Amy Sarjeant (CCDC, USA), Tom Blanton (ICDD, USA), J. M. Delgado and G. Diaz de Delgado (ULA, Venezuela), John Bonilla (UIS, Colombia), and Hernando Camargo (U. Santo Tomas, UST, Colombia) will be the instructors.

Efforts are being devoted to establishing the Colombian Crystallographic Society. The Congreso Colombiano de Quimica should provide a venue to reach this goal. An OpenLab on Powder Diffraction is being planned by J. A. Henao and J. M. Delgado at UIS, Colombia, for 2018.

It is worth mentioning that the X-ray Laboratory at UIS, Colombia, has been providing an excellent service to academic institutions and industries within Colombia and in Latin America. This laboratory is among the best equipped centres in South America.

Uruguay - RUCr. A Workshop on Integrative Methods in Structural Biology was held 16-19 February 2016 (http:// pasteur.uy/en/last-news/integrative-methods-in-structural-biologyto-enhance-high-impact-research-in-health-and-disease); participants: 30 students (Uruguay, UK, Argentina), 13 lecturers (Uruguay, Argentina, France, Spain, Brazil, UK). The IUCr-UNESCO Bruker OpenLab Uruguay 2 was held 23-29 February 2016 (http://cryssmat.fq.edu.uy/OpenLab/ index.html); participants: 44 students, 11 lecturers. Segundo Encuentro de la Red Uruguaya de Cristalografia (RUCr) was held 30-31 August 2016 (https://sites.google.com/site/ 2encuentrorucr/home); participants: 50 (two invited from Argentina and Brazil).

Chile (Comision Nacional de Investigacion Cientifica y Tecnologia). In 2016, three schools or courses were held in different universities. At the Pontificia Universidad Catolica de Chile in Santiago in August 2016, in conjunction with the University of Notre Dame, A Practical Course in Chemical Crystallography was held. At the Universidad Santa Maria in Valparaiso, the first and second Schools of Crystallography and X-ray Diffraction were held in March and December 
2016, respectively. In the Pontificia Universidad Catolica de Valparaiso, the Interschools Contest 'CristalEscolar' was held for the third consecutive year, where several institutions carried out experiments and exhibited their crystal-growth activities.

During the 2nd LACA Meeting, with the participation of the IUCr President Marvin Hackert and the IUCr Representative for LACA Santiago Garcia-Granda, an assembly of LACA was held during which the executive authorities were renewed, the Statutes were approved and it was decided to organize a Deliberative Council.

The latest version of the LACA Statutes and By-Laws was approved by the General Assembly in Merida, Yucatan, Mexico, and has now been submitted for registration using the services of a private law and accounting firm. Since LACA was founded, the Brazilian Crystallographic Association sponsored the first steps of its registration as a non-profit scientific association. In 2016, using funds from the Brazilian National Research Council (CNPq), an exclusive (.org) domain and host server space were acquired for the LACA web site with a five-year contract. The same CNPq grant will be used to pay for registration fees.

The LACA Executive Board and Council have now taken office, but one important point to be solved is the way of obtaining a basic yearly contribution from the country members. A flux of continued income will be needed to cover functional expenses for maintenance of the administrative structure. LACA is tax-exempt but every year the registration must be reinstated and there is a cost for the accounting services. This is a task for the present authorities.

During the LACA Assembly it was also decided that the Third Meeting of LACA would be held in Chile in October 2018 and that the First School of LACA, dedicated to crystallography of small molecules, would be held in Montevideo, Uruguay, in February 2018.

For 2017, the participation of Latin-American colleagues will be promoted at the Hyderabad Congress, where a workshop will be held to discuss the progress of crystallography in Latin America, and it is hoped that several national meetings will be organized. Organization of a new OpenLab in December 2017 in Costa Rica is planned. Unlike previous OpenLabs, this will be promoted by the LACA authorities.

\section{S. Garcia-Granda, IUCr Representative}

\subsection{International Organization for Crystal Growth (IOCG)}

The most important event concerning IOCG (http:// www.iocg.org/) in 2016 was the official meeting of the association, the 18th International Conference on Crystal Growth and Epitaxy ICCGE-18, Nagoya, Japan, 7-12 August. The Opening Ceremony of the conference took place in the presence of His Imperial Highness, The Crown Prince of Japan. A lecture was given by the Nobel Laureate Isamu Akasaki.

Eleven general sessions and ten topical sessions were organized. The conference was very successful (about 1400 participants) and well organized. The week before the conference, the 16th International Summer School on Crystal Growth ISSCG-16 was held at Lake Biwa, Shiga, Japan, with the participation of 120 students. Both the conference and the school were supported by the IUCr. Many members and consultants of the Commission on Crystal Growth and Characterization of Materials (CCGCM) were directly involved in the organization of both the conference and the school, but I would like to underline in particular the contribution of Koichi Kakimoto, Chair of ICCGE-18 and a member of the CCGCM. It is important to note that three symposia of the IOCG Conference were officially co-organized by representatives from the IUCr, namely Janakiraman Kumar (Defect Formation), François Puel (Industrial Crystallization) and J.-M. Garcia-Ruiz (Organic and Biological Crystallization).

The IOCG Conference also provides an opportunity to consolidate the organization's officers and Executive Committee members. The new President of IOCG is Koichi Kakimoto, also a member of the CCGCM. Co-Vice-Presidents are T. F. Kuech (USA) and E. Vlieg (NL), both members of the CCGCM, the Secretary is H. A. Dabkowska (Canada), and the Treasurer is J. Derby (USA). The members of the Executive Committee are J. M. Garcia-Ruiz (Spain), S. Baldochi (Brazil), J. Y. Wang (People's Republic of China), all being consultants/members of the CCGCM, Y. Mori (Japan), S. Krukowski (Poland), A. Voloshin (Russia), M. Heuken (Germany) and J. De Yoreo (USA).

The IOCG is very active in promoting crystal-growth conferences and schools. It should be mentioned that Eastern countries are gaining more and more interest in this field.

\section{A. Zappettini, IUCr Representative}

\subsection{International Centre for Diffraction Data}

The Commission on Powder Diffraction maintains close links with the ICCD and also with the International X-ray Absorption Society (IXAS) (http://www.ixasportal.net/ixas/).

\section{P. Whitfield, IUCr Representative}

\subsection{Worldwide Protein Data Bank (wwPDB)}

The Protein Data Bank has been an essential resource for macromolecular crystallographers for more than 40 years, and its policies and development have been strongly influenced by the crystallographic community. Today the PDB is a partnership of four entities, referred to collectively as the Worldwide PDB (wwPDB). The partners comprise the RCSB-PDB in the USA, PDBe in Europe, PDBj in Japan and BMRB (NMR database) in the USA. These centres collaborate intimately and share the load, maintaining a single archive that is accessible to researchers, educators and students throughout the world.

Recognizing the importance of this partnership to the crystallographic community, the wwPDB was formally desig- 
nated a Scientific Associate of the IUCr in 2015. The IUCr provides a representative (currently Professor Ted Baker) on the wwPDB Advisory Committee (wwPDB-AC). This Committee also has representatives from the NMR and cryoEM communities, as well as regional representation.

The wwPDB partners focus on fast and accurate processing of entries, annotation and remediation of older entries in the archive. Much of the development work is done in the background, by expert Task Forces drawn from the relevant communities, but implementation of new policies and release of new tools must be ratified by the wwPDB-AC.

As of April 2017 the archive comprises nearly 130000 macromolecular structures, of which about $90 \%$ have been determined by crystallography. Some 11000 structures were deposited in the past year, at a rate of increase that places increasing demands on the efficiency of annotation, checking and validation. At the same time much development work is being undertaken, both by the wwPDB partners and in the relevant communities as the range of techniques giving structural data continues to expand.

It is pleasing to note that the lead taken by our IUCr journals in requiring that $\mathrm{PDB}$ validation reports are provided with submitted articles is now being followed by other journals, including most recently journals from the Nature stable. There is a clear and obvious need for referees to be given information that allows them to assess the quality of structural data.

The remediation of carbohydrate structures in the archive is continuing, to ensure that they conform to proper conventions of atom labeling and stereochemistry. Glycan chains on proteins are often poorly ordered and many archival entries violate stereochemical rules. Changes can only be made with authors' consent, however, so remediation is a slow process.

With 1.5 million downloads per day across the three wwPDB sites, it is obvious that the archive is of enormous importance to the whole life-sciences community. The IUCr can be proud of the contribution made by the crystallographic community, and I am happy to be able to report that the relationship between the IUCr and the wwPDB is strong, and is much appreciated by the wwPDB.

\section{E. N. Baker, IUCr Representative}

\section{Representatives on Other Bodies}

\subsection{IUPAC Interdivisional Committee on Terminology,} Nomenclature and Symbols (ICTNS)

There was only one activity of the ICTNS during 2016 that related to crystallography. A group wrote a technical report concerning the revised definition of the mole; the new definition would change Avogadro's number by less than 1 part in $10^{8}$.

\section{P. Brock, IUCr Representative}

10.2. International Council for Scientific and Technical Information (ICSTI)

A one-day meeting was held in Denver, USA, 10 September 2016, attended by B. McMahon in place of A. M. Glazer.

This comprised:

General Assembly Meeting (including Member Initiative Presentations);

Information Trends and Opportunities Committee (ITOC) Workshop on Enabling Innovations for Researcher Workflows and Scholarly Communication (Chair: Markus Ekman);

Technical Activities Coordinating Committee (TACC) Workshop on Trends in Scientific Software Development, Sharing and Use;

WorldWideScience Alliance Annual Meeting;

ICSTI Executive Board Meeting.

In the ITOC Workshop the following talks were presented:

Innovations in Scholarly Communication: Openness, Efficiency and Reproducibility Drivers by Jeroen Bosman and Bianca Kramer of Utrecht Library in The Netherlands.

Wikidata and Wikimedia Commons as a Platform for Collaborative Annotation and Reuse for Scientific Data by Lambert Heller - German National Library of Science and Technology (TIB).

From Principles to Action - The FORCE11 Approach to Innovation in Scholarly Communications by Cameron Neylon, Professor of Research Communication at the Centre for Culture and Technology at Curtin University.

An Open Science Framework for Managing and Sharing Research Workflows by Courtney Soderberg, Center for Open Science, Charlottesville, Virginia, USA.

In the TACC Workshop the following talks were presented: Jay Billings. Oak Ridge National Laboratory and DOE Office of Scientific and Technical Information, described The New Department of Energy Software Center.

Andrea Ross, of the Eclipse Foundation, spoke (rather generally) about the mechanics and advantages of opensource software development in a talk entitled Eclipse Foundation: A Symphony of R\&D Collaboration.

James Willenbring, Sandia National Laboratories, described The IDEAS Scientific Software Productivity Project and how to refactor code to work well on new computing platforms.

Eleonora Presani, Project Manager, Elsevier Research Intelligence, spoke on Elsevier's SoftwareX Journal. [This provided an interesting comparator to the publication of new programs and software packages in J. Appl. Cryst. and we noted that editorial procedures and requirements on authors were broadly similar. The software/code metadata items required by the Elsevier journal may also provide a useful model for enhancing the content of the software directory (formerly SinCris) on the IUCr web site.]

Fernando Perez, University of California Berkeley, described The Jupyter Project. [The Jupyter project was born out of the IPython Project in 2014 and has evolved to support an open source, interactive data science, scientific computing platform for over 40 programming languages.] 
At the ICSTI Executive Board J. R. Helliwell attended in place of A. M. Glazer, who was unable to attend. B. McMahon attended as an Observer. The main items discussed were in the overview report from the ICSTI Executive Secretary Tony Llewellyn. Main items of interest were that:

The IUPAC and IUPAP delegates were not present but IUCr was heartily thanked for their continued presence. [Our impression was that to have at least one Science Union in attendance was important so as to form a touchstone with science, and scientist, viewpoints for the other ICSTI members.]

The ICSTI financial assets were as last year (approx. EUR 100 000). The ICSTI cash flow was in a slight deficit (approx. EUR 3000).

The plan in recent years of attaching the ICSTI General Assembly and Workshops to a major event was proposed to be continued and was supported as very sensible. Possible events for 2017 included the European Publishers Conference in Berlin, Germany, or the next Research Data Alliance Plenary to be held in Barcelona, Spain.

Following the ICSTI meeting in Denver, a memorandum of understanding was signed with RDA (Research Data Alliance) whereby ICSTI becomes an Organizational Affiliate of RDA and RDA becomes an Associate Member of ICSTI.

I acknowledge with gratitude the close collaboration with the IUCr Journals Executive Managing Editor, P. R. Strickland, and with the IUCr's alternate Representative to CODATA, B. McMahon.

\section{A. M. Glazer, IUCr Representative}

\subsection{International Council for Science (ICSU)}

The International Council for Science (ICSU) is a nongovernmental organization with a global membership that includes 31 International Scientific Unions and 122 national scientific bodies representing 142 countries. ICSU was founded in 1931 to promote international scientific activity in the different branches of the physical sciences and its application for the benefit of humanity. It is one of the oldest nongovernmental organizations in the world and represents the evolution and expansion of two earlier bodies known as the International Association of Academies (IAA; 1899-1914) and the International Research Council (IRC; 1919-1931).

In 1998, its members agreed that the organization's activities would be better reflected by modifying the name from the International Council of Scientific Unions to the International Council for Science, while retaining the rich history of its existing acronym, ICSU. ICSU's strength and uniqueness lie in its dual membership of National Scientific Members and International Scientific Unions. This wide spectrum of interdisciplinary expertise allows ICSU to address major international scientific issues. The General Assembly of ICSU meets every three years and is responsible for setting the general direction, policies and priorities for the next triennium. The 31st General Assembly of the International Council for Science was held in Auckland, New Zealand, 30 August - 3
September 2014. The next General Assembly will be held in Taipei, 23-24 October 2017.

Traditionally the IUCr is represented by its Immediate Past President, but as Professor Gautam Desiraju was busy with preparations for the Hyderabad Congress, E. N. (Ted) Baker represented the IUCr at the 31st ICSU General Assembly in 2014 in Auckland and I have been tracking subsequent events. The President of ICSU for 2014-2017 is Gordon McBean, a climate-change expert from Canada and part of the IPCC organization awarded the 2007 Nobel Prize. Heide Hackmann became the new Executive Director for ICSU in March 2015 and works with a staff of about 18 in Paris. ICSU has three Regional Offices, serving Africa (Pretoria, South Africa), Asia and the Pacific (Kuala Lumpur, Malaysia), and Latin America and the Caribbean (Mexico City, Mexico).

This report will focus on three significant developments since the last report: ICSU grants, Open Data and merger talks. ICSU supported a Grants Programme that funded four projects in 2015. The IUCr was the lead applicant of one of the funded awards (with support from the ECA, UNESCO, SAASTA and Indaba) titled Building Science Capacity in Africa via Crystallography. The award provided EUR 30000 to support several conferences for capacity building of crystallography in Africa with a goal of cementing the African Crystallographic Association. The most recent of these was The First Pan-African Conference on Crystallography held in Dschang, Cameroon, 6-10 October 2016, where a mix of scientists, students and policy makers from 35 countries discussed ways in which crystallography can be a vehicle for promoting science in Africa. The 2016-2019 ICSU Grants Programme was revised to support fewer (but larger) grants than the one the IUCr helped obtain to support its African initiative in 2015. The IUCr partnered with IUPAP to submit a joint proposal that was one of three funded by ICSU for this period. Congratulations to Michele Zema who led the IUCr efforts and our thanks to IUPAP and the many organizations (UNESCO, TWAS etc.) and large-scale facilities that supported this joint effort. The acronym LAAMP (Lightsources for Africa, the Americas and the Middle East Project) has been chosen for the initiative. The grant is for EUR 300000 over three years. In addition to this grant providing support for new initiatives, the scope of the proposal will help support a number of OpenLabs.

ICSU launched Science International as a series of meetings to strengthen the voice of global science in international policy. This was done in cooperation with TWAS, IAP and ISSC. The first such meeting was held in December 2015 in Pretoria, South Africa, with a focus on Big Data and Open Data. A working group was formed to draft an accord on Open Data in a Big Data World, which is now available via the ICSU web site. The IUCr wrote a Response co-authored by B. McMahon, L. Van Meervelt, J. R. Helliwell and M. L. Hackert that is available on the IUCr web site. The discussion of best practices to achieve the goals of open access that is also sustainable continues to be a topic of discussion, often with reference to 'FAIR' (Findable/Assessable/Accessible)/Interoperable/Reusable) data. 
The fate of ICSU is uncertain as active discussions are underway about a possible merger of ICSU with ISSC (International Social Science Council). An Extraordinary General Assembly of ISSC and ICSU was held in Oslo, Norway, on 24 October 2016 to vote on the principle of the merger of ISSC and ICSU, and on a planning framework for the development of a new, single science organization for both the social and natural sciences. $76 \%$ of the ICSU members and $87 \%$ of the ISSC members voted in favour of a merger, in principle, of the two organizations, thereby setting the merger process in motion. Many of the International Unions represented expressed concerns. Many details remain to be sorted out such as dues, identifying any official national representation, the fate of the current working ICSU Commissions, ways to insure minimal representation of both the social and physical sciences, how to include medicine and engineering in the discussion of global concerns, etc. The IUCr was fortunate that former General Secretary Sven Lidin was able to be the IUCr delegate at the meeting in Oslo. A Committee is working on how to address the concerns expressed by many of the International Unions about handling dues, identifying official national representation etc.

I look forward to working with ICSU and representing the IUCr in Taipei later this fall when ICSU meets to hear reports from its many active committees.

\section{L. Hackert, IUCr Representative}

10.4. ICSU Committee on Data for Science and Technology (CODATA)

CODATA is the interdisciplinary Committee on Data for Science and Technology of the International Council for Science (ICSU). Full details of CODATA activities are available from its web site at http://www.codata.org.

The SciDataCon (see http://www.scidatacon.org/2016/) held in September 2016 in Denver, USA, was entitled Advancing the Frontiers of Data in Research, and formed part of an International Data Week, organized jointly by CODATA, the Research Data Alliance and the ICSU World Data System. The IUCr organized a Microsymposium on Crystallography and Structural Data Bases (http://www. scidatacon.org/2016/sessions/). A detailed report on the International Data Week can be found at http://forums. iucr.org/viewtopic.php?f=21\&t=381.

The CODATA Task Groups approved by the 30th General Assembly in Denver in September 2017 for the period 20162018 are as follows (those marked with an asterisk are continuations of existing Task Groups):

Agriculture Data, Knowledge for Learning and Innovation. Building Foundational Training in Research Data Science.

Citizen Science and the Validation, Curation, and Management of Crowdsourced Data (with WDS).

Coordinating Data Standards amongst Scientific Unions.

Earth and Space Science Data Interoperability (ESSDI)*.
Linked Open Data for Global Disaster Risk Research (LODGD)*.

Practice and Impact of Digital Data*.

Preservation of and Access to Scientific and Technical Data in Developing Countries (PASTD)*.

The Task Group for Fundamental Constants continues under its status as a standing activity of CODATA.

The IUCr is to be represented on the Task Group for Coordinating Data Standards amongst Scientific Unions by Brian McMahon.

The Officers of CODATA through to the next General Assembly to be held in 2018 are: President: Geoffrey Boulton (UK; 2014-2018); Past President: Guo Huadong (People's Republic of China); Vice-Presidents: Takashi Gojobori (Japan), Niv Ahituv (Israel); Secretary General: Bonnie Carroll (USA); Treasurer: John Broome (Canada); Ordinary Members: Sarah Callaghan (UK), Jane Hunter (Australia), Paul Laughton (South Africa), Der-Tsai Lee (Taiwan), Jianhui Li (People's Republic of China), Alena Rybkina (Russia), Paul Uhlir (USA), Joseph Muliaro Wafula (Kenya), Sally Wyatt (The Netherlands) and Mary Zborowski (Canada).

Since CODATA had played a large role in the 2015 leadership document Open Data in a Big Data World: An International Accord (see https://www.icsu.org/publications/ open-data-in-a-big-data-world), the IUCr considered this in detail. The IUCr endorsed the Science International 2015 Accord on Open Data in a Big Data World but also provided a detailed response to the short form of the Accord in which the position of crystallography was included. Copies of the IUCr position paper are available at the IUCr web site: http:// www.iucr.org/iucr/open-data. This IUCr position paper was very well received by the CODATA General Assembly in Denver and the attendees at Denver.

J. R. Helliwell, IUCr Representative, and B. McMahon, alternate IUCr Representative

\subsection{ICSU Committee on Space Research (COSPAR)}

COSPAR's (http://cosparhq.cnes.fr/) main objective is to promote international collaboration in scientific research in space, with an emphasis on the exchange of results, information and opinions. Developing world standards for the space environment and its protection requires perpetual creation of national and international organizations and specialist working groups.

COSPAR acts mainly as a body responsible for organizing biennial Scientific Assemblies. After a great deal of consideration, the 41st Assembly planned for 30 July - 7 August 2016 in Istanbul was cancelled following the military coup in Turkey on 15 July. The decision to cancel was a difficult one to make for organizers from COSPAR and the local sides, but it was necessary due to the safety concerns. It was understood by all the participants. The report on COSPAR's financial affairs, Finance Committee graphs, 2016 budget, national contributions to COSPAR in 2017, and 2017/2018 drafts of the 
COSPAR budget due to be discussed in Istanbul were approved by electronic voting.

The 42nd Assembly will take place in Pasadena, USA, in 2018. The 43rd Scientific Assembly will be held in Sydney, Australia, in late July or mid-August 2020.

Most COSPAR activities are related to space topics (astronomy, astrobiology, geophysics, atmosphere studies, investigation of natural and artificial ecosystems, as well as space travel). The most interesting for the IUCr is the COSPAR's Scientific Commission on Materials Science in Space (MSS Comission G), chaired by V. Shevtsova (Belgium) and co-chaired by S. Amiroudine (France), T. Koenemann, (Germany) and S. Yoda (Japan). This Commission coordinates fundamental experiments in materials and fluid sciences performed in space, utilizing reduced gravity for their objectives.

Advances in Space Research (ASR, http://ees.elsevier.com/ asr/, impact factor 1.409 in 2015) is the official journal of COSPAR. It covers all areas of space research including - but not limited to - space studies of earth surface, climate, meteorology, fundamental physics in space, materials physics in space, space debris, weather and earth observation of space phenomena. ASR also includes COSPAR's information bulletin, Space Research Today.

The new COSPAR journal entitled Life Sciences in Space Research (calculated Research Gate impact factor of 1.97) is a quarterly peer-reviewed scientific journal covering astrobiology, origins of life, life in extreme environments, habitability, effects of space flight on the human body, radiation risks and other aspects of life sciences relevant in space research.

In 2016 the mutual IUCr-COSPAR Capacity Building Workshop on Crystallography for Space Science took place in Puebla, Mexico, 17-29 April (see http://www.inaoep.mx/ cospar2016/). This was organized and run by Juan M. GarciaRuiz, Maria E. Mendoza, Guillermo T. Tagle, Hanna A. Dabkowska and Mariano Mendez. The programme highlighted the fundamentals of crystallography, investigating minerals in/from space, reports on crystallographic and crystal-growth experiments performed in space, and actual and future investigation of space debris by crystallographic methods. Twenty-seven PhD students, post-docs and young staff members, mostly from Latin America, took part in the workshop. For many of them it was their first contact with crystallography. The IUCr helped to cover the costs of bringing some young participants to this meeting as well as that of travel of teachers of crystallography basics. Professor Wulf Depmeier of the IUCr Executive Committee presented an interesting talk at this meeting. My report from this workshop can be found at http://www.iucr.org/news/meetingreports/iucr-newsletter/cospar-workshop. The topic of the workshop Crystallography for Space Sciences is novel, as this was the first COSPAR workshop focused on crystallography, which is becoming important in research carried out on Mars and some other celestial bodies.

There is a proposal to organize a similar workshop in another area of the world soon.
In 2016 COSPAR co-sponsored another Capacity Building Workshop on Impact of Space Weather on Earth, Paratunka, Kamchatka, Russia, 15-26 August 2016.

To find out more about other COSPAR activities please go to http://cosparhq.cnes.fr/events.

\section{H. A. Dabkowska, IUCr Representative}

\subsection{International Organization for Standardization}

There were no activities during 2016 that related to crystallography.

\section{P. Brock, IUCr Representative}

\section{Finances}

Extracts from the full financial statements, namely the Income and Expenditure account, Balance Sheet and Summary of Fund Accounts, are given in Tables 1, 2 and 3, respectively. For comparison, the figures for 2015 are provided in italics. The accounts are presented in $\mathrm{CHF}$.

The ICSU exchange rates, based on the official UN rates, have been used in the preparation of these accounts. As a consequence of the many fluctuations in exchange rates during the year, the following procedure has been adopted for the accounts. Assets and liabilities in currencies other than $\mathrm{CHF}$ at 31 December 2016 have been translated into CHF in the balance sheet at the rate operative at that date. For the income and expenditure accounts, transactions have been translated into $\mathrm{CHF}$ by applying the rates appropriate to the individual dates of these transactions. As a consequence of the fluctuation in exchange rates, overall an apparent loss has arisen on the assets of the Union, in terms of $\mathrm{CHF}$, amounting to $\mathrm{CHF}$ 129880 . In the accounts this has been assigned as a 'Realized gain' (CHF 2 845) and 'Unrealized loss' (CHF 132 725). The loss attributable to investment activities has been assigned to the General Fund and the overall loss attributable to trading activities has been divided amongst the fund accounts in direct proportion to the balances on these accounts at 31 December 2016. It should be noted that this overall loss in CHF is not a real loss of money, but rather a loss on paper resulting from the accounts being expressed in $\mathrm{CHF}$.

Investments are noted in the balance sheet at their market value at 31 December 2016.

The balance sheet shows that the assets of the Union, including the loss resulting from fluctuations in rates of exchange, have decreased during the year, from $\mathrm{CHF}$ 3587207 to CHF 3046504 . The movement in market value of the investments was CHF 6435 in 2016 (CHF -86 731 in 2015).

The following transfers were made from the Acta Crystallographica Fund: CHF 200000 to the Publications and Journals Development Fund; CHF 350000 to the Research and Education Fund and CHF 50000 to the General Assembly and Congress Fund. CHF 20000 was transferred from the 
Table 1

Income and Expenditure Account (in Swiss Francs) for the year ended 31 December 2016.

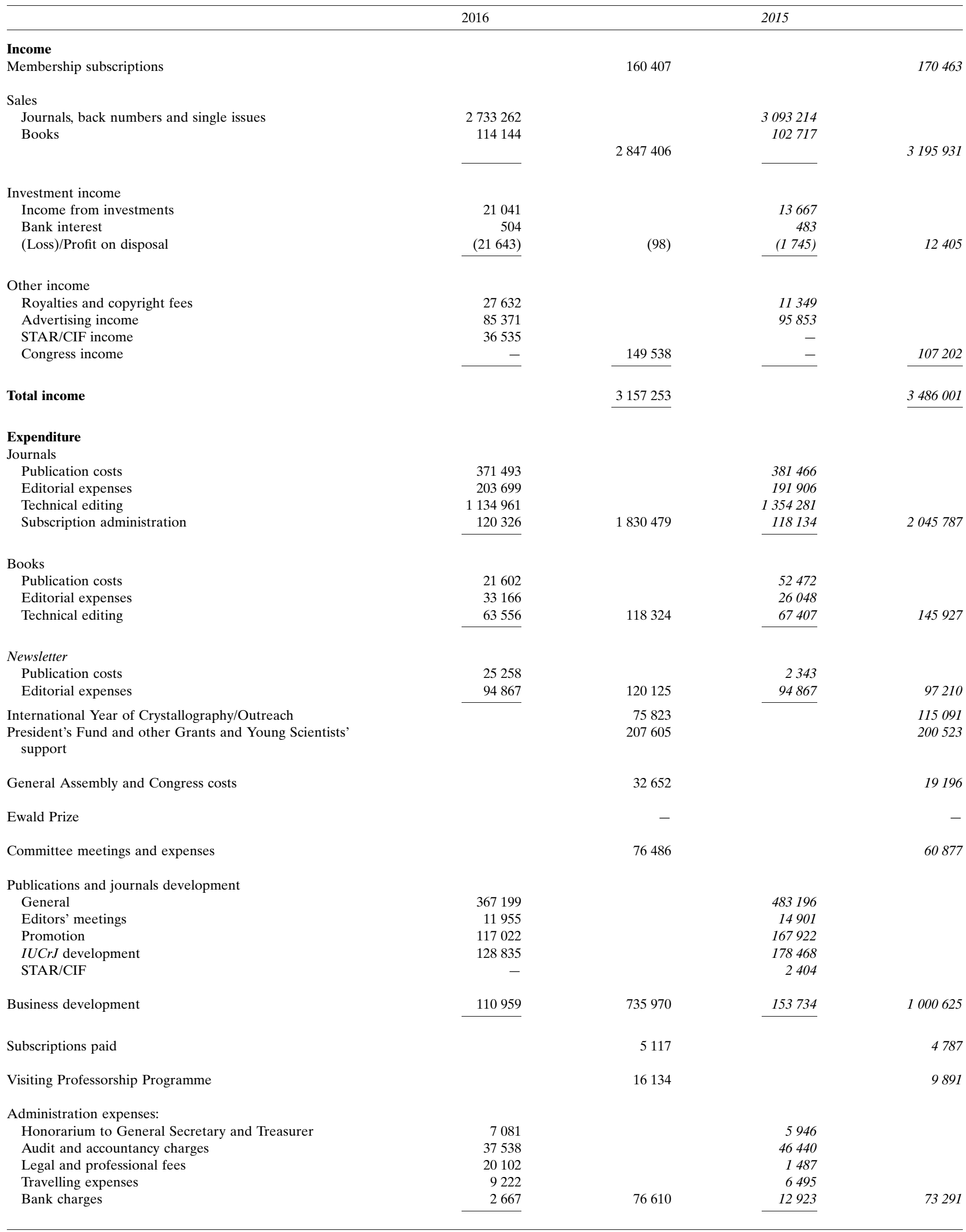


Table 1 (continued)

2016

Executive Secretary's office:

Salaries and expenses

Travel expenses of IUCr Representatives on other bodies

Sponsorship of meetings

IUCr/FIZ agreement

Bad debts

Commission expenses

Depreciation

Total expenditure

Deficit of income over expenditure (before realized exchange fluctuations)

Realized fluctuations in rates of exchange

Exchange movement on trading activities

(Deficit) of income over expenditure (after realized exchange losses)

Movement in market value of investments in year

Unrealized fluctuation in rates of exchange

Exchange movement on trading activities

Investment activities

$(66670)$

(66 055)

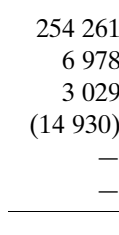

25426

3029

$4930)$

$-$

Total recognized gains/(losses) relating to the year

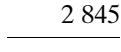

(414 413)

249338

29848

3574511

(417 258)

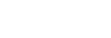

6435

(407 978)

(132 725)

(540 703)

3587207

3046504
2015

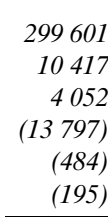

299594

36442

4109241

(623 240)

2846

(620 394)

(86 731)

(707 125)

(5 210)

(17 692)

(712 335)

4299542

3587207

Closing fund accounts at 31 December

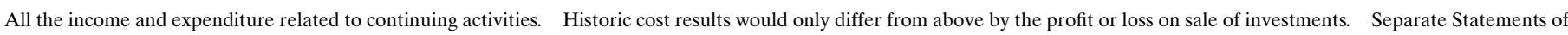
Total Recognized Gains and Losses and Reconciliation of Movements in the Fund Account are not given, as the information is incorporated in the above.

Journal of Applied Crystallography Fund to the President's Fund.

The following comments refer to figures in the full accounts.

The General Fund account shows a deficit of CHF 332 006, as compared with a deficit in 2015 of $\mathrm{CHF} 351$ 933. The administrative expenses were CHF 328026 in 2016 as compared with CHF 375981 in 2015. Of this amount, CHF 145704 was charged to the publications of the Union.

The expenses of the Union Representatives on other bodies were CHF 6 978. The cost of the Finance Committee meetings held in 2016 was CHF 25 333, while the Executive Committee meetings cost CHF 49612. The income from the IUCr/ Fachinformationszentrum agreement (to provide low-cost copies of the Inorganic Crystal Structure Database) was CHF 14 930. The subscriptions from Adhering Bodies were CHF 160407 . Interest on bank accounts and investments credited to the General Fund was CHF 21545.

Grants totalling CHF 7896 were paid from the President's Fund in 2016.

The Journals Funds accounts for 2016 show a surplus of CHF 507667 before the transfer of CHF 620000 to the other fund accounts, as compared with a surplus of CHF 445335 in 2015 before the transfer of $\mathrm{CHF} 420000$ to the other fund accounts.

The cost of the technical-editing office has been divided between the Journals Funds and the International Tables Fund in percentages based on the staff time spent on each publication. The technical-editing costs for the Journals Funds were CHF 1120510 as compared with CHF 1342706 in 2015. The Journals Funds have also been charged with administration expenses as in previous years as shown in the General Fund.

The International Tables account shows a deficit of $\mathrm{CHF}$ 35 464, as compared with a deficit of CHF 103403 in 2015. The net sales income was CHF 84618 in 2016 as compared with CHF 76968 in 2015.

The cost for the Union in producing the Newsletter in 2016 was CHF 64283.

In the Publications and Journals Development Fund account, the computing, business development and promotion expenses are divided between the General Fund, the Journals Fund and the International Tables Fund. STAR/CIF costs, IUCrJ development costs, IUCrData development costs, 
Table 2

Balance sheet (in Swiss Francs) as at 31 December 2016.

\begin{tabular}{|c|c|c|c|c|}
\hline & 2016 & & 2015 & \\
\hline \multicolumn{5}{|l|}{ Fixed assets } \\
\hline Investments at market value & & 2571596 & & 3139842 \\
\hline \multicolumn{5}{|l|}{ Current assets } \\
\hline Stock & & 79102 & & 62222 \\
\hline \multicolumn{5}{|l|}{ Cash at bank and in hand } \\
\hline Cash with Union officials & 14564 & 830806 & 21727 & 1041957 \\
\hline Debtors, accrued income and payments in advance & & 245521 & & 344750 \\
\hline Subscriptions due from Adhering Bodies & & 57862 & & 32953 \\
\hline Total current assets & & 1213291 & & 1481882 \\
\hline Total assets being total funds & & 3046504 & & 3587207 \\
\hline
\end{tabular}

Table 3

Summary of Fund Accounts (in Swiss Francs) as at 31 December 2016.

\begin{tabular}{|c|c|c|c|c|c|c|c|}
\hline & \multirow{2}{*}{$\begin{array}{l}\text { As at } \\
1 \text { January } 2016\end{array}$} & \multirow[t]{2}{*}{$\begin{array}{l}\text { Transfers } \\
\text { between } \\
\text { funds }\end{array}$} & \multirow[t]{2}{*}{$\begin{array}{l}\text { (Deficit)/ } \\
\text { surplus of } \\
\text { income over } \\
\text { expenditure } \\
\text { for the } \\
\text { year }\end{array}$} & \multirow[t]{2}{*}{$\begin{array}{l}\text { Increase in } \\
\text { market } \\
\text { value of } \\
\text { investments }\end{array}$} & \multicolumn{2}{|c|}{ Fluctuations in exchange rates } & \multirow[t]{2}{*}{$\begin{array}{l}\text { Balance } \\
\text { at } 31 \text { December } \\
2016\end{array}$} \\
\hline & & & & & Trading & Investments & \\
\hline \multicolumn{8}{|l|}{ Fund accounts } \\
\hline General Fund & (3 414 181) & - & (332 006) & 6435 & 78424 & $(66055)$ & (3727 383) \\
\hline President's Fund & 149501 & 20000 & (7 896) & - & (3 389) & - & 158216 \\
\hline Acta Crystallographica Fund & 4638730 & $(600000)$ & 452102 & - & (94 175) & - & 4396657 \\
\hline Journal of Applied Crystallography Fund & 791281 & $(20000)$ & 40736 & - & $(17028)$ & - & 794989 \\
\hline International Tables Fund & (725 870) & - & (35 464) & - & 15966 & - & (745 368) \\
\hline Publications and Journals Development Fund & 730681 & 200000 & $(148676)$ & - & (16 399) & - & 765606 \\
\hline Research and Education Fund & 546790 & 350000 & (306 641) & - & (12 376) & - & 577773 \\
\hline Ewald Fund & 550831 & - & - & - & $(11551)$ & - & 539280 \\
\hline Newsletter Fund & (35 052) & - & $(64283)$ & - & 2083 & - & (97 252) \\
\hline Journal of Synchrotron Radiation Fund & 32974 & - & 14828 & - & $(1002)$ & - & 46800 \\
\hline General Assembly and Congress & 251849 & 50000 & (34 193) & - & (5 613) & - & 262043 \\
\hline \multirow[t]{2}{*}{ Outreach and Education } & 69673 & - & 7080 & - & $(1610)$ & - & 75143 \\
\hline & 3587207 & - & $(414410)$ & 6435 & $(66670)$ & $(66055)$ & 3046504 \\
\hline
\end{tabular}

Special Issue costs, archiving and web input costs are also charged to the Publication and Journals Development account.

CHF 166691 for financial support to young scientists, to enable them to attend scientific meetings sponsored by the Union, was charged to the Research and Education Fund. Visiting Professorships (CHF 16 134), outreach and education costs (CHF 82 903), and Crystallography in Africa costs (CHF
46 335) were also charged to the Research and Education Fund.

In 2007 a General Assembly and Congress Fund was established so that the costs associated with the General Assembly and Congress could be spread over the triennium. In 2016 the expenses charged to this Fund were CHF 34193.

An Outreach and Education Fund has been established. In 2016 donations totalling CHF 36720 were received. 